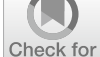

updates

Cite as

Nano-Micro Lett.

(2020) 12:86

Received: 21 January 2020

Accepted: 26 February 2020

Published online: 6 April 2020

(C) The Author(s) 2020

\section{D Layered Double Hydroxide Nanosheets and Their Derivatives Toward Efficient Oxygen Evolution Reaction}

\author{
Xueyi $\mathrm{Lu}^{1}$, Hairong Xue ${ }^{1}$, Hao Gong ${ }^{1}$, Mingjun Bai ${ }^{1}$, Daiming Tang ${ }^{1}$, Renzhi Ma ${ }^{1}$, \\ Takayoshi Sasaki ${ }^{1} \bowtie$ \\ Xueyi Lu and Hairong Xue have contributed equally to this work. \\ $\bowtie$ Renzhi Ma, Ma.Renzhi@nims.go.jp; Takayoshi Sasaki, Sasaki.Takayoshi@nims.go.jp \\ 1 International Center for Materials Nanoarchitectonics (WPI-MANA), National Institute for Materials \\ Science (NIMS), Tsukuba, Japan
}

\title{
HIGHLIGHTS
}

- Synthesis strategies of layered double hydroxides (LDHs) were summarized with classifications of traditional coprecipitation, homogeneous precipitation, and newly developed topochemical oxidation.

- Diverse approaches of structural modulation and hybridization to enhance the electrocatalytic activity of LDHs were systematically reviewed.

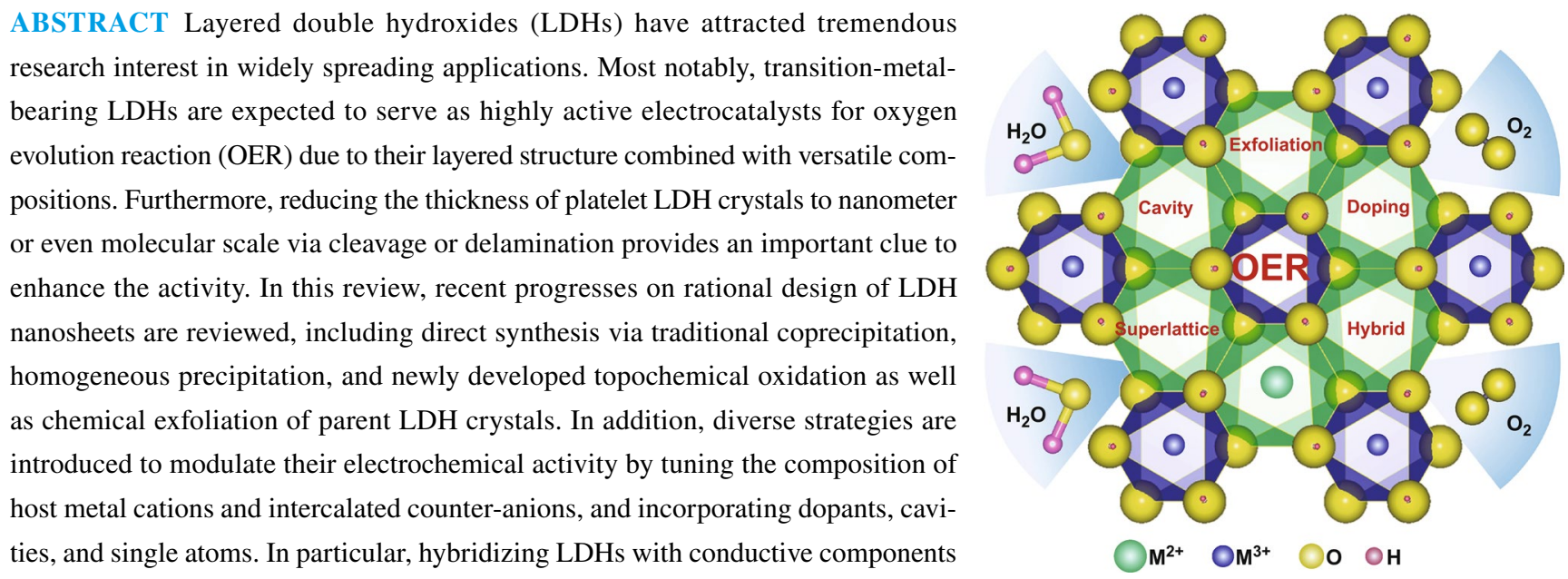
or in situ growing them on conductive substrates to produce freestanding electrodes can further enhance their intrinsic catalytic activity. A brief discussion on future research directions and prospects is also summarized.

KEYWORDS Layered double hydroxides; Nanosheets; Derivatives; Catalysts; Oxygen evolution reaction 


\section{Introduction}

Electrochemical water splitting, involving hydrogen evolution reaction (HER) and oxygen evolution reaction (OER), is considered as one of alternative renewable energy systems to replace traditional fossil fuels [1-3]. Compared with other alternatives such as solar and wind power, water splitting is more efficient to utilize intermittent energy by converting electricity to clean chemical energy carriers (e.g., hydrogen) [4]. However, both reactions of water splitting suffer from sluggish kinetics due to the inertia, especially for the OER which experiences a four-electron (4e) transfer process [5]. Exploring efficient electrocatalysts is crucial to address this issue. The state-of-the-art commercial catalysts of water splitting rely on precious metals of the platinum group, with $\mathrm{Ru}$, Ir, and their oxides toward OER, while Pt is the benchmark catalyst for HER [6, 7]. However, the scarcity and precious nature hinder their large-scale application. Moreover, $\mathrm{Ru}$, Ir, and their oxides might suffer from oxidation at high potential and $\mathrm{Pt}$ would undergo dissolution in the electrolyte during long-time operation [8-10].

During the past decades, substantial efforts have been devoted to developing high-performance catalysts based on low-cost transition metal elements. Among them, layered double hydroxides (LDHs) recently attracted considerable research interest owing to their intriguing electrocatalytic activities, earth abundance, ultrastability, and low-toxic properties [11-14]. LDHs can be represented by a general formula as $\mathrm{M}_{1-x}^{2+} \mathrm{M}_{x}^{3+}(\mathrm{OH})_{2}\left(\mathrm{~A}^{n-}\right)_{x / n} \cdot y \mathrm{H}_{2} \mathrm{O}$ [15-21]. As depicted in Fig. 1, LDHs consist of brucite-like layers with a fraction of octahedrally coordinated divalent metal cations replaced by trivalent ones, resulting in positive charge of the host layers. Exchangeable inorganic or organic anions are accommodated in the interlayer galleries to compensate for the positive charge. Moreover, the hydroxyl groups of the host layers are connected to the anions or water molecules by hydrogen bonds. The $x$ value equals the molar ratio of $\mathrm{M}^{3+} /\left(\mathrm{M}^{2+}+\mathrm{M}^{3+}\right)$, which is in the range of 0.17-0.33 [22]. Thanks to the controllable $\mathrm{M}^{2+} / \mathrm{M}^{3+}$ molar ratio, tunability of the metal cations, and exchangeable charge-compensating anions, a large number of host-guest assemblies and nanoarchitectures can contribute to the design for desirable physical and chemical properties. The properties of LDHs have been tailored to fulfill the specific demand of different applications, ranging from electrocatalysis, photoelectrocatalysis, adsorption materials to additives in polymers, and so on. During the OER catalytic process, both $\mathrm{M}^{2+}$ and $\mathrm{M}^{3+}$ are involved in redox reactions by adsorbing and desorbing reactants, intermediates, and products (Fig. 1b) [23]. There may be possible electron transfer occurring between $\mathrm{M}^{2+}$ and $\mathrm{M}^{3+}$ in the process. $\mathrm{A}^{\mathrm{n}-}$, acting as the counterions to compensate for the positive charge, may affect adsorption/ desorption process on LDH host layer surface and/or in the interlayer space.

The lateral size and thickness have a great effect on physical and chemical properties [24]. In particular, when the thickness reduced to nanometer or even molecular scale, the resulting nanosheets can maximize the exposing active sites and specific surface area, which would effectively contribute to increased intrinsic electrocatalytic activities, facilitate the transport of reactant species, and finally promote the activity toward water splitting $[25,26]$.

In this review, we summarize recent progress in the structure design and exfoliation of LDHs, development of their derivates as well as exploring their applications in electrochemical water splitting. First, we will introduce various
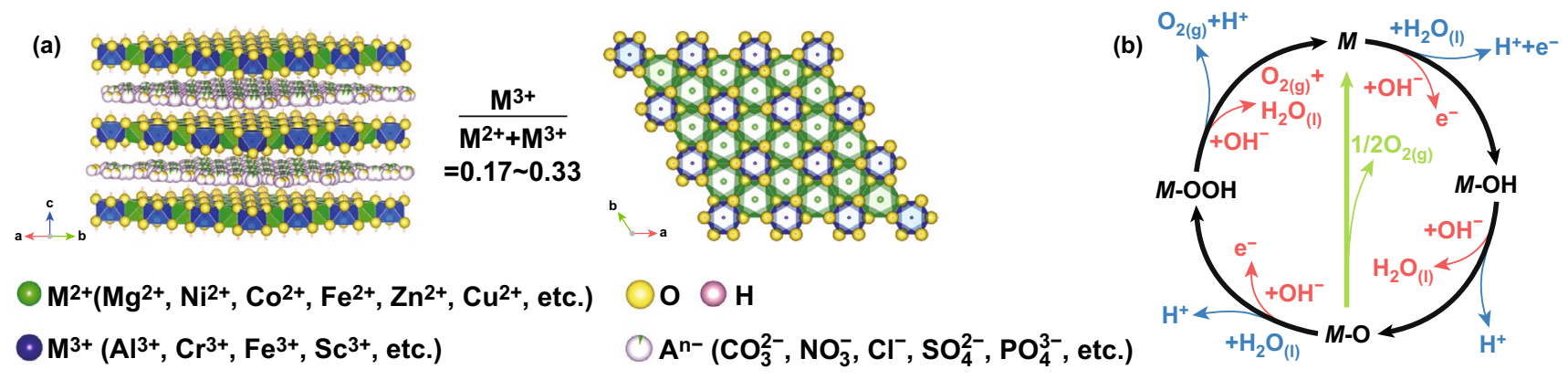

Fig. 1 a Typical structure model of LDHs and in-plane cation arrangement. b OER mechanisms in acid (blue) and alkaline (red) conditions. Reproduced with permission from Ref. [23]. Copyright 2006 The Royal Society of Chemistry 
preparation methods of LDH nanosheets, mainly classified into two categories-direct synthesis in a bottom-up approach and top-down chemical exfoliation of the layered precursory compounds. Aiming to overcome the poor conductivity of LDHs, various strategies will be covered, including doping metal or nonmetal elements, introducing cavities, decorating LDHs with functional nanoparticles, hybridizing LDHs with conductive components, and growing LDHs on conductive substrate to produce 3D freestanding electrodes. Based on these developments, we highlight the applications of LDHs and their derivatives as OER catalysts toward electrochemical water splitting.

\section{Synthetic Strategies}

The reliable synthesis of 2D LDHs with controllable lateral size and thickness is crucial for exploring their structural, physical, and electrochemical properties. Stimulated by their interesting potential applications, tremendous efforts have been devoted to developing various strategies for producing 2D LDHs. The typical preparation methods of 2D LDHs can be classified into "top-down" and "bottom-up" approaches. The general "top-down" approach usually uses physical shear force or chemical intercalation to break the interaction between adjacent layers, attaining mono- or fewlayered nanosheets from their bulk counterparts. Oppositely, the bottom-up method relies on the direct preparation of 2D LDH nanosheets via chemical reactions/syntheses.

\subsection{Direct Synthesis of LDH Nanosheets}

Direct synthesis of 2D nanosheets may be considered as a straightforward and attractive bottom-up procedure [15]. Various mechanical and chemical strategies toward direct synthesis of LDH nanosheets have been explored, including applying a laser beam on metals in aqueous solution, utilizing a layer growth inhibitor in a microemulsion, and using a special reactor to create a rapid reaction environment, etc.

\subsubsection{Physicochemical Approach}

2.1.1.1 Pulsed Laser Ablation Hur et al. [27] introduced a new method to synthesize LDHs and their ultrathin nanosheets in de-ionized water by pulsed laser ablation without any chemical or heat treatment. Laser ablation tech- nique has recently been used for the formation of nanomaterials in liquid environment, including Ag particles [28], $\mathrm{ZnO}$ particles [29], Au-Ag alloy [30, 31], and other stable phases depending on the properties of target materials and surrounding liquid. The preparation process of LDHs was carried out in two steps. The first is laser ablation of a metal target for trivalent cations in de-ionized water at room temperature using Q-switched Nd-yttrium aluminum garnet laser, and the second is laser ablation over another metal target for bivalent source in the previously prepared trivalent metallic colloid. By controlling the ablation time, wavelength, and fluence, $\mathrm{Zn}-\mathrm{Al}, \mathrm{Co}-\mathrm{Fe}, \mathrm{Co}-\mathrm{Al}$, and $\mathrm{Mg}-$ $\mathrm{Fe}$ LDHs were formed with a molecular thickness, corresponding to the thickness of the exfoliated 2D nanosheets (Fig. 2a-d). Figure 2e-h shows that the lateral sizes of these LDHs are approximately $300,100,100$, and $200 \mathrm{~nm}$, respectively. Moreover, all these colloidal nanosheets were found to be stable without any agglomeration or formation of lamellar structures. Among them, $\mathrm{Mg}-\mathrm{Fe}$ and $\mathrm{Co}-\mathrm{Fe} \mathrm{LDH}$ layers present extremely large lateral size comparable with that of the regular LDHs when being prepared quickly on transmission electron microscopy (TEM) grid. The TEM images showed that the $\mathrm{Mg}-\mathrm{Fe}$ LDHs present a rolling and folding morphology with a thickness approaching $0.5 \mathrm{~nm}$.

Employing the method of pulsed laser ablation in liquid (PLAL), Müller et al. synthesized a series of [Ni-Fe]-LDHs with intercalated nitrate ions and water$\left[\mathrm{Ni}_{1-x} \mathrm{Fe}_{x}(\mathrm{OH})_{2}\right]\left(\mathrm{NO}_{3}\right)_{y}(\mathrm{OH})_{x-y} \cdot n \mathrm{H}_{2} \mathrm{O}$ [32]. Iron or nickel powder was firstly mixed in $10 \mathrm{~mL}$ aqueous metal nitrate solutions using a magnetic stirrer. For the formation of bimetallic LDHs, one kind of metal was used as the ablation target, while the nitrate salt of the other metal was dissolved in the precursor solution. During PLAL, nanoparticles were formed by rapid cooling of plasma comprised of elements for the solid ablation target and the surrounding liquid. After the synthesis process, the LDH nanoparticle suspensions were separated from the metallic ablation targets using a strong magnet. The composition of LDHs with mixed metals was carefully controlled by varying the ablation targets, type of metal ions, and their concentrations, as well as laser pulse energies. Powder X-ray diffraction (XRD) measurements implied that the Fe-rich nanoparticles are poorly crystalline, while the Nirich nanoparticles display diffraction patterns consistent with the LDH structure. Mössbauer and X-ray absorption spectroscopic data indicated that the $\mathrm{Fe}$ was incorporated as $\mathrm{Fe}^{3+}$ to replace partial $\mathrm{Ni}^{2+}$ in $[\mathrm{Ni}-\mathrm{Fe}]-\mathrm{LDH}$. The TEM data showed that the lateral sizes ranged from $\sim 7$ to $22 \mathrm{~nm}$. 

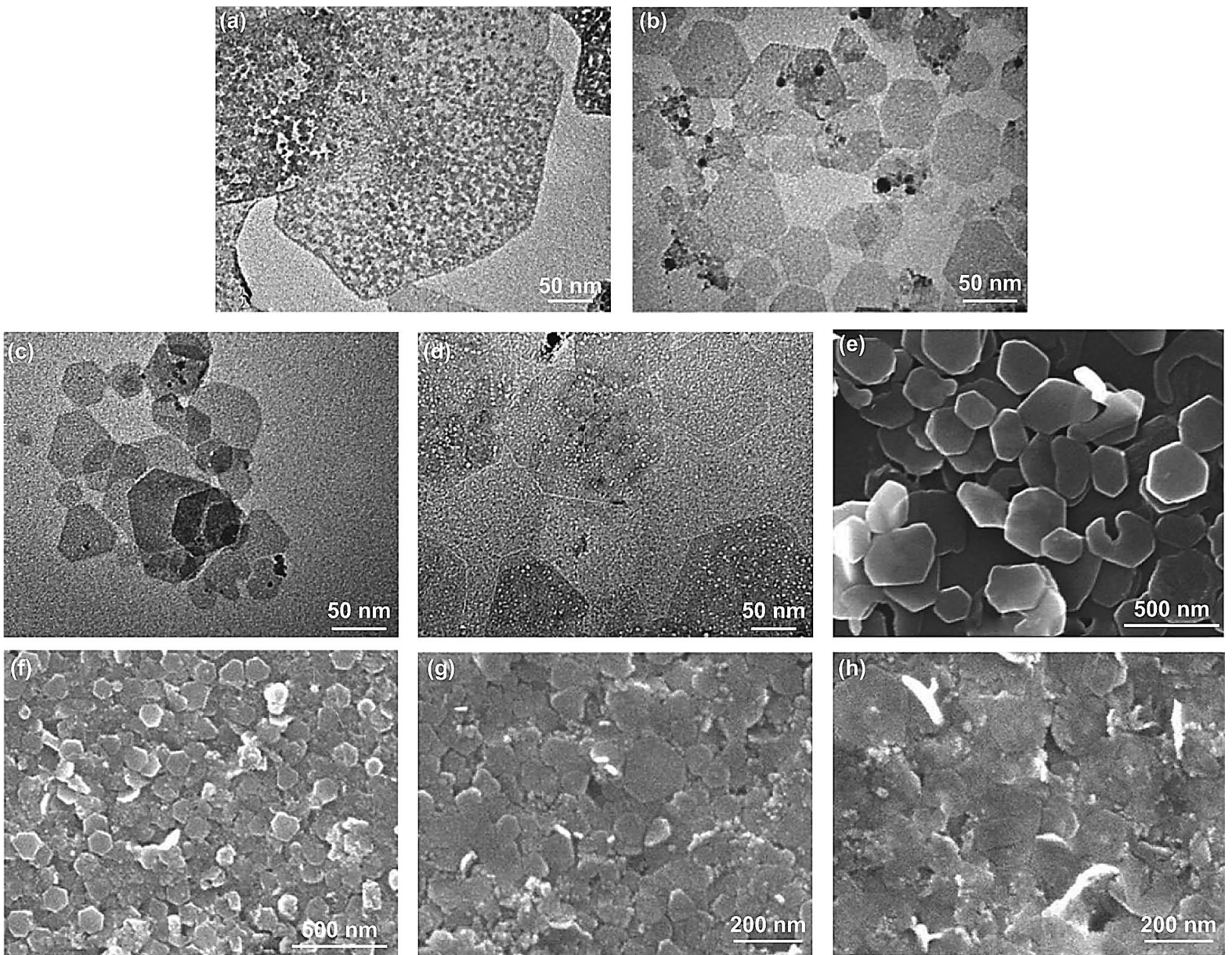

Fig. 2 TEM and SEM images of four different LDH nanosheets prepared by pulsed laser ablation. a, e Zn-Al LDH, b, f Co-Fe LDH, c, g CoAl LDH, d, h Mg-Fe LDH. Reproduced permission from Ref. [27]. Copyright 2010 American Institute of Physics

Laser ablation process has proved to be an attractive method to prepare ultrathin LDH layers with a uniform size. More importantly, the high laser power and short reaction time can effectively alleviate the contamination of carbonates.

2.1.1.2 Microwave Irradiation Microwave irradiation serves as a facile and convenient way to synthesize uniform materials by altering the reaction kinetics and selectivity during the nucleation process. Xu et al. used a onestep microwave-assisted approach to prepare $\mathrm{Zn}-\mathrm{Co}-\mathrm{LDH}$ nanosheets, which avoided the low yield and the complex synthesis via the liquid exfoliation method (Fig. 3a-d)
[33]. Zinc nitrate hexahydrate, cobalt nitrate hexahydrate, and urea were firstly dissolved in de-ionized water and then transferred to a round-bottomed flask, followed by microwave irradiation at $900 \mathrm{~W}$. They found that the XRD peaks of $\mathrm{Zn}-\mathrm{Co}-\mathrm{LDH}$, especially the 003, 006, and 113 peaks, became stronger with the increase in microwave power. The AFM images demonstrated that the reaction time had a large effect on the morphology, the lateral size getting larger with increasing the reaction time. The thickness of the obtained nanosheets was measured to be $\sim 2 \mathrm{~nm}$ by peak-force-model atomic force microscopy (PF-AFM) (Fig. 3e, f). Such a simple and effective method could be extended to large-scale synthesis. 

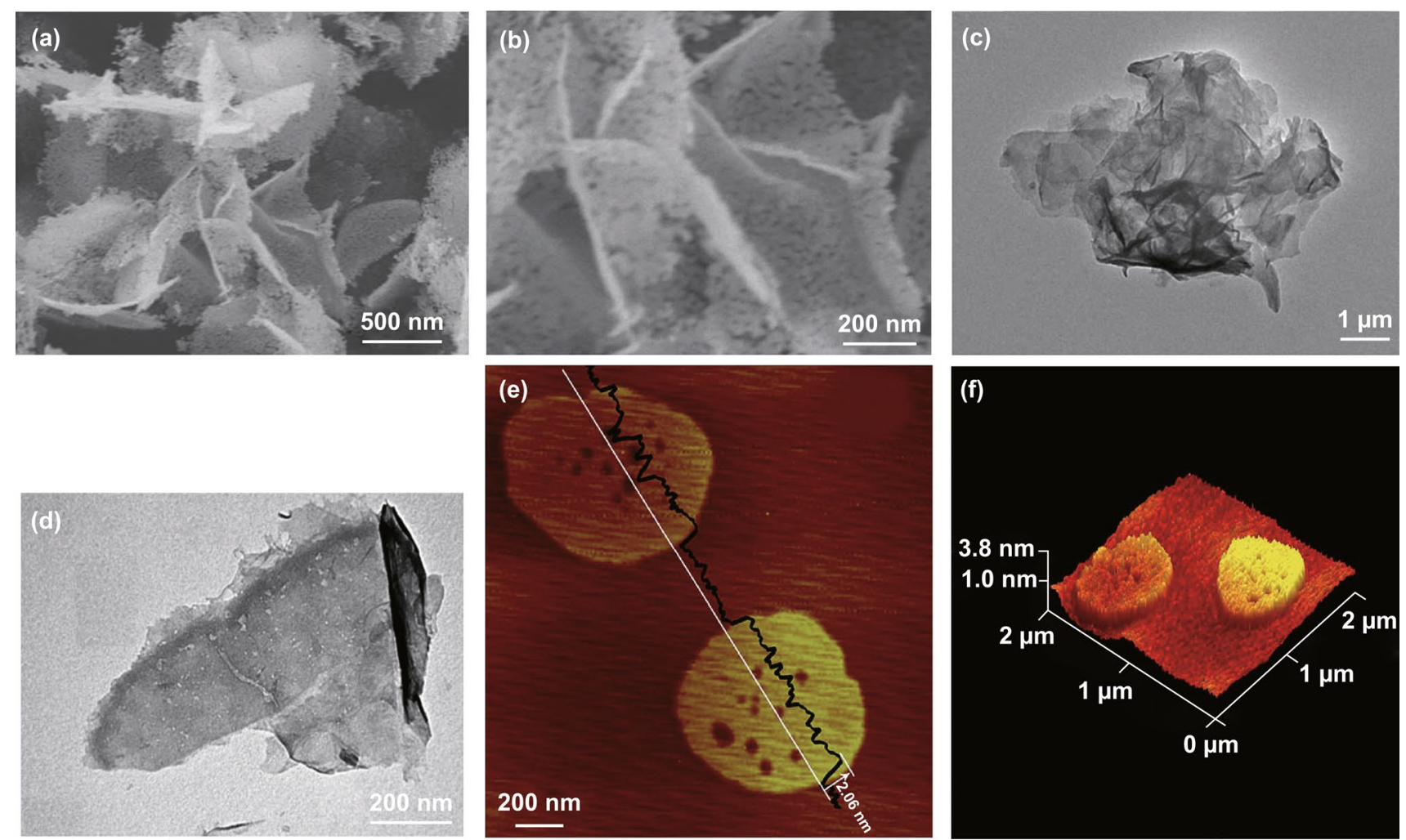

Fig. 3 a, b SEM and c, d TEM images of Zn-Co-LDH nanosheets. e Height profile and $\mathbf{f}$ the 3D PF-AFM images of Zn-Co-LDH nanosheets prepared by microwave irradiation. Reproduced with permission from Ref. [33]. Copyright 2015 The Royal Society of Chemistry

\subsubsection{Chemical Approach}

Yan et al. developed a single-step method to synthesize MgAl-LDHs ultrathin nanosheets in large scale with the assistance of hydrogen peroxide (Fig. 4a) [34]. $\mathrm{Mg}\left(\mathrm{NO}_{3}\right)_{2} \cdot 6 \mathrm{H}_{2} \mathrm{O}, \mathrm{Al}\left(\mathrm{NO}_{3}\right)_{3} \cdot 9 \mathrm{H}_{2} \mathrm{O}$, and urea were firstly dissolved into $100 \mathrm{~mL} 30 \% \mathrm{H}_{2} \mathrm{O}_{2}$ to yield a solution containing $0.01 \mathrm{M} \mathrm{Mg}^{2+}$ and $0.005 \mathrm{M} \mathrm{Al}^{3+}$. Then, the mixture was loaded into a Teflon tube and heated at $150{ }^{\circ} \mathrm{C}$ for 24 h. A translucent colloidal suspension was achieved after the reaction. The key point to obtain LDH nanosheets is that the oxygen molecules derived from in situ decomposition of $\mathrm{H}_{2} \mathrm{O}_{2}$ are accommodated in the interlayer space of the resulting LDHs. Due to their violent movements, the interlayer spacing increased and the electrostatic interaction of layers diminished until layers separated completely. It is illustrated that as the percentage of $\mathrm{H}_{2} \mathrm{O}_{2}$ increases, the resultant solution becomes more transparent with higher yield (Fig. 4b). The 003 XRD peak shifted to a low angle when adding $\mathrm{H}_{2} \mathrm{O}_{2}$, indicating that the interlayer spacing of $\mathrm{MgAl}-\mathrm{LDH}$ was expanded. On reaching $30 \% \mathrm{H}_{2} \mathrm{O}_{2}$, a semitransparent colloidal suspension was obtained which could be kept stable for several weeks in air without the formation of precipitates. SEM image exhibited hexagonal morphology of the MgAl-LDHs plates with a size of $5-10 \mu \mathrm{m}$. The height analysis was carried out by AFM at steps between a nanosheet and the substrate surface, yielding a thickness value of $1.44 \mathrm{~nm}$.

$\mathrm{Hu}$ et al. reported a facile one-step synthesis of LDH monolayers in a reverse microemulsion (Fig. 4d) [35]. $\mathrm{Mg}\left(\mathrm{NO}_{3}\right)_{2} \cdot 6 \mathrm{H}_{2} \mathrm{O}$ and $\mathrm{Al}\left(\mathrm{NO}_{3}\right)_{3} \cdot 9 \mathrm{H}_{2} \mathrm{O}$ were introduced into an oil phase of isooctane with sodium dodecyl sulfate as surfactant and 1-butanol as co-surfactant. The $\mathrm{pH}$ of the solution was adjusted to 10 by $\mathrm{NaOH}$. The aqueous phase containing the nutrients for the growth of LDH would be dispersed in the oil phase to form droplets surrounded by dodecyl sulfate groups. The droplets served as nanoreactors and provided limited space and nutrients for the formation of LDH platelets. Therefore, both the diameter and thickness can be effectively controlled. Such system also allowed the negatively charged dodecyl sulfate chains to interact with the LDH planes to balance the charge. The XRD patterns 
(a)
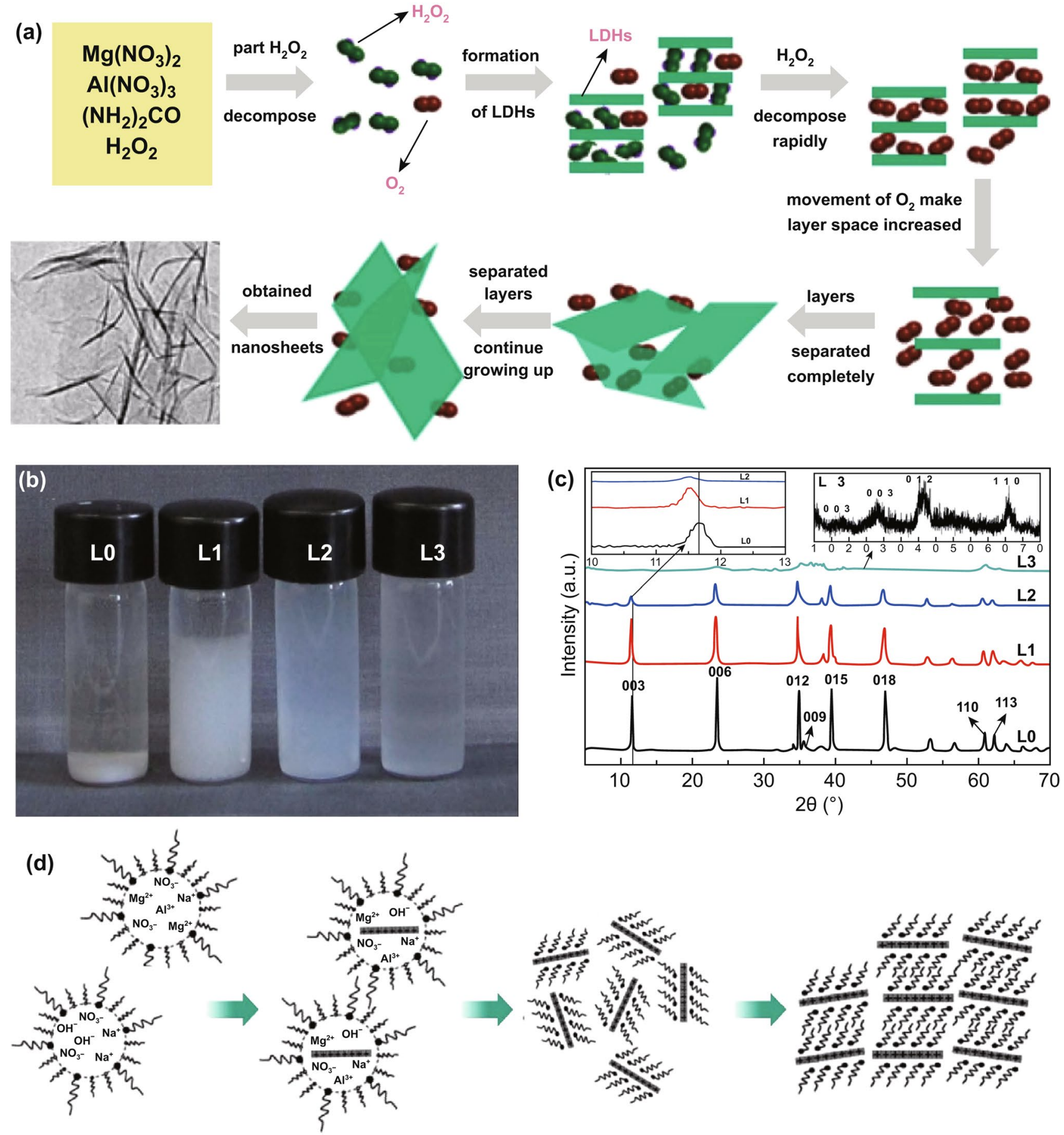

Fig. 4 a Suggested scheme for preparing exfoliated MgAl-LDH nanosheets. b, c Digital graphs of MgAl-LDHs suspension with different contents of $\mathrm{H}_{2} \mathrm{O}_{2}$ and the corresponding XRD patterns. Reproduced with permission from Ref. [34]. Copyright 2012 Elsevier Inc. d Schematic illustration of the nucleation and growth of LDH platelets. Reproduced with permission from Ref. [35]. Copyright 2006 The Royal Society of Chemistry 
of the gel-like materials presented two broad reflections at ca. $2 \theta=7.5^{\circ}$ and $20^{\circ}$, while strong basal plane Bragg reflection of LDHs was missing, suggesting a lack of an organized layered structure of the sample. Upon drying, the pattern showed a gradual growth of a $2 \theta=3^{\circ}$ Bragg reflection, indicating that the sample gains some structural order. All those reflections could be indexed as a rhombohedral unit cell with $a=2 d_{110}=3.04 \AA$ and $c=3 d_{003}=77.88 \AA$, agreeing well with the unit cell dimensions of the $\mathrm{Mg}_{2} \mathrm{Al}-\mathrm{LDH}$ intercalated with dodecyl sulfate that was obtained by ion exchange method from the pristine nitrate form. The AFM topology revealed isolated oval objects which have a uniform height distribution around $1.5 \mathrm{~nm}$ and a diameter distribution centered around $40 \mathrm{~nm}$.

\subsection{Chemical Exfoliation of Parent LDH Crystals}

Chemical exfoliation of parent LDH crystals provides another effective route to produce 2D nanosheets. Compared with direct synthesis process, it is more facile to control the growth rate and chemical composition of LDHs. Moreover, ion intercalation/exchange is a crucial step in chemical exfoliation route, which introduces diverse anions into the interlayer space of LDHs, contributing to the modification of LDH structure and tuning of properties.

\subsubsection{Synthesis of Layered Precursor Compounds}

The prerequisite of top-down strategy is to obtain multilayered host compounds in high quality. LDH crystals are usually prepared via a solution-based process, which may be classified as coprecipitation, homogeneous precipitation, and topochemical oxidation. Coprecipitation involves the precipitation of a solution containing divalent and trivalent metal salts under an alkaline condition or constant $\mathrm{pH}$, e.g., by adding $\mathrm{NaOH}$ or $\mathrm{Na}_{2} \mathrm{CO}_{3}$ [36-38]. In the early stages, almost all of the LDH parent materials were prepared by the coprecipitation. Later, homogeneous precipitation typically uses a reagent such as urea $\left(\mathrm{CO}\left(\mathrm{NH}_{2}\right)_{2}\right.$ or hexamethylenetetramine (HMT, $\mathrm{C}_{6} \mathrm{H}_{12} \mathrm{~N}_{4}$ ), which is hydrolyzed to slowly release ammonia and to generate an alkaline environment. Compared with coprecipitation, homogeneous precipitation generally leads to LDH products in high crystallinity due to homogenous nucleation and growth procedure [39, 40]. On the other hand, topochemical oxidation, a newly developed process involving a topotactic oxidative intercalation, started from brucite-like divalent metal hydroxides [41]. Using cobalt chloride $\left(\mathrm{CoCl}_{2} \cdot 6 \mathrm{H}_{2} \mathrm{O}\right)$ and ferrous chloride $\left(\mathrm{FeCl}_{2} \cdot 4 \mathrm{H}_{2} \mathrm{O}\right)$ as the precursors, Ma et al. [42] developed a new process to synthesize transition-metal-bearing LDHs; brucite-like $\mathrm{Co}^{2+}-\mathrm{Fe}^{2+}$ hydroxide was firstly synthesized via HMT hydrolysis under nitrogen protection, and the product was later transformed to $\mathrm{Co}_{2 / 3} \mathrm{Fe}_{1 / 2}(\mathrm{OH})_{2} \mathrm{LDH}$ via topotactic oxidative intercalation with iodine in chloroform $\left(\mathrm{I}_{2} / \mathrm{CHCl}_{3}\right)$. Brownish product was obtained by filtering and rinsing with anhydrous ethanol repeatedly. This innovative topochemical approach was also employed to successfully prepare $\mathrm{Co}^{2+}-\mathrm{Co}^{3+} \mathrm{LDH}$, which cannot be produced by traditional coprecipitation or homogeneous precipitation method because there is no stable dissociated $\mathrm{Co}^{3+}$ or $\mathrm{Co}(\mathrm{OH})_{3}$ in the aqueous solution [43]. Different from the heterometallic $(\mathrm{Co}-\mathrm{Fe})$ hydroxide, more crucial control was required to complete the oxidation degree of the same element by incorporating mixed valences. For example, after achieving the brucite-type hydroxide of hexagonal $\beta-\mathrm{Co}(\mathrm{OH})_{2}$ by refluxing $\mathrm{CoCl}_{2}$ in HMT solution, Ma et al. [43] employed bromine $\left(\mathrm{Br}_{2}\right)$ in acetonitrile $\left(\mathrm{CH}_{3} \mathrm{CN}\right)$ to transform it into $\mathrm{Co}^{2+}-\mathrm{Co}^{3+} \mathrm{LDH}$. They found that the oxidative intercalation process consumed 40 times the required amount of $\mathrm{Br}_{2}$ and the oxidation took 5 days to ensure the complete conversion into single $\mathrm{Co}^{2+}-\mathrm{Co}^{3+} \mathrm{LDH}$ phase without residue. Lee et al. developed a novel synthetic approach to hydrotalcite-like $\mathrm{Co}^{2+}$ (or $\left.\mathrm{Ni}^{2+}\right)-\mathrm{Fe}^{3+}$-LDHs using a one-pot topochemical oxidation reaction by anthraquinone-2-sulfonate anions (AQS2) [44]. AQS2 served as a mild oxidizing agent which allows the sole oxidation of $\mathrm{Fe}^{2+}$ into $\mathrm{Fe}^{3+}$ to form the LDH phase and were intercalated into the interlayer space of the LDH during the course of a slow precipitation. The process was also carried out by refluxing the $\mathrm{CoCl}_{2}$ (or $\left.\mathrm{NiCl}_{2}\right)-\mathrm{FeCl}_{2}-\mathrm{AQS} 2-\mathrm{HMT}$ solution with a stoichiometric ratio 2:1 of $\mathrm{Co}$ (or $\mathrm{Ni}$ )/Fe under $\mathrm{N}_{2}$ atmosphere for $3 \mathrm{~h}$. The standard redox potential of $\mathrm{AQS} 2^{2-} / \mathrm{AQS} 2$ was $-0.6 \mathrm{~V}$ (vs. $\mathrm{Ag} / \mathrm{AgCl}$ ), which is possible to oxidize the $\mathrm{Fe}^{2+}$ ions in the $\mathrm{Fe}(\mathrm{OH})_{2}$ phase because of the lower standard potential in $\mathrm{Fe}(\mathrm{OH})_{3} / \mathrm{Fe}(\mathrm{OH})_{2}(-0.58 \mathrm{~V})$. Brown and dark yellow solid precipitates were attained for the $\mathrm{Co}-\mathrm{Fe} \mathrm{LDH}$ and $\mathrm{Ni}-\mathrm{Fe}$ $\mathrm{LDH}$, respectively. The average lateral size of both samples was detected to be $0.5 \mu \mathrm{m}$, and the thickness was around $70 \mathrm{~nm}$. All diffraction peaks of XRD patterns were readily indexed as a hydrotalcite-like phase similar to those in $\alpha$-CoAQS2-LDH phase [45]. 


\subsubsection{Ion Intercalation/Exchange}

Ion intercalation/exchange is effective to synthesize LDH with desired ions and in turn regulate the expected properties of materials [46-49]. Ion intercalation spontaneously happens during the chemical synthesis of LDHs because counterions are needed to balance the host layer charge. In addition to inorganic anions including alkoxide, molybdate, polyoxometalates, etc., various organic molecules, such as glucose [50], carbon dots [51], and ethylene glycol [52], can also be intercalated. Intercalating guests between LDH host layers not only expand the interlayer spacing for convenient transport of ions/electrons, but also facilitate the subsequent exfoliation of LDHs into ultrathin nanosheets [53].

\subsubsection{Exfoliation}

Bulk LDHs are solids with strong in-plane chemical bonds while relatively weak interlayer forces. Exfoliating or delaminating bulk LDHs into few-layered or monolayered nanosheets could expose abundant active sites and contribute to an enhanced intrinsic catalytic activity. Since the report of exfoliation of graphite into monolayer graphene, diverse approaches, including soft chemical exfoliation and plasma exfoliation, have been developed and widely used.

\subsubsection{Soft Chemical Exfoliation in Liquid/Sol-} vent The first attempt to exfoliate LDH was reported by Adachi-Pagano et al. [54]. They prepared dodecyl sulfate (DS ${ }^{-}, \mathrm{C}_{12} \mathrm{H}_{25} \mathrm{SO}_{4}^{-}$)-intercalated $\mathrm{Zn}_{2} / \mathrm{Al}-\mathrm{DS}^{-}-\mathrm{LDH}$ and tried delaminating it in various organic solvents. The results showed that the LDH could be exfoliated in butanol, pentanol, and hexanol and remain stable for a long time. $\mathrm{Zn}_{2} / \mathrm{Al}-\mathrm{DS}^{-}-\mathrm{LDH}$ was partially delaminated in other solvents, such as water, methanol, ethanol, propanol, and hexane. Hydration state of the $\mathrm{DS}^{-}-\mathrm{LDH}$ was found to be a vital factor for determining the exfoliation extent. Venugopal et al. applied such exfoliation method to different types of divalent and trivalent LDHs, including $\mathrm{Mg} / \mathrm{Al}-\mathrm{LDHs}$, Ni/Al-LDHs, and Zn/Al-LDHs intercalated with sodium dodecyl sulfate or sodium dodecylbenzene sulfonate [55]. It turned out that the LDHs with low $\left[\mathrm{M}^{2+}\right] /\left[\mathrm{M}^{3+}\right]$ ratios can achieve higher exfoliation yield. LDHs were rarely exfoliated in nonpolar solvents (e.g., hexane), while they were delaminated best in alcohols, such as 1-butanol, 1-octanol, and so on.
Toluene was also studied as the dispersant of $\mathrm{DS}^{-}$-intercalated LDH for liquid delamination [56]. As depicted in Fig. 5a-e, after being stirred in toluene and sonicating for $5 \mathrm{~min}, \mathrm{DS}^{-}$-intercalated $\mathrm{Mg}_{0.67} / \mathrm{Al}_{0.33}-\mathrm{LDH}$ and $\mathrm{Co}_{0.67} / \mathrm{Al}_{0.33}$-LDH were rapidly exfoliated into monolayers with a clear transparent dispersion which showed a clear Tyndall light scattering effect. The exfoliation mechanism was proposed based on molecular dynamics simulation. For the LDH compounds incorporated with long-chain surfactant molecules, the Van der Waals interactions between chains anchored onto adjacent host layers play a role in holding the sheets together. The treatment with the solvents was expected to weaken or disrupt such van der Waals interactions and the $\mathrm{DS}^{-}$converted the hydrophilic LDHs into hydrophobic, which promotes solvation with nonpolar solvent molecules, such as toluene.

Formamide is also a common solvent to perform liquid exfoliation. Hibino and Jones firstly reported the exfoliation of LDHs in formamide by creating a desirable interlayer environment to intercalate a large volume of solvent [58]. They prepared $\mathrm{Mg}_{n} / \mathrm{Al}_{k}$-LDHs intercalated with different amino acid anions, including glycine, seine, and L-aspartic acid. Diverse polar solvents were examined as dispersants, such as water, ethanol, acetone, formamide, ethylene glycol, and diethyl ether. Among all the combinations, they found that the glycine and formamide led to the optimum result. When $0.03 \mathrm{~g} \mathrm{Mg}_{3} / \mathrm{Al}$-glycine-LDH was mixed with $10 \mathrm{~mL}$ formamide under stirring, rapid exfoliation occurred in a few minutes. They also reported the modification of $\mathrm{Mg}-\mathrm{Al}$ LDHs with various amino acids to create an interlayer environment that was suitable for solvation of formamide, which would break the hydrogen bonding network and lead to delamination [59].

Liu et al. performed a systematic research of the delamination of $\mathrm{Co}-\mathrm{Al} \mathrm{LDHs}$ in formamide (Fig. 5f-j) [53]. Hexagonal $\mathrm{Co}-\mathrm{Al}-\mathrm{CO}_{3} \mathrm{LDH}$ platelets of $4 \mu \mathrm{m}$ in lateral size were firstly prepared by the urea method and then converted to $\mathrm{Cl}^{-}-\mathrm{LDH}$ by treating with a $\mathrm{NaCl}-\mathrm{HCl}$ mixed solution [60]. After that, $\mathrm{Co}-\mathrm{Al}$ LDH intercalated with diverse anions was obtained via an anion exchange process employing corresponding salts, including $\mathrm{NO}_{3}{ }^{-}, \mathrm{ClO}_{4}{ }^{-}$, acetate, lactate, dodecyl sulfate, and oleate. The exchanged product $(0.1 \mathrm{~g})$ was mixed with $100 \mathrm{~mL}$ formamide and agitated vigorously in a mechanical shaker at a speed of $160 \mathrm{rpm}$ for 2 days. A pink transparent suspension was attained, containing welldefined nanosheets with a lateral size up to $2 \mu \mathrm{m}$. The height 

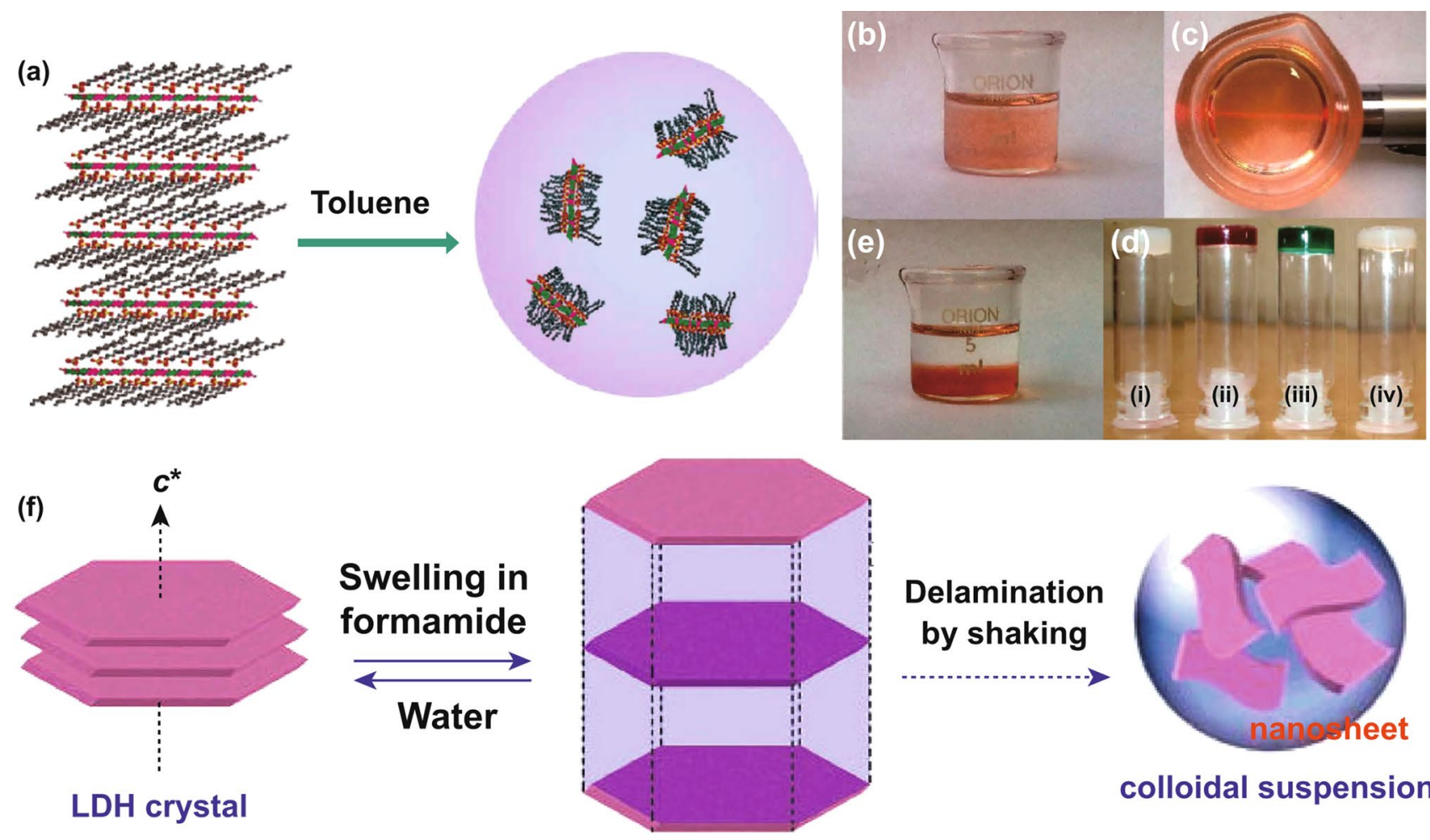

LDH crystal

\section{Swollen phase}
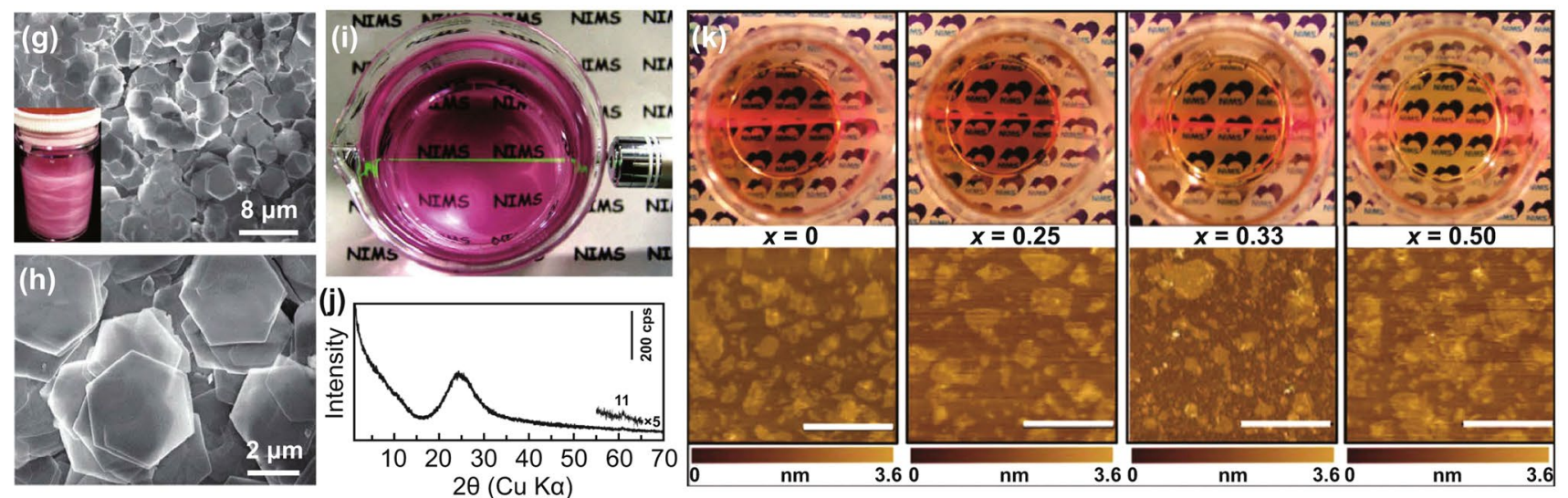

Fig. 5 a Delamination process of a surfactant-intercalated LDH by toluene. b, $\mathbf{c}$ Photograph and Tyndall effect of Co-Al LDH dispersion exfoliated by toluene. $\mathbf{d}$ Test-tube inversion test demonstrating the formation of toluene gels for dispersion of $\mathrm{Mg}-\mathrm{Al} \mathrm{LDH}$ (i), $\mathrm{Co}-\mathrm{Al} \mathrm{LDH}$ (ii), Ni-Al LDH (iii), and Zn-Al LDH (iv). e The Co-Al LDH dispersion exfoliated by toluene after 7 days. Reproduced with permission from Ref. [56]. Copyright 2011 American Chemical Society. $\mathbf{f}-\mathbf{j}$ Delamination process, low- and high-magnification SEM images, photograph and XRD pattern of the $\mathrm{Co}-\mathrm{Al}-\mathrm{CO}_{3} \mathrm{LDH}$ sample and the suspension. Reproduced with permission from Ref. [53]. Copyright 2006 American Chemical Society. $\mathbf{k}$ Photographs of nanosheet suspensions of the $\mathrm{Co}_{1-x}-\mathrm{Ni}_{x} \mathrm{LDHs}(x=0,0.25,0.33$ and 0.5$)$ and the corresponding AFM images. Reproduced with permission from Ref. [57]. Copyright 2009 American Chemical Society

profile of AFM revealed that the nanosheets possessed a fairly flat morphology with an average thickness of $\sim 0.8 \mathrm{~nm}$, which can be explained as the sum of crystallographic thickness of the LDH layer $(0.48 \mathrm{~nm})$ and an absorbed monolayer of formamide molecules $(\sim 0.3 \mathrm{~nm})$ [61]. Such thickness value manifested the unilamellar structure of the exfoliated nanosheets. Liang et al. developed a topochemical synthesis of $\mathrm{Co}-\mathrm{Ni} \mathrm{LDHs}$ from brucite-like $\mathrm{Co}-\mathrm{Ni}$ hydroxide with bromine as an oxidizing agent. Excess bromine in acetonitrile promoted partial oxidation of $\mathrm{Co}^{2+}$ into 
$\mathrm{Co}^{3+}$ [57]. Through the subsequent ethanol-assisted anion exchange process, a variety of inorganic and organic anionic forms of Co-Ni LDHs were achieved. The as-prepared $\mathrm{NO}_{3}{ }^{-}$-intercalated $\mathrm{CoNi} \mathrm{LDHs}$ without substantial carbonate contamination were successfully delaminated into unilamellar nanosheets bearing positive charges upon contact with formamide (Fig. 5k). Different characteristic colors were presented for the translucent suspensions of nanosheets, depending on the variable $\mathrm{Co} / \mathrm{Ni}$ ratios. It is worth noting that LDHs could also be delaminated in aqueous solution. Iyi and coworkers added aqueous zwitterion solution into $\mathrm{ClO}_{4}{ }^{-}$-intercalated $\mathrm{MgAl}-\mathrm{LDH}$ and successfully attained semitransparent colloidal suspension [62].

2.2.3.2 Plasma Exfoliation The concept of plasma was firstly proposed by Langmuir in 1928 [63], which has induced enormous research interest in materials synthesis and surface modifications during the past decades [64-68]. Besides being used to modifying surface [69], creating defects [70], and synthesizing materials [71], plasma has also been developed as technologies to exfoliate layered compounds, including graphite [72], black phosphorus [73], and also LDHs [74]. Wang et al. for the first time reported the efficient exfoliation of ultrathin $\mathrm{CoFe}$ LDH nanosheets by means of water plasma [75]. The plasma partially etched the interlayer anions and destroyed the electrostatic interactions between the host layers, thus resulting in fast exfoliation and simultaneously generating multivacancies in the asexfoliated LDH nanosheets. Later on, they also successfully realized the exfoliation of bulk CoFe LDHs into ultrathin nanosheets by $\mathrm{N}_{2}$ plasma [76]. CoFe LDHs were firstly prepared by hydrothermal reaction and then treated by $\mathrm{N}_{2}$ plasma for $60 \mathrm{~min}$. After the $\mathrm{N}_{2}$ plasma treatment, bulk CoFe LDHs were delaminated into ultrathin nanosheets. Numerous atomic-sized holes were also produced in the meantime with more exposed edge sites. As revealed by the height profiles of AFM, the thickness was decreased from $\sim 20$ to $\sim 1.6 \mathrm{~nm}$. Many holes were also observed in the basal plane of the exfoliated LDH nanosheets induced by the etching effect of plasma.

\section{Structure Modulation toward Application in Oxygen Evolution Reaction}

Transition metal-based LDH materials have attracted considerable interest as the promising OER catalysts in alkaline system, due to their unique $2 \mathrm{D}$ layered structure, electronic property, and low cost. However, the catalytic performance of LDHs for OER is still restricted by their low electrical conductivity $\left(10^{-13}-10^{-17} \mathrm{~S} \mathrm{~cm}^{-1}\right)$, limited active sites, inferior thermostability, and weak adsorption of oxygenated intermediates [77]. Therefore, the following parts will mainly discuss a series of effective strategies for obtaining remarkable electrocatalytic activities toward OER.

\subsection{Doping}

LDHs can be regarded as metal-doped monometallic hydroxides [11]. Monometallic hydroxides (e.g., nickel hydroxides and cobalt hydroxides) were usually synthesized under ambient conditions in air, which would lead to the inevitable oxidation of $\mathrm{Ni}^{2+}$ or $\mathrm{Co}^{2+}$ into their trivalent state. Therefore, positively charged $\mathrm{Ni}^{3+}$-doped $\mathrm{Ni}(\mathrm{OH})_{2}$ and $\mathrm{Co}^{3+}-\mathrm{Co}(\mathrm{OH})_{2}$ would be produced under the regular conditions from the transformation of monometallic hydroxides [78-81]. Although many studies have been devoted to monometallic $\mathrm{Ni}(\mathrm{OH})_{2}$ - and $\mathrm{Co}(\mathrm{OH})_{2}$-based materials for OER, their electrocatalytic activity is still not satisfactory. Introducing metallic dopants with various valent states into monometallic hydroxide is viewed as an ideal strategy to enhance their intrinsic catalytic activity because of the redistribution of localized $\pi$-symmetry electrons through bridging $\mathrm{O}^{2-}$ and endowing favorable adsorption/desorption of oxygen-containing species [82]. Besides, replacing some lattice oxygen in metal hydroxides with nonmetal elements (e.g., B, $\mathrm{N}, \mathrm{P}, \mathrm{S}, \mathrm{F}$ ) is also a promising strategy to modulate the electronic structure of hydroxides. Incorporating other metal or nonmetal elements would efficiently improve the conductivity and in turn promote the electrochemical performance of LDHs for water splitting. Hu et al. prepared $\mathrm{NiCo}$ and $\mathrm{CoCo}$ LDHs with $\mathrm{Br}^{-}$anions via a topochemical approach. The electrochemical measurements showed that the $\mathrm{NiCo} \mathrm{LDH}$ exhibited lower overpotential and Tafel slopes for OER than that of pure CoCo nanosheets, which can be attributed to the synergistic effects between different metal ions [12]. Lu et al. demonstrated a facile and practical pathway to fabricate $3 \mathrm{D}$ porous sulfur-incorporated $\mathrm{NiCoFe} \mathrm{LDH}$ nanosheets on carbon cloth and achieved superb electrocatalytic activity and stability for OER [83]. The enhanced performance is attributed to the hierarchical nanostructure and sulfur doping which endows the electrode with high electrical conductivity [83]. 
Due to the versatile composition of LDHs, a large number of active sites can be easily incorporated into the structure of LDHs to modulate the electronic structure and active species. However, the OER activity of bimetallic LDHs is still not close to their optimal state, which can be further enhanced by doping the third metallic element with the formation of trimetallic LDHs. The additional doping can not only modify the electronic configuration of bimetallic LDHs, but also create synergetic effects between host layers and the dopants, which would enhance the intrinsic activity for OER and bring new properties toward other electrochemical applications, such as hydrogen evolution reaction (HER) and oxygen reduction reaction (ORR). Mukerjee et al. produced high-surface-area $\mathrm{Ni}-\mathrm{Fe}-\mathrm{Co}$ films on Raney nickel supports and found that such catalysts exhibited enhanced OER mass activity as compared to the $\mathrm{Ni}-\mathrm{Fe}$ catalyst. The enhancements were ascribed to two aspects: (1) the charge transfer effect leads to the formation of conductive $\mathrm{Ni}^{\mathrm{III}} \mathrm{OOH}$ species at lower overpotential, therefore activating the $\mathrm{Fe}$ sites that are inaccessible to electron transfer in the nonconductive $\mathrm{Ni}^{\mathrm{II}}(\mathrm{OH})_{2}$. (2) Introducing Co effectively induces the shrinkage of the $\mathrm{Ni}$ and Fe local geometry and likely results in an optimized $\mathrm{Fe}-\mathrm{OH} / \mathrm{OOH}$ bond strength as revealed by XAS analysis [84]. Duan et al. fabricated $\mathrm{Mn}^{4+}$-doped NiFe LDHs by a simple coprecipitation method at room temperature [85]. The as-prepared NiFeMn LDHs presented a flowerlike morphology assembled by the ternary LDH nanosheets with an average lateral size of $50 \mathrm{~nm}$ and thickness of $3.7 \mathrm{~nm}$. Such $\mathrm{Mn}^{4+}$-doped NiFeMn LDH exhibited lower onset potential of $200 \mathrm{mV}$ and faster OER current increase as compared to undoped NiMn LDH and NiFe LDH. A smaller Tafel slope of $47 \mathrm{mV} \mathrm{dec}{ }^{-1}$ was also observed. A high stability was also achieved for delivering constant current density of $20 \mathrm{~mA} \mathrm{~cm} \mathrm{~cm}^{-2}$ over $15 \mathrm{~h}$. The high catalytic activity is ascribed to the intrinsic electrocatalytic active $\mathrm{Ni}^{2+}$ and $\mathrm{Fe}^{3+}$ and the synergy between $\mathrm{Mn}$ dopants and these active sites. The DFT calculation proved that $\mathrm{Mn}^{4+}$ doping could narrow the bandgap of NiFe LDH with exposing more conductive electronic structure and thus improve the electric conductivity. The resistance of NiFeMn LDH disk-shaped pellet is $1.6 \times 10^{3} \Omega \mathrm{sq}^{-1}$ that is lower than that of the corresponding NiFe LDH $\left(2.2 \times 10^{3} \Omega \mathrm{sq}^{-1}\right)$. Moreover, doping Mn into NiFe LDH can also facilitate the formation of intermediates of ${ }^{*} \mathrm{O}$ and ${ }^{*} \mathrm{OH}$, accelerating the OER catalytic process.

\subsection{Introduction of Cavity}

Introducing cavities have been regarded as efficient strategies to tune the coordination valence and surface chemical environment of electrocatalysts [86-88]. Wang et al. applied water and $\mathrm{N}_{2}$ plasma to exfoliate bulk CoFe LDHs into ultrathin nanosheets [75, 76]. As illustrated in Fig. 6, cavities were introduced into the nanosheets during the exfoliated process. With the assistance of $\mathrm{N}_{2}$ plasma, nitrogen could also be doped to alter the surrounding electronic arrangement of the increased reactive sites facilitating the adsorption of OER intermediates [76]. In addition, introducing defects could further effectively tune the electrocatalytic activity of reactive sites by increasing the number of dangling bonds around reactive sites and decreasing the coordination number of reactive sites. Later on, they successfully realized the selective formation of cation vacancies in NiFe LDH nanosheets (Fig. 6g) [89]. The as-prepared $\mathrm{NiFe}$ LDHs- $\mathrm{V}_{\mathrm{Fe}}$ and $\mathrm{NiFe} \mathrm{LDH}-\mathrm{V}_{\mathrm{Ni}}$ electrocatalysts exhibited outstanding activity for OER, which exhibits a superior stability with almost no decay of the LSV curves after 2000 cycles [76]. The high performance may be ascribed to the introduction of rich iron and nickel vacancies in the LDH nanosheets and increase in the adsorbing capacity of OER intermediates by surface electronic tuning. DFT computational results further verified the OER performance can be enhanced by the Fe or $\mathrm{Ni}$ vacancies.

\subsection{Functional Nanoparticles-Decorated LDHs}

Recent works have reported that the LDHs decorated with functional nanoparticles can effectively enhance the electrocatalytic activity for OER [90-93]. Metal nanoparticles with high electrical conductivity can accelerate the electron transfer and increase the heterogeneous interaction of LDHs during the OER process [94]. Gao et al. fabricated Ni nanoparticles (Ni NPs) on the NiFe LDH ultrathin nanosheets (Ni NP/NiFe LDH) by a onestep hydrothermal method [93]. Within the Ni NP/NiFe $\mathrm{LDH}$, the charge transfer resistance is reduced by highly conductive Ni NPs. Furthermore, the LDH nanosheets with highly exposed surface provide abundant catalytically active sites, and the intimate contact between $\mathrm{Ni}$ 
(a)
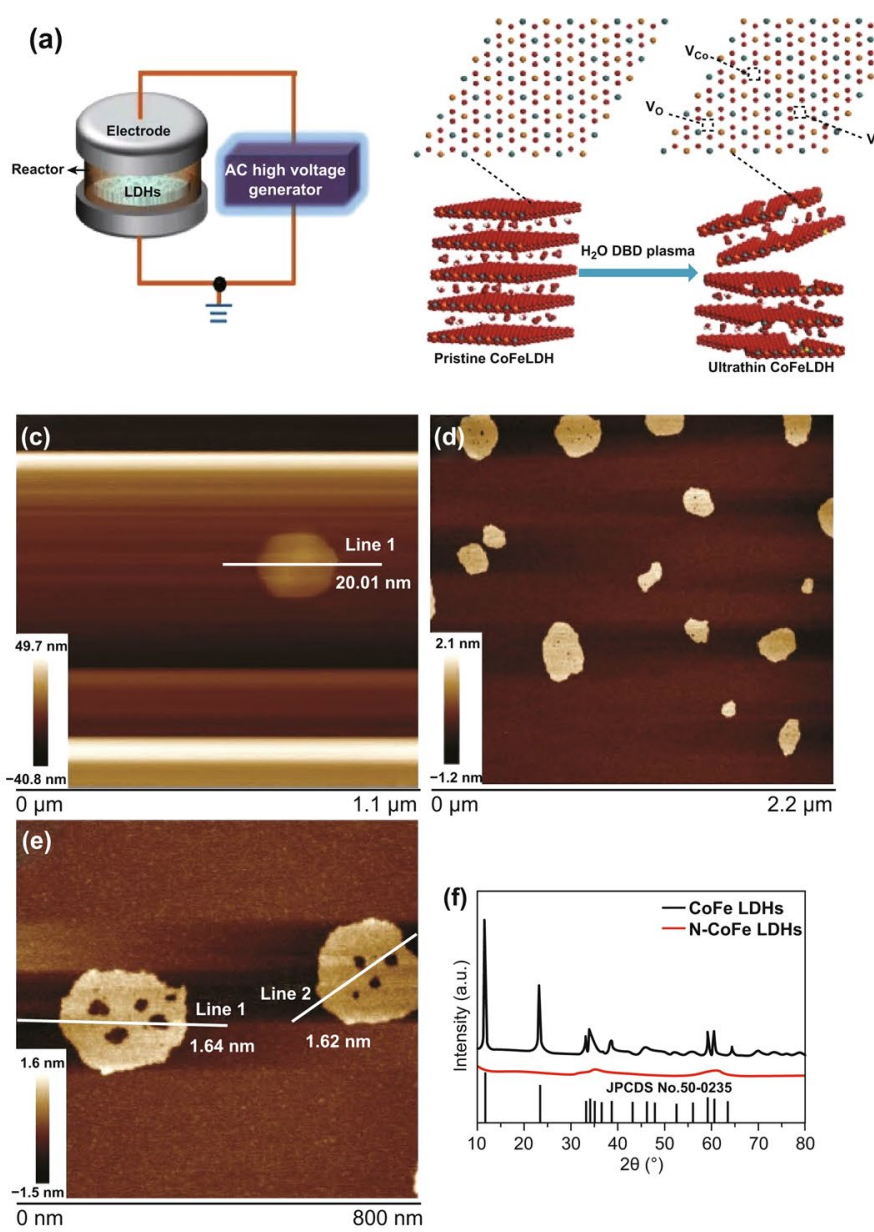
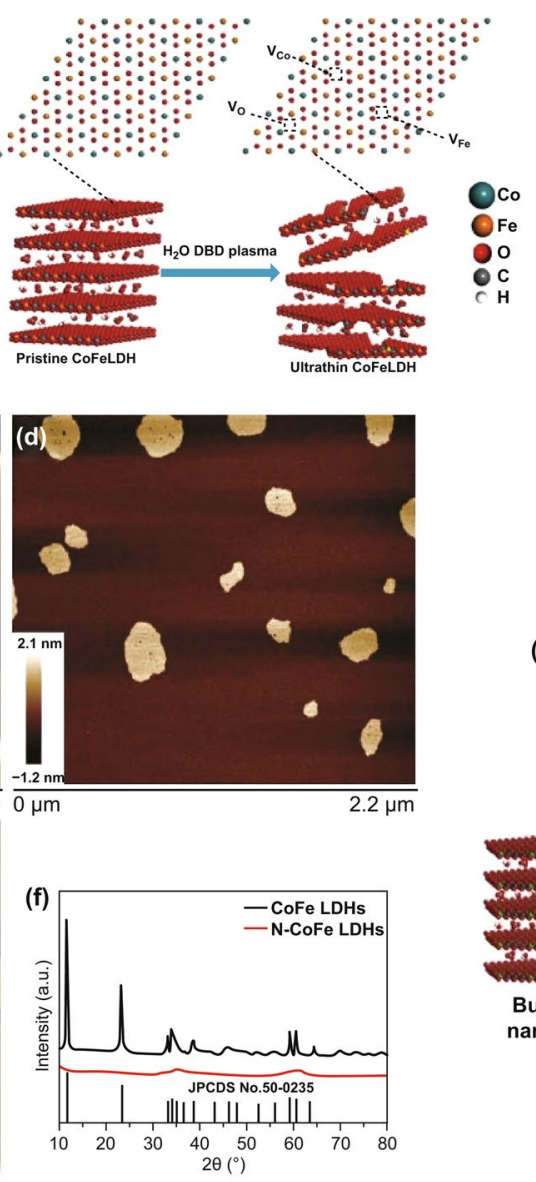

(b)

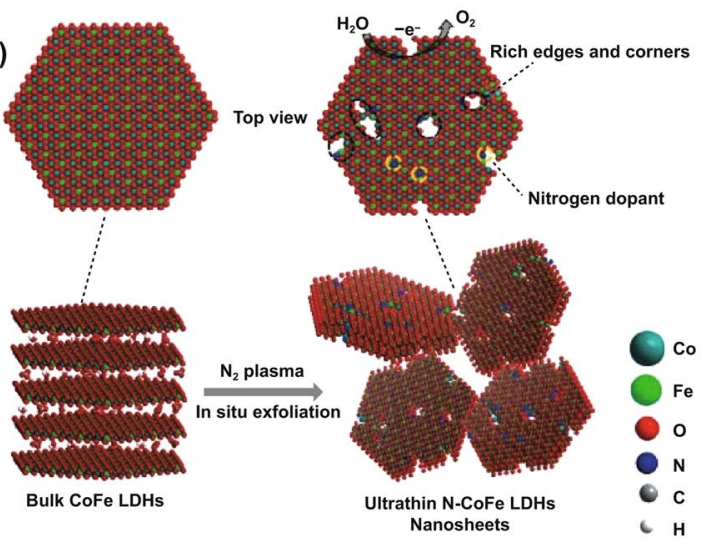

(g)
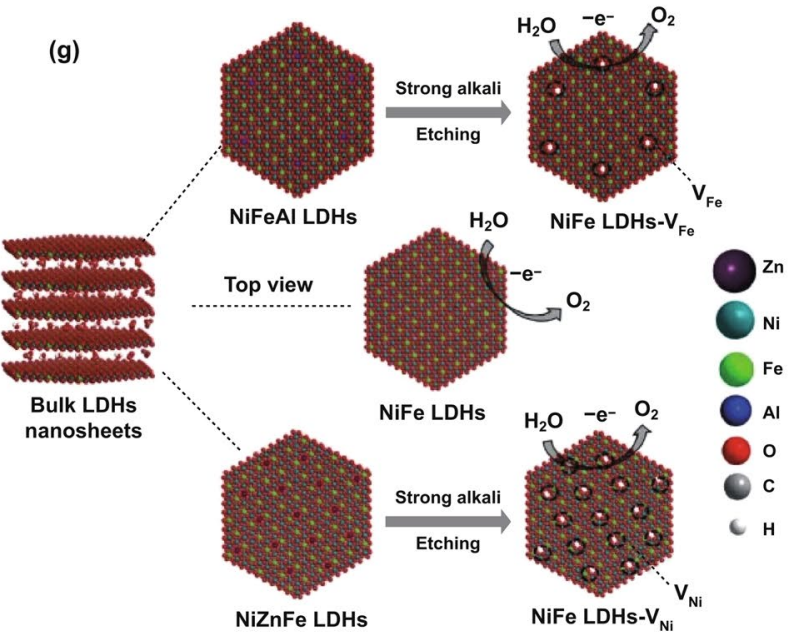

Fig. 6 a Schematic illustration of the water-plasma-enabled exfoliation process of CoFe LDH nanosheets. Reproduced with permission of Ref. [75]. Copyright 2017 WILEY-VCH Verlag GmbH \& Co. KGaA, Weinheim. b Illustration of the exfoliation process of bulk CoFe LDH into nanosheets by $\mathrm{N}_{2}$ plasma. c AFM image of the bulk CoFe LDH. d-f AFM images and XRD pattern of the ultrathin N-CoFe LDH nanosheets. Reproduced with permission of Ref. [76]. Copyright 2018 WILEY-VCH Verlag GmbH\& Co. KGaA, Weinheim. g The synthesis of NiFe $\mathrm{LDHs}_{\mathrm{Fe}}$ and NiFe LDH-V $\mathrm{Ni}_{\mathrm{Ni}}$ by strong alkali etching LDHs. Reproduced with permission of Ref. [89]. Copyright $2018 \mathrm{WILEY}-\mathrm{VCH}$ Verlag GmbH\& Co. KGaA, Weinheim

NPs and NiFe LDH forms the profitably synergic effects. Such Ni NP/NiFe LDH catalyst reveals high catalytic performance for OER due to aforementioned superiorities. Similarly, Zhu et al. reported Au-supported NiFe LDHs arrays on Ni foam (NiFe LDH@ Au/Ni foam) prepared by hydrothermal reaction combined with chemical deposition (Fig. 7a, b) [92]. As an OER catalyst, NiFe LDH@ $\mathrm{Au} / \mathrm{Ni}$ foam requires very low overpotentials of 221, 235, and $270 \mathrm{mV}$ to reach the current densities of 50,100, and $500 \mathrm{~mA} \mathrm{~cm}^{-2}$ in alkaline solution, respectively, showing a remarkable OER performance (Fig. 7c). Besides the high conductivity of Au, the high catalytic activity for OER can be attributed to the following reasons. On the one hand, Au with high electronegativity can adsorb more electrons to generate and stabilize $\mathrm{Ni}^{3+}$ with high oxidation state, thus improving the OER efficiency. On the other hand, strongly electrophilic $\mathrm{Ni}^{3+}$ facilitates the formation of the hydroperoxy species $(\mathrm{OOH})$ as the key intermediates for $\mathrm{O}_{2}$ evolution. Recent studies have focused on the single-atom metal-modified electrocatalysts which show higher electrocatalytic activity compared with nonmodified ones $[66,95,96]$. Zhang et al. developed a single-atom $\mathrm{Au}(0.4 \mathrm{wt} \%)$-decorated NiFe LDH (sAu/NiFe LDH) electrocatalyst with a sixfold enhancement on the OER activity (Fig. 7d, e) [97]. After dispersing atomic $\mathrm{Au}$ on $\mathrm{NiFe} \mathrm{LDH}$, the overpotential of $\mathrm{Au} / \mathrm{NiFe} \mathrm{LDH}$ was 

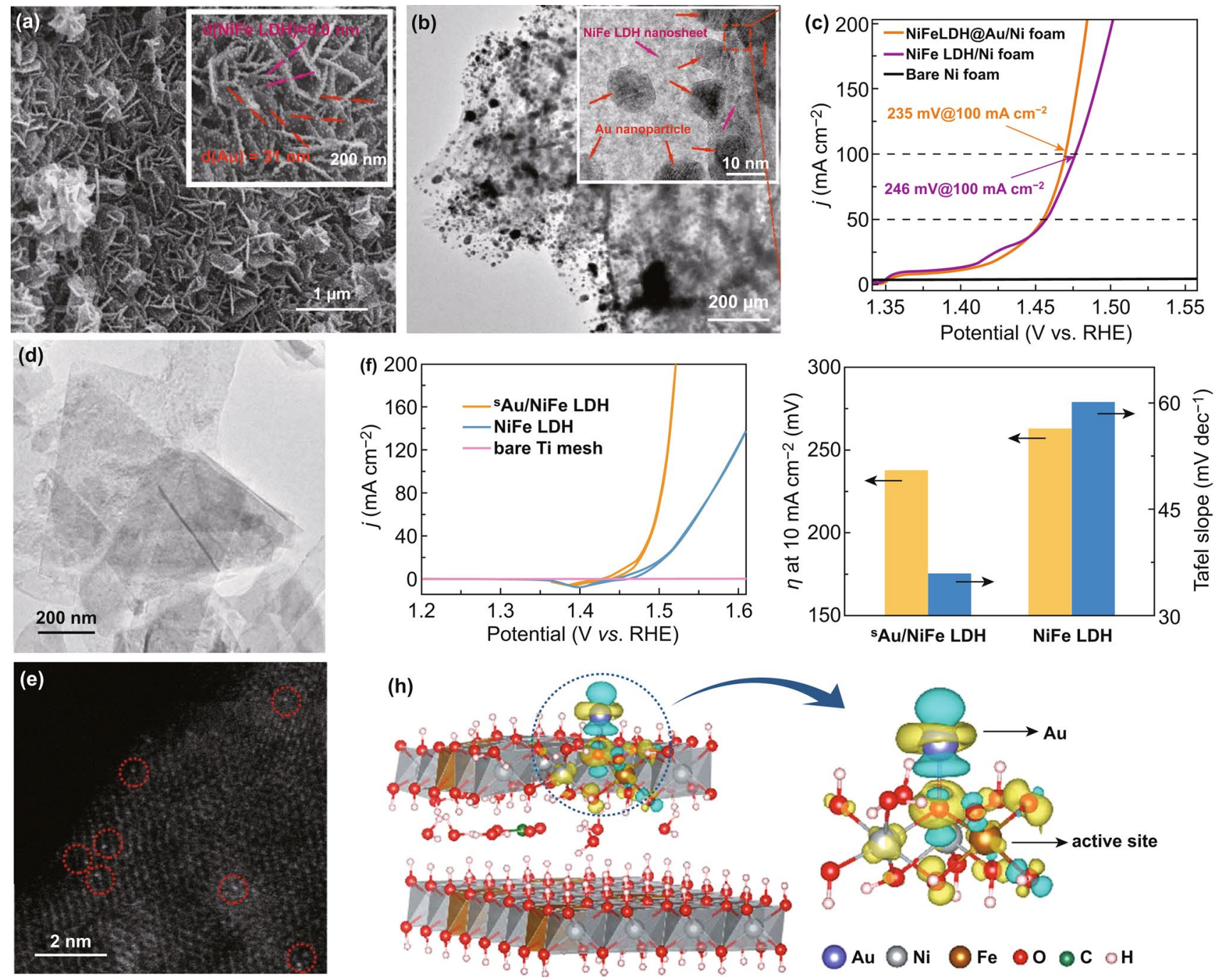

Fig. 7 a SEM images, b TEM images of NiFe LDH@Au/Ni foam. c LSV curves of as-prepared catalysts at $1 \mathrm{mV} \mathrm{s}^{-1}$ in $1.0 \mathrm{M} \mathrm{KOH}$. Reproduced with permission of Ref. [92]. Copyright 2017 American Chemical Society. d TEM image, e HAADF-STEM image of sAu/NiFe LDH. f Cyclic voltammetry (CV) curves of the catalysts at $5 \mathrm{mV} \mathrm{s}^{-1}$ with $95 \% \mathrm{iR}$ compensation in $1 \mathrm{M} \mathrm{KOH}$. g Overpotential $(\eta)$ at $10 \mathrm{~mA} \mathrm{~cm}^{-2}$ and Tafel slope of pure NiFe LDH and sAu/NiFe LDH. h Differential charge densities of NiFe LDH supported with and without Au atom. Reproduced with permission of Ref. [97]. Copyright 2018 American Chemical Society

reduced to $0.21 \mathrm{~V}$, close to the calculated result $(0.18 \mathrm{~V})$ (Fig. 7f, g). The excellent OER activity is ascribed to the charge redistribution of active $\mathrm{Fe}$ and its surrounding atoms, which is induced by the neighboring $\mathrm{Au}$ atom on the NiFe oxyhydroxide generated from LDH and stabilized by $\mathrm{CO}_{3}{ }^{2-}$ and $\mathrm{H}_{2} \mathrm{O}$ during the OER process. The calculation results indicate that a net Au-to-LDH charge redistribution generated by the integrated charge density difference can transfer to surrounding atoms (e.g., $\mathrm{O}, \mathrm{Ni}$, and $\mathrm{Fe}$ ), promoting the adsorption of $\mathrm{OH}^{-}$and optimizing the adsorption of intermediates (e.g., $\mathrm{O}^{*}$ and $\mathrm{OOH}^{*}$ ), thus reducing the overpotential from $\mathrm{O} *$ to $\mathrm{OOH}^{*}$ in the rate-limiting step (Fig. 7h). As mentioned above, the formation of heterostructures between LDHs and metal nanoparticles is considered beneficial to enhance OER activity. Francisco and coworkers integrated $\mathrm{Rh}$ species with $\mathrm{NiFe}$ $\mathrm{LDH}$, whereas $\mathrm{Rh}$ acts as oxidized dopants and metallic clusters $(<1 \mathrm{~nm})$, which can dramatically improve OER kinetics with overpotential 7 and $35 \mathrm{mV}$ smaller than that of $\mathrm{NiFe} \mathrm{LDH}$ at 10 and $100 \mathrm{~mA} \mathrm{~cm}{ }^{-2}$, respectively [98]. Song et al. reported a facile one-step method synthesizing $\mathrm{Ru}$ atoms supported on a monolayer NiFe LDH with 
precise location instead of random dispersion [99]. The overpotential of such Ru/mono-NiFe is 104 and $134 \mathrm{mV}$ lower than that of mono-NiFe and bulk-NiFe, respectively. Such catalysts also showed high stability with no obvious decline after 600 cycles.

In addition to the metal nanoparticles, the incorporation of nonmetal nanoparticles to LDHs has also been considered as an effective approach to improve the electrocatalytic performance [100, 101]. Valdez et al. found that the OER performance of CoFe LDHs can be enhanced by modifying with $\mathrm{CoFe}$ hydroxide nanoparticles, due to the synergistic effect between the CoFe LDHs and CoFe hydroxide nanoparticles (Fig. 8a-d) [100]. The Fe with high dispersibility could change the electronic properties of Co-Fe LDH catalysts. The interaction between the electrons of $\mathrm{CoFe} \mathrm{LDH}$ surface and those from $\mathrm{Fe}$ or $\mathrm{Co}$ of the nanoparticles lowers the OER overpotential. Carbon quantum dot (CQD) with a small particle size $(<5 \mathrm{~nm})$ is a new class of nanocarbon, which shows high conductivity, fast electron transfer, and electron reservoir properties [102-104]. Kang et al. combined NiFe LDHs with CQDs to construct the CQD/NiFe LDH hybrids by a two-step solvothermal reaction, in which the CQDs $(\sim 5 \mathrm{~nm})$ are anchored on the ultrathin NiFe LDH nanoplates with the thickness of around $1 \mathrm{~nm}$ (Fig. 8e-h) [101]. The CQD/NiFe LDH hybrids achieve a small overpotential of $235 \mathrm{mV}$ at the current density of $10 \mathrm{~mA} \mathrm{~cm}{ }^{-2}$
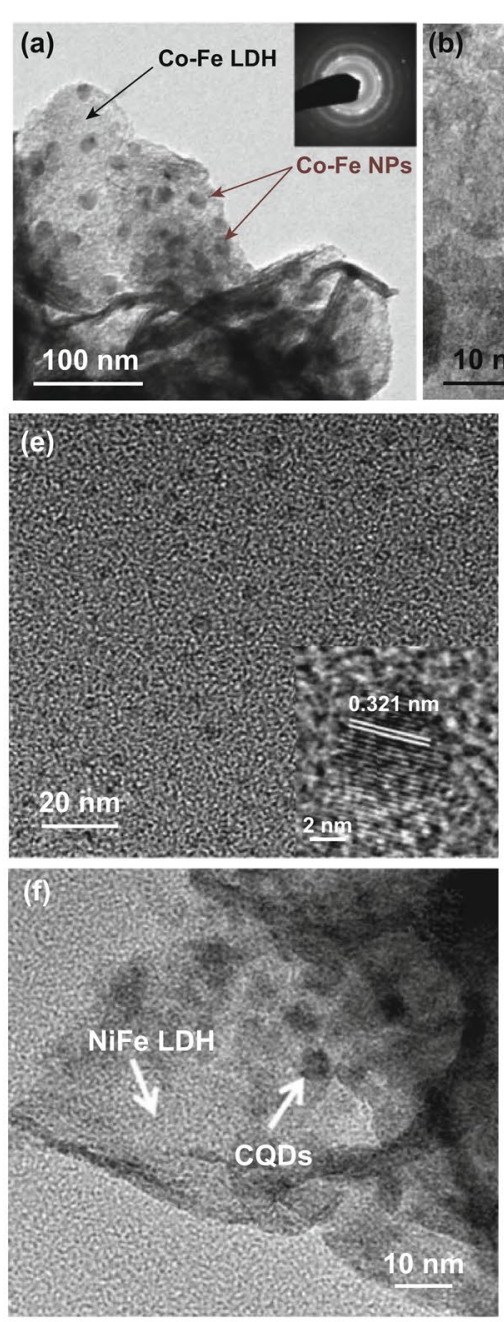
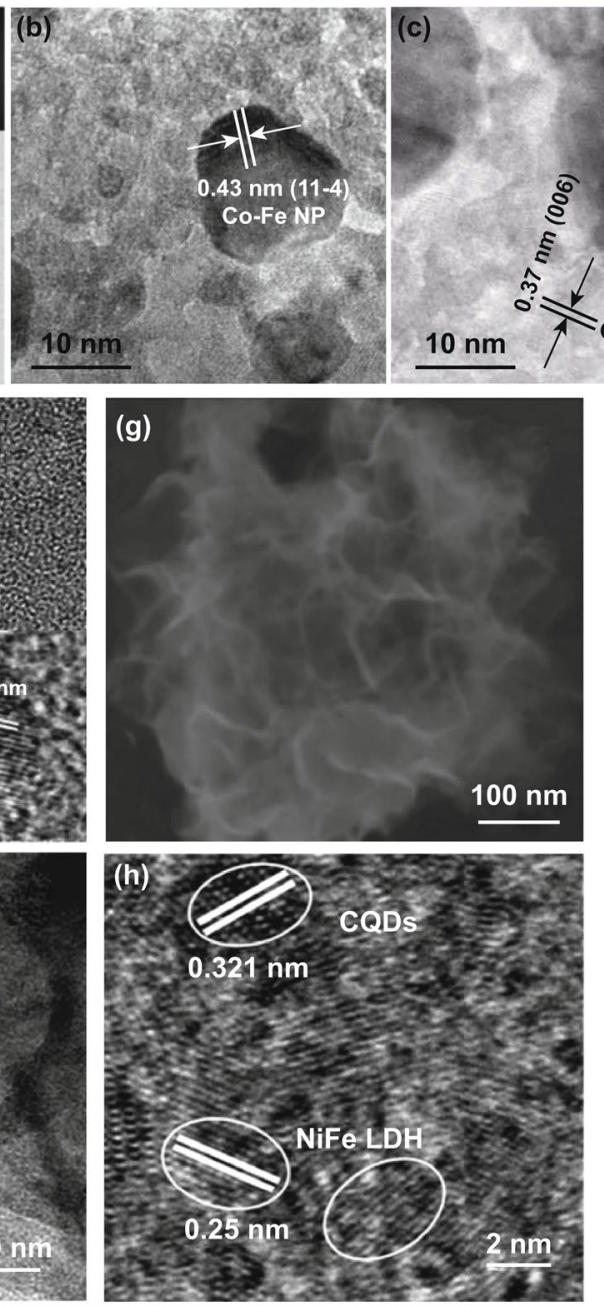
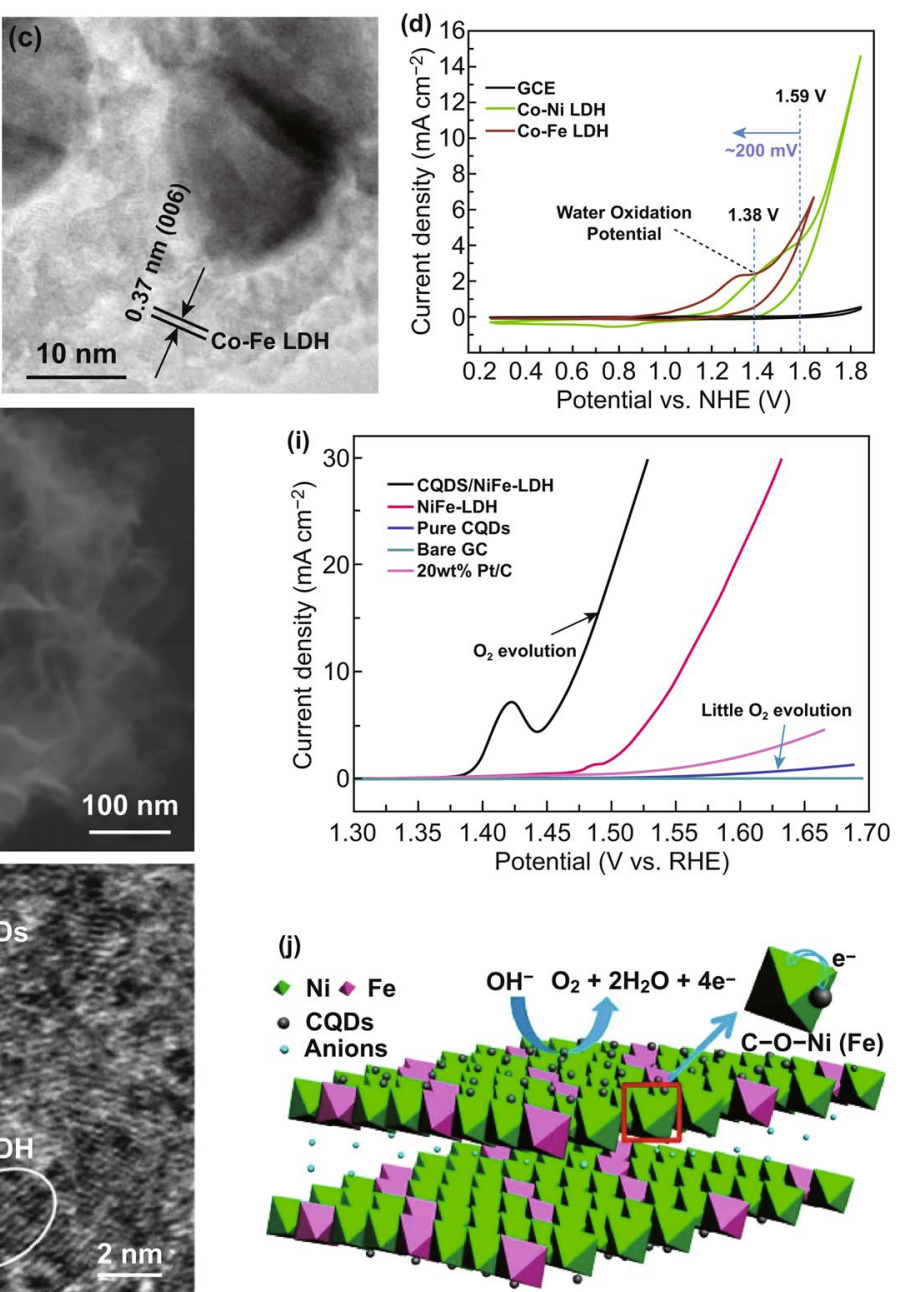

Fig. 8 a TEM and SAED images (inset of a), $\mathbf{b}$ and $\mathbf{c}$ HRTEM images of Co-Fe LDH decorated with Co-Fe hydroxide NPs. $\mathbf{d}$ CV curves of the three catalysts at $20 \mathrm{mV} \mathrm{s}^{-1}$ in $0.1 \mathrm{M}$ phosphate buffer. Reproduced with permission of Ref. [100]. Copyright 2015 The Electrochemical Society. e TEM image and HRTEM image (inset of e) of CQD. $\mathbf{f}$ TEM image, $\mathbf{g}$ SEM image, $\mathbf{h}$ HRTEM image of the CQD/NiFe LDH hybrid. $\mathbf{i}$ LSV curves of as-prepared catalysts at $5 \mathrm{mV} \mathrm{s}^{-1}$ in $0.1 \mathrm{M} \mathrm{KOH}$. j Schematic model of the roles of CQDs in the CQD/NiFe LDH hybrid catalyst. Reproduced with permission of Ref. [101]. Copyright 2014 American Chemical Society 
in $1 \mathrm{M} \mathrm{KOH}$, showing the high OER activity (Fig. 8i). The strong bonding and interaction between NiFe LDH nanoplates and CQDs accelerate the charge transport between them, leading to the enhanced catalytic activity for OER (Fig. 8j).

\subsection{LDHs/Conductive Components Hybrids}

Despite the considerable progress in controlling the structure of LDHs-based OER catalysts, their development is still seriously hindered by the poor conductivity and confined space for catalytic reactions. To further boost the catalytic performance of LDHs toward OER, it is necessary to combine
LDHs with new components. Carbon-based materials (e.g., carbon nanotubes (CNTs) and graphene) as catalyst supports have been widely used in various catalytic systems, because of the beneficial physical and chemical properties including high electronic conductivity, good mechanical strength, outstanding thermal stability, and large specific area [14, 105]. Constructing LDH-based catalysts on carbon-based materials can significantly improve the electrocatalytic performance for OER. As one-dimensional conductors, CNTs possess good electrocatalytic activities, which can be used to further boost OER activities of LDHs by functionalization [101, 106, 107]. Dai et al. successfully grew ultrathin NiFe LDH nanoplates on mildly oxidized multiwalled CNTs by

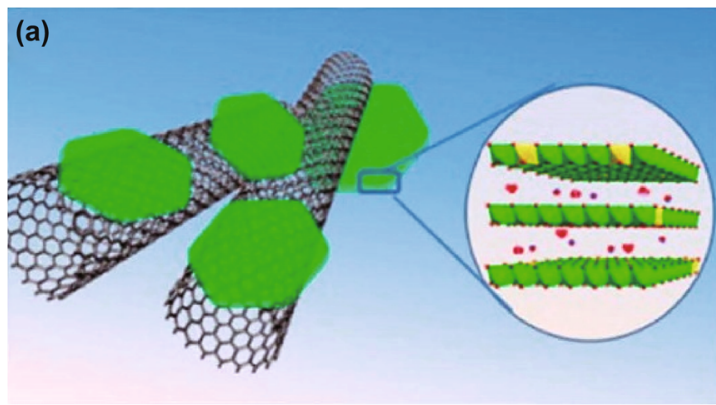

(d)
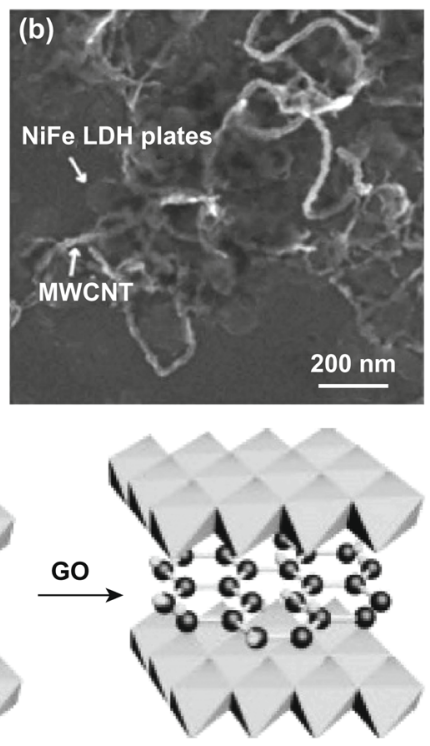
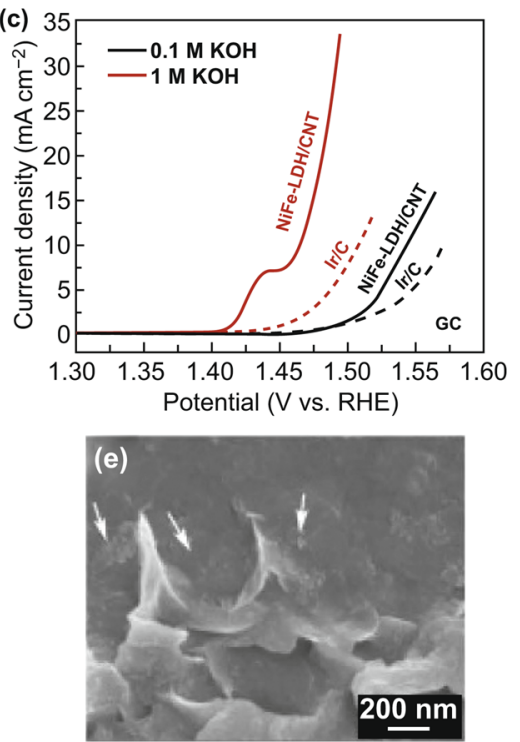
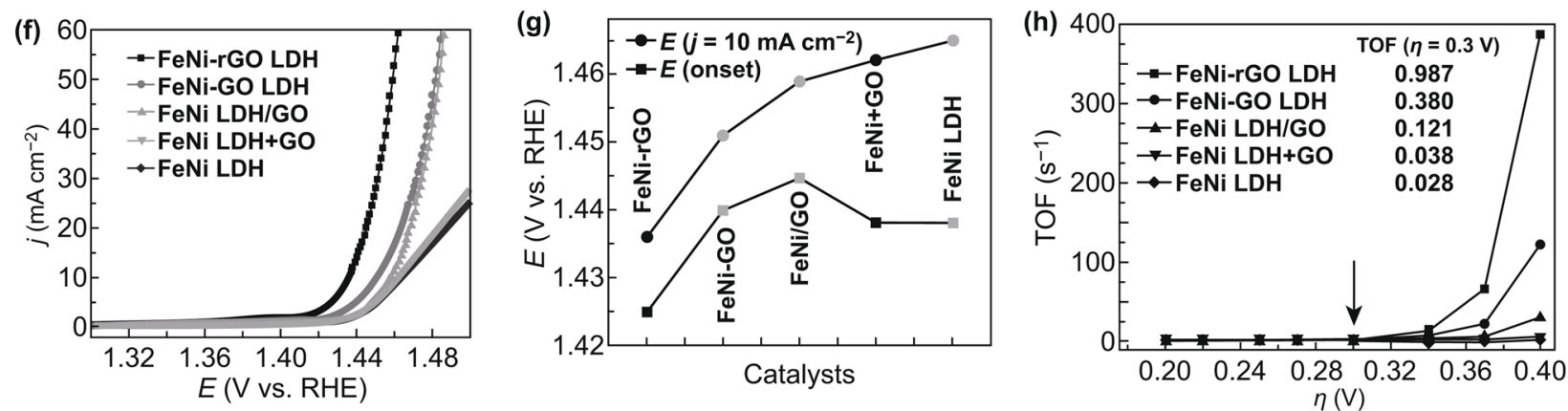

Fig. 9 a Schematic diagrams of the NiFe LDH/CNT hybrid architecture and LDH crystal structure. b SEM image of NiFe LDH/CNT hybrid catalyst. c $95 \%$ iR-corrected LSV curves of the three catalysts at $5 \mathrm{mV} \mathrm{s}^{-1}$ in 0.1 and $1 \mathrm{M} \mathrm{KOH}$. Reproduced with permission of Ref. [108]. Copyright 2013 American Chemical Society. d Fabrication process, e SEM image of FeNi-GO LDHs. f LSV curves of the catalysts at $5 \mathrm{mV} \mathrm{s}{ }^{-1}$ in $1 \mathrm{M} \mathrm{KOH}$. g Onset potentials and potentials at $10 \mathrm{~mA} \mathrm{~cm}$ of the as-prepared catalysts during the OER process. $\mathbf{h}$ TOF values of the catalysts as a function of overpotential and TOF values at an overpotential of $0.3 \mathrm{~V}$ (inset of $\mathbf{h}$ ). Reproduced with permission of Ref. [111]. Copyright 2014 WILEY-VCH Verlag GmbH\& Co. KGaA, Weinheim 
solvothermal treatment (Fig. 9a, b) [108]. The electronic conductivity and dispersion of NiFe LDHs are improved by introducing multiwalled CNT support. Moreover, the exposure of active sites can also be increased. The strong interaction between NiFe LDHs and CNTs ensures the fast electron transfer during the OER process. As a result, the $\mathrm{NiFe} \mathrm{LDH} /$ CNT catalyst with a high TOF value shows high catalytic activity and durability for OER in basic solution (Fig. 9c). Among various carbon-based materials, graphene nanosheet has been considered an ideal 2D carbon material [109, 110]. After functionalization of surface, the obtained graphene oxide (GO) has rich oxygenic groups which favor the assembly between GO nanosheets and LDH layers through electrostatic attraction force, thus resulting in the formation of the interlayered hybrid sheets [111]. These hybrid sheets exhibit an enhanced electrocatalytic activity, owing to the conductive graphene sheets, highly exposed and dispersed active sites, and strong synergistic effects. Up to now, graphene and its derivatives (e.g., GO, reduced graphene oxide (rGO), and heteroatom-doped graphene) have been extensively utilized to couple with LDHs [19, 111-113]. Yang et al. fabricated FeNi-LDH/GO hybrid nanosheets (FeNi-GO LDH) via the alternate stack of the GO layers and FeNi double hydroxide cation layers (Fig. 9d, e) [111]. The FeNi-GO LDH catalyst shows high OER activity with low overpotential $(0.21 \mathrm{~V})$ and small Tafel slope $\left(\sim 40 \mathrm{mV} \mathrm{dec}{ }^{-1}\right)$. After reducing GO to $\mathrm{rGO}$, the overpotential for OER of as-prepared FeNi-rGO $\mathrm{LDH}$ catalyst can be further decreased to $0.195 \mathrm{~V}$, while its TOF value at the overpotential of $0.3 \mathrm{~V}$ is as high as $0.98 \mathrm{~s}^{-1}$ (Fig. 9f-h). The excellent electrocatalytic performance for OER of the NiFe-rGO LDH is mainly attributed to the FeNi double hydroxide with high OER catalytic activity and the rGO layers with high conductivity. Based on the electronegativity theory, the introduction of heteroatomdoped graphene favors the dispersibility and stability of 2D nanolayers on graphene [113, 114]. Wei et al. reported nanometer-sized NiFe LDHs grown on N-doped graphene framework (nNiFe LDH/NGF) catalysts (Fig. 10a) [115]. The defects and nitrogen dopant of graphene are beneficial to adsorb and anchor metal cations, and then the $\mathrm{nNiFe}$ LDHs nucleate and grow within the mesopores of graphene, finally obtaining the uniformly dispersed $\mathrm{nNiFe}$ LDHs in the $\mathrm{N}$-doped graphene frameworks. The $\mathrm{nNiFe} \mathrm{LDH/NGF}$ catalyst shows high catalytic activity and low Tafel slope for OER, profiting from fully exposed active sites, suppressed particle aggregation, intimate interfacial coupling, interconnected conductive network, and hierarchical porous structure (Fig. 10b-d). In recent years, the introduction of topological defects in carbon-based materials has proven to be an effective method for boosting the electrocatalytic performance [116]. For instance, Yao et al. coupled exfoliated $\mathrm{Ni}-\mathrm{Fe}$ LDH nanosheet (NS) with defective graphene (DG) by electrostatic stacking (Fig. 10e-h) [112]. This hybrid catalyst needs a low overpotential $(0.21 \mathrm{~V})$ to achieve a current density of $10 \mathrm{~mA} \mathrm{~cm}{ }^{-2}$ in the OER process, exhibiting the high electrocatalytic activity (Fig. 10i). The defects in graphene can not only directly serve as active sites but also offer more anchor sites to capture $\mathrm{Ni}$ and $\mathrm{Fe}$ atoms through the $\pi-\pi$ interaction, thus leading to fast electron transfer kinetics, high catalytic activity, and stability (Table 1).

Moreover, Ma et al. sandwiched transition metal ( $\mathrm{Co}-\mathrm{Al}$, $\mathrm{Co}-\mathrm{Ni}$ ) LDH nanosheets and graphene, for the first time, to form true superlattice lamellar nanocomposite by direct heterostacking [126]. Synergistic effect could be harvested based on the shortest distance and highest efficiency in charge transfer and ion diffusion during a redox process. The heteroassembly of superlattice structure would redistribute the electric charge between adjacent crystals in the stack. Moreover, the neighboring unilamellar nanosheets may induce lattice strain or structure change owing to the electrostatic interaction, thus resulting in synergetic effects to enhance the electrocatalytic activity. In addition, the conductivity of LDHs could be substantially improved by hybridization with conductive components in forming superlattice structure. To address the aggregate, insulating nature and poor stability issues of LDH in OER, Ma et al, proposed an approach of heteroassembly of hydroxide nanosheets and graphene to achieve full potential of the two complementing 2D counterparts [118, 127]. NiFe LDH was firstly synthesized by a homogeneous precipitation method in the presence of HMT and AQS. After being exfoliated into monolayers, they were assembled with GO and rGO into superlattice structure under stirring (Fig. 11a). In such heterostructure, graphene served as conducting paths to enhance charge transfer and mass transport due to its extremely high specific surface area $\left(2600 \mathrm{~m}^{2} \mathrm{~g}^{-1}\right.$ in theory) and high electrical conductivity $\left(\sim 10^{6} \mathrm{~S} \mathrm{~cm}^{-1}\right)$. Figure $11 \mathrm{~b}, \mathrm{c}$ reveals the HRTEM images of the superlattice structures. The electrostatic face-to-face stacking of negatively charged graphene and positively charge $\mathrm{Ni}-\mathrm{Fe}$ LDH nanosheets in alternating sequence at a molecular scale contributed to the direct interfacial contact between carbon 

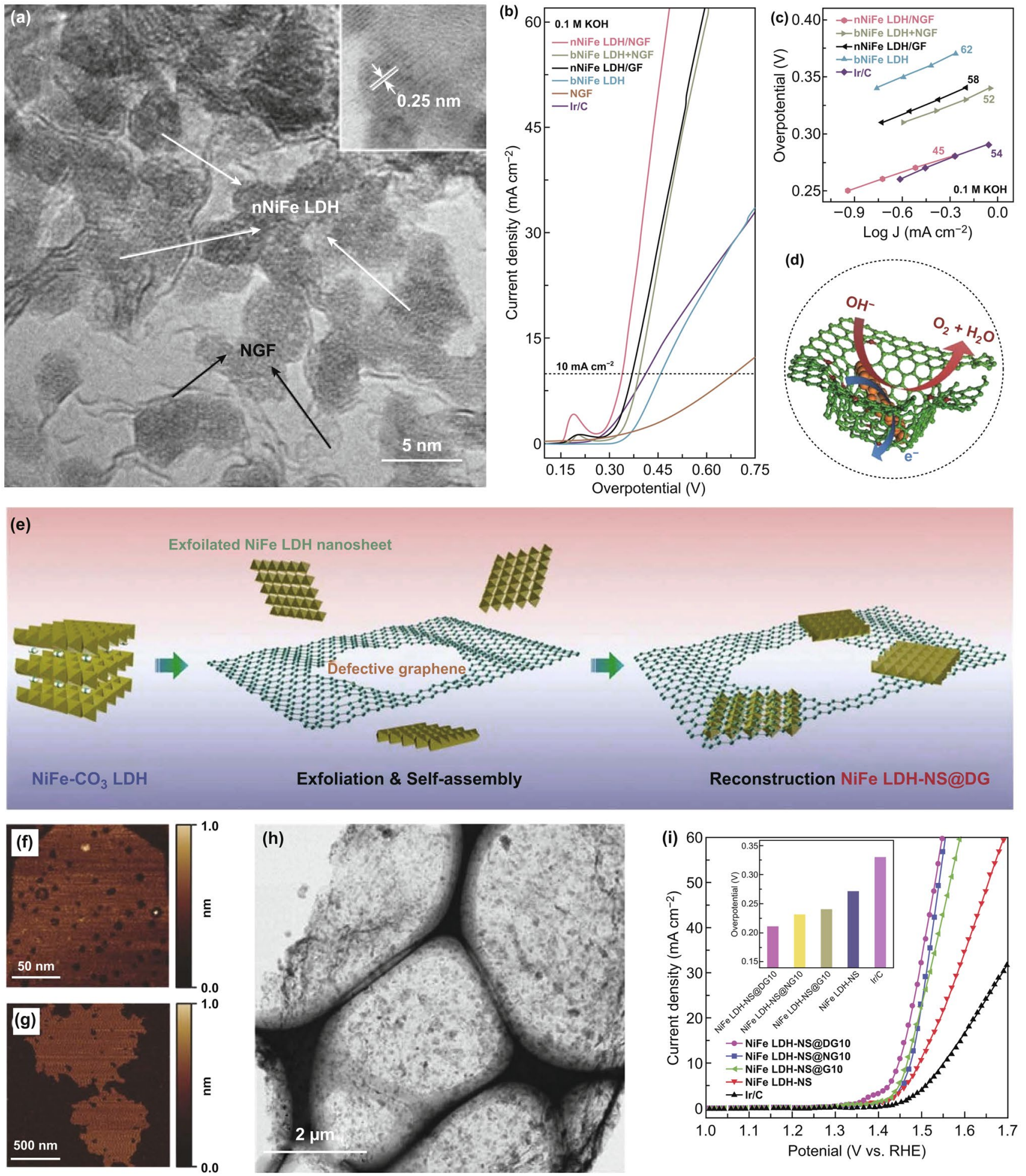

Fig. 10 a TEM image and HRTEM image (inset of a) of nNiFe LDH/NGF catalyst. b $95 \%$ iR-corrected LSV curves of the catalysts at $5 \mathrm{mV} \mathrm{s}^{-1}$ in $0.1 \mathrm{M} \mathrm{KOH}$. c Tafel plots of the different catalysts for comparison. d Schematic diagram of the spatially confined nNiFe LDH/NGF hybrids. Reproduced with permission of Ref. [115]. Copyright 2015 WILEY-VCH Verlag GmbH\& Co. KGaA, Weinheim. e Schematic diagram of the fabrication of NiFe LDH-NS@ DG hybrid. AFM images of $\mathbf{f}$ exfoliated NiFe LDH-NS and $\mathbf{g}$ DG. h TEM image of NiFe LDH-NS@DG catalyst. i $i R$-corrected LSV curves of as-prepared catalysts at $5 \mathrm{mV} \mathrm{s}^{-1}$ in $1 \mathrm{M} \mathrm{KOH}$ and their overpotential at $10 \mathrm{~mA} \mathrm{~cm}^{-2}$ (inset of i). Reproduced with permission of Ref. [112]. Copyright 2017 WILEY-VCH Verlag GmbH\& Co. KGaA, Weinheim 
Table 1 Comparison of OER activities of different catalysts

\begin{tabular}{|c|c|c|c|c|}
\hline Catalysts & Electrolyte & $\eta @ 10 \mathrm{~mA} / \mathrm{cm}^{2}(\mathrm{mV})$ & Tafel $\left(\mathrm{mV} \mathrm{dec}{ }^{-1}\right)$ & $\overline{\text { Refs. }}$ \\
\hline $\mathrm{NiFe}$ LDH & $1 \mathrm{M} \mathrm{KOH}$ & 347 & 67 & {$[12]$} \\
\hline NiFe LDH (exfoliated) & $1 \mathrm{M} \mathrm{KOH}$ & 302 & 40 & {$[12]$} \\
\hline $\mathrm{Ni}_{2} \mathrm{CoFe} \mathrm{LDH}+\mathrm{GO}$ & $0.1 \mathrm{M} \mathrm{KOH}$ & 345 & 74.5 & [117] \\
\hline $\mathrm{Ni}_{2} \mathrm{Co}^{\mathrm{III}} \mathrm{Fe}-\mathrm{LDH} / \mathrm{N}-\mathrm{GO}$ & $0.1 \mathrm{M} \mathrm{KOH}$ & 320 & 56.8 & [117] \\
\hline $\mathrm{Ni}_{2 / 3} \mathrm{Fe}_{1 / 3} \mathrm{LDH}$ & $1 \mathrm{M} \mathrm{KOH}$ & 310 & 76 & [118] \\
\hline $\mathrm{Ni}_{2 / 3} \mathrm{Fe}_{1 / 3}-\mathrm{GO}$ & $1 \mathrm{M} \mathrm{KOH}$ & 230 & 42 & [118] \\
\hline NiCo LDH/CP (exfoliated) & $1 \mathrm{M} \mathrm{KOH}$ & 300 & 40 & [119] \\
\hline $\begin{array}{l}\mathrm{NiFe} \mathrm{LDH} \\
\left(\mathrm{CO}_{3}{ }^{2-}\right)\end{array}$ & $1 \mathrm{M} \mathrm{KOH}$ & 330 & 44.3 & [120] \\
\hline$\alpha-\mathrm{CoFe} \mathrm{LDH}$ & $1 \mathrm{M} \mathrm{KOH}$ & 295 & 52 & [11] \\
\hline $\mathrm{NiFe} \mathrm{LDH} / \mathrm{N}$-doped graphene & $0.1 \mathrm{M} \mathrm{KOH}$ & 337 & 45 & [115] \\
\hline $\mathrm{NiFe}$ LDH nanosheets/3D carbon network & $0.1 \mathrm{M} \mathrm{KOH}$ & 380 & 77.9 & [121] \\
\hline $\mathrm{NiFe}$ LDH/graphitic mesoporous carbon & $1 \mathrm{M} \mathrm{KOH}$ & 320 & 57 & [122] \\
\hline 3DGN/CoAl-NSs & $1 \mathrm{M} \mathrm{KOH}$ & 252 & 36 & [123] \\
\hline CoNi-LDH@PCPs & $1 \mathrm{M} \mathrm{KOH}$ & 350 & 58 & [124] \\
\hline $\mathrm{FeNi}-\mathrm{LDH} / \mathrm{CoP} / \mathrm{CC}$ & $1 \mathrm{M} \mathrm{KOH}$ & 231 mV@20mA/cm² & 33.5 & [125] \\
\hline
\end{tabular}

and $3 d$ transition metals, which significantly shortens the diffusion distance. Therefore, such superlattice achieved an extremely small overpotential of $210 \mathrm{mV}$ at $10 \mathrm{~mA} \mathrm{~cm}^{-1}$ and Tafel plot of $40 \mathrm{mV}$ decade ${ }^{-1}$. The high performance kept stable for $10 \mathrm{~h}$ without apparent degradation. Islam et al. synthesized bifunctional 2D superlattice electrocatalysts of alternating LDH transition metal dichalcogenide (TMD) heterostructures through interstratification with the exfoliated nanosheets (Fig. 12) [128]. The electrostatic self-assembly of $2 \mathrm{D}$ building blocks with opposite charge produces superlattice composites, such as Ni-Al $\mathrm{LDH}_{-} \mathrm{MoS}_{2}$ and $\mathrm{Ni}-\mathrm{Fe}$ $\mathrm{LDH}_{-} \mathrm{MoS}_{2}$ superlattices. Density functional theory calculations predicted that the interfacial charge transfer between LDH and TMD components would be enhanced and thus improved the electrocatalytic activity. Xiong et al. fabricated $\mathrm{MoS}_{2} / \mathrm{NiFe} \mathrm{LDH}$ superlattice by alternate restacking of $\mathrm{MoS}_{2}$ and $\mathrm{NiFe} \mathrm{LDH}$ nanosheets which exhibited a low overpotential of $210 \mathrm{mV}$ at $10 \mathrm{~mA} \mathrm{~cm}^{-2}$ for OER [129]. They assumed that the high performance can be attributed to the optimal adsorption energies of OER intermediates on the superlattice originated from a strong electronic coupling effect at the heterointerfaces (Fig. 12f).

Besides aforementioned carbon-based materials, 2D layered transition metal carbides/carbonitrides (MXene) with metallic conductivity and hydrophilic surface became the promising candidates to assemble with LDHs for improving the catalytic performance [130]. Yu et al. developed a new-type hierarchical FeNi-LDH/ $\mathrm{Ti}_{3} \mathrm{C}_{2}$ MXene hybrid electrocatalyst for OER, in which the interconnected porous network of FeNi-LDH nanoplates is in situ assembled on the ultrathin $\mathrm{Ti}_{3} \mathrm{C}_{2}$ MXene sheets (Fig. 13a) [130]. Figure $13 \mathrm{~b}-\mathrm{f}$ demonstrates that the FeNi-LDH nanoplates are firmly immobilized on $\mathrm{Ti}_{3} \mathrm{C}_{2}$ sheets to form a highly active network, preventing their adverse detachment/aggregation. In addition, the hydrophilic $\mathrm{Ti}_{3} \mathrm{C}_{2} \mathrm{MXene}$ with high conductivity can not only effectively accelerate the ion transport and charge transfer, but also promote the $\mathrm{Ni}^{2+} / \mathrm{Ni}^{3+, 4+}$ redox process for OER. Within the LDH/MXene nanohybrids, the electron extraction from FeNi-LDH could improve the binding strength of $\mathrm{O}$ through shifting the d-band center of $\mathrm{Ni} / \mathrm{Fe}$ atoms to higher energy, indicating the less occupied antibonding states between adsorbed $\mathrm{O}$ intermediates and FeNi-LDH (Fig. 13g, h). Owing to the above advantages, the FeNi-LDH/ $\mathrm{Ti}_{3} \mathrm{C}_{2} \mathrm{MXene}$ hybrid electrocatalyst shows fast reaction kinetics with high catalytic activity and good durability for OER (Fig. 13i).

\subsection{Construction of 3D Freestanding Electrodes Based on LDHs}

Constructing 3D architectures of LDH-based materials is very important for electrocatalytic application, due to their unique advantages including more active sites for electrocatalysis, facilitated penetration of electrolytes, and fast 
(a)
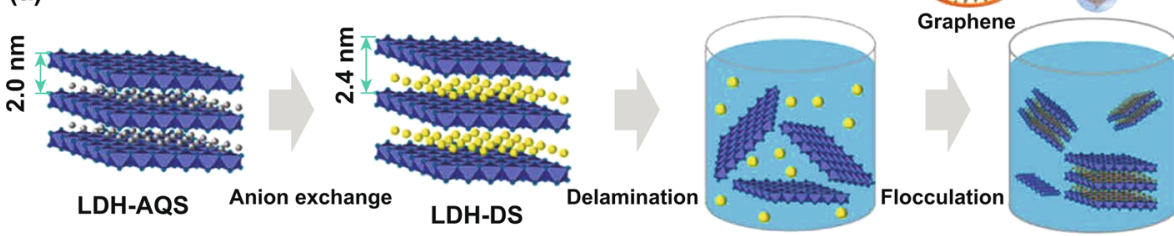

LDH nanosheets

Superlattic composite
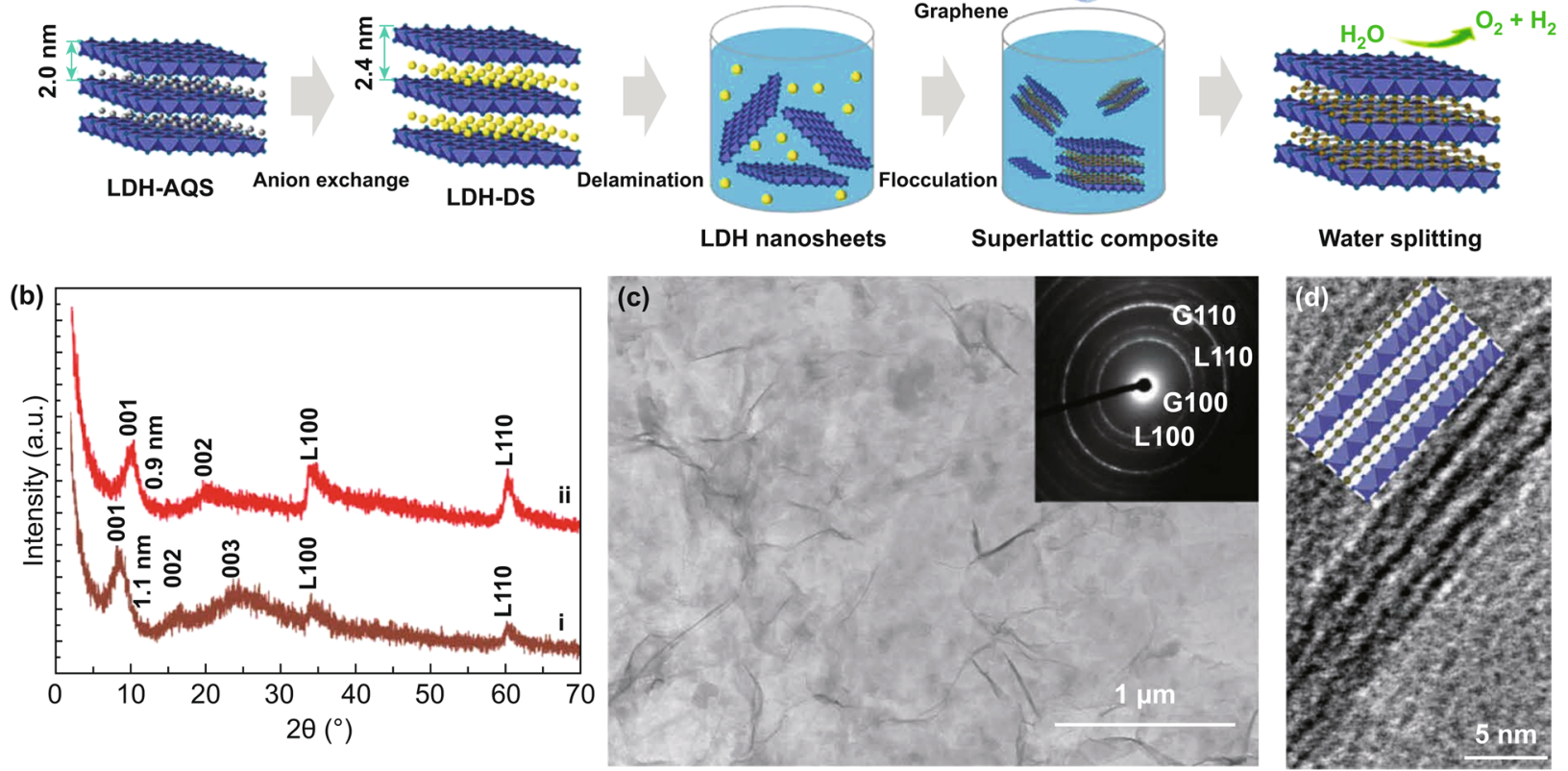

Water splitting

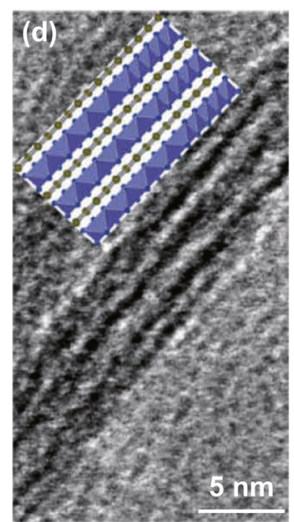

(e)
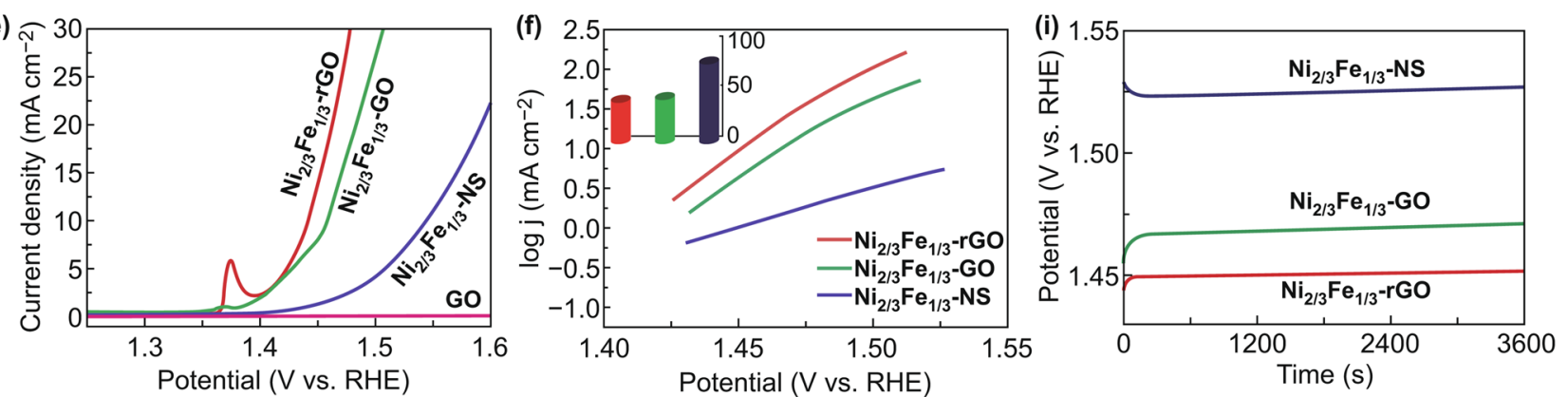

(g)

(h)

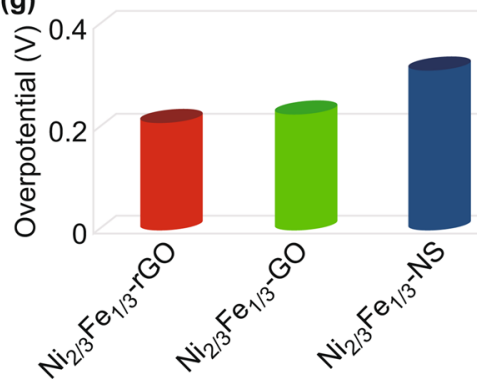

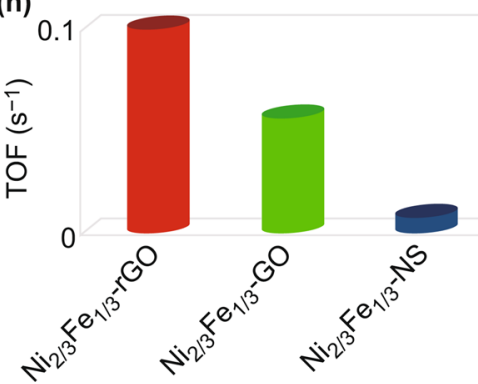

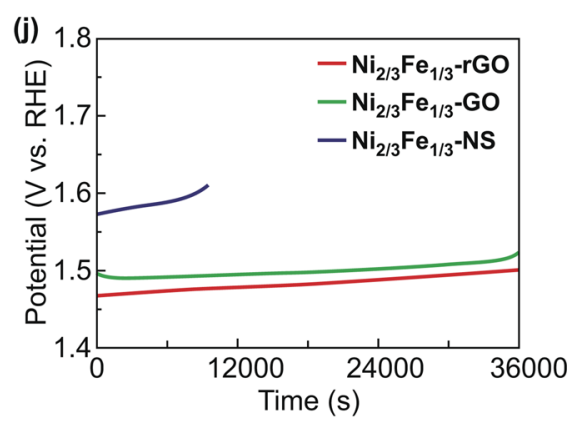

Fig. 11 a Process of hetero-assembling $\mathrm{Ni}-\mathrm{Fe} \mathrm{LDH}$ nanosheets and graphene for water splitting. b XRD patterns of $\mathrm{Ni}_{2 / 3} \mathrm{Fe}_{1 / 3}-\mathrm{NS} / \mathrm{GO}$ superlattice (i) and rGO (ii). c, d TEM and HRTEM images of the superlattice. e-j Electrochemical evaluation of the NiFe LDH/GO and NiFe LDH/ rGO superlattices. Reproduced with permission of Ref. [118]. Copyright 2015 American Chemical Society

transport of electrons/ions [11, 131, 132]. Therefore, the fabrication of LDHs on 3D conductive supports to form 3D hierarchical architectures can substantially enhance the catalytic performance due to their synergistic properties. Zhang et al. combined single-layer CoAl LDH nanosheets with 3D graphene network to fabricate a 3DGN/CoAl-NSs catalyst for OER via the self-assembly method (Fig. 14a-c) [123]. The catalytic activity and durability of the as-prepared 3D GN/CoAl-NS catalyst are comparable or even better than those of many LDH-based OER catalysts. The 3DGN/ 
(a)

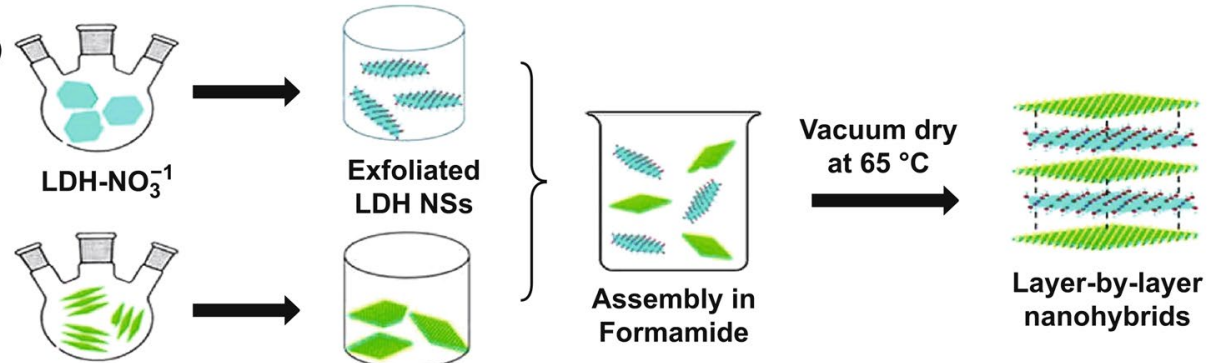

Bulk MoS

Exfoliated NSs

(b)
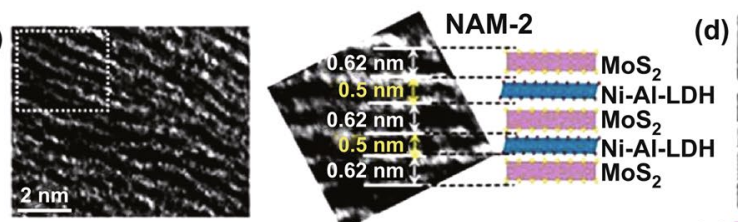

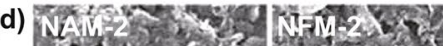

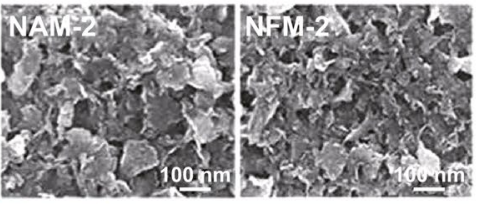

(c)
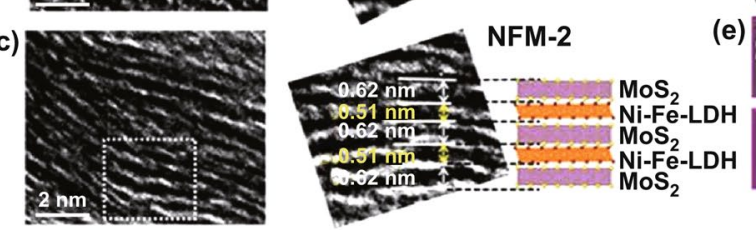

(e) NAMI-2, Ni

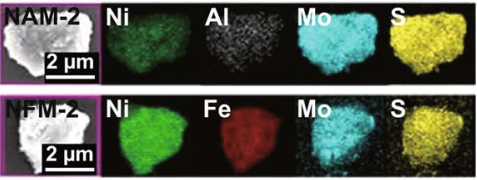

(f)

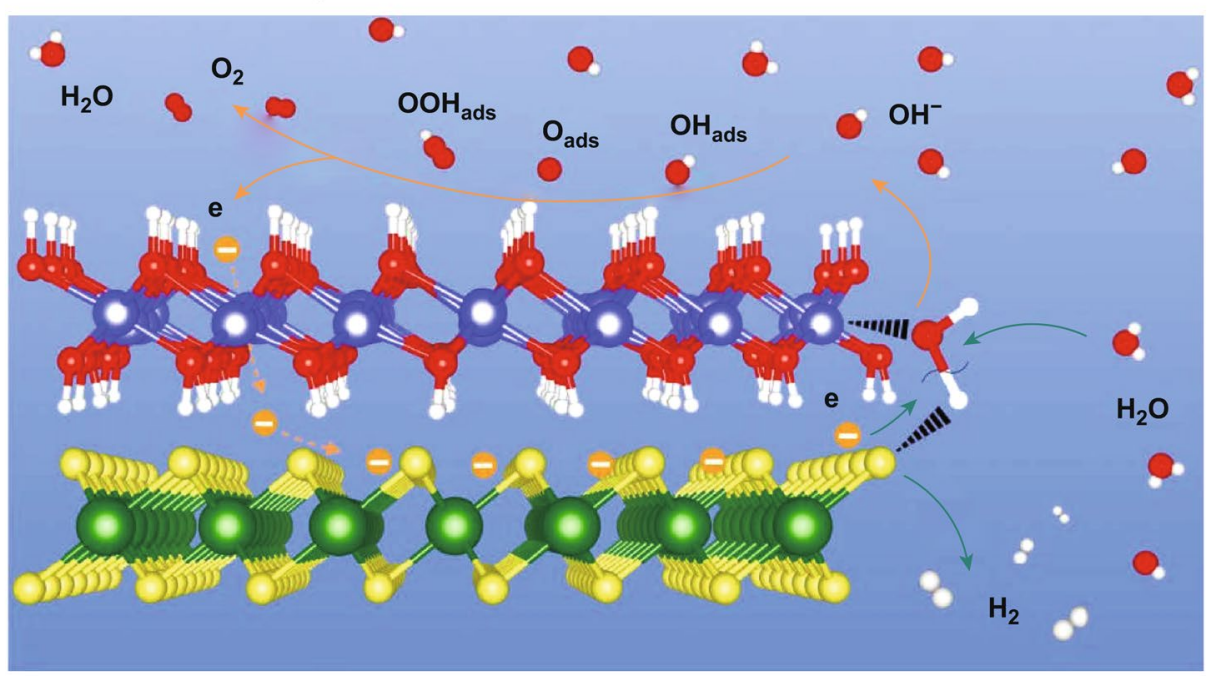

Fig. 12 a Synthesis process, b, c cross-sectional TEM images, d FE-SEM images, and e EDS elemental mappings of NiAl LDH/MoS 2 and $\mathrm{NiFe} \mathrm{LDH} / \mathrm{MoS}_{2}$. Reproduced with permission from Ref. [128]. Copyright 2018 American Chemical Society. f Schematic illustration of the electrocatalytic mechanism of water splitting on the interface of $\mathrm{MoS}_{2} / \mathrm{LDH}$ superlattice. Reproduced with permission from Ref. [129]. Copyright 2019 American Chemical Society

CoAl-NS reveals a low Tafel slope of $36 \mathrm{mV} \mathrm{dec}^{-1}$ and a small overpotential of $252 \mathrm{mV}$ at $10 \mathrm{~mA} \mathrm{~cm}^{-2}$ (Fig. 14d). This outstanding catalytic performance and stability for OER are ascribed to the following superiorities. The large porous structure provides more accessible surface to contact with electrolytes. More exposed active edges facilitate the transfer process of the proton-coupled electrons during the OER process. In addition, the CoAl LDH nanosheets firmly covered on 3DGN could improve the electron/charge transfer and reaction kinetics and prevent the adverse aggregating of nanosheets. Qiao et al. incorporated NiCo LDH into $\mathrm{N}$-doped graphene hydrogels (NG-NiCo) to fabricate a 3D architecture as electrocatalysts (Fig. 14e-h) [113]. The numerous functional groups on the functionalized graphene can promote the adsorption of the reaction intermediates. The in situ growth of NiCo LDH ensures the reduced contact 

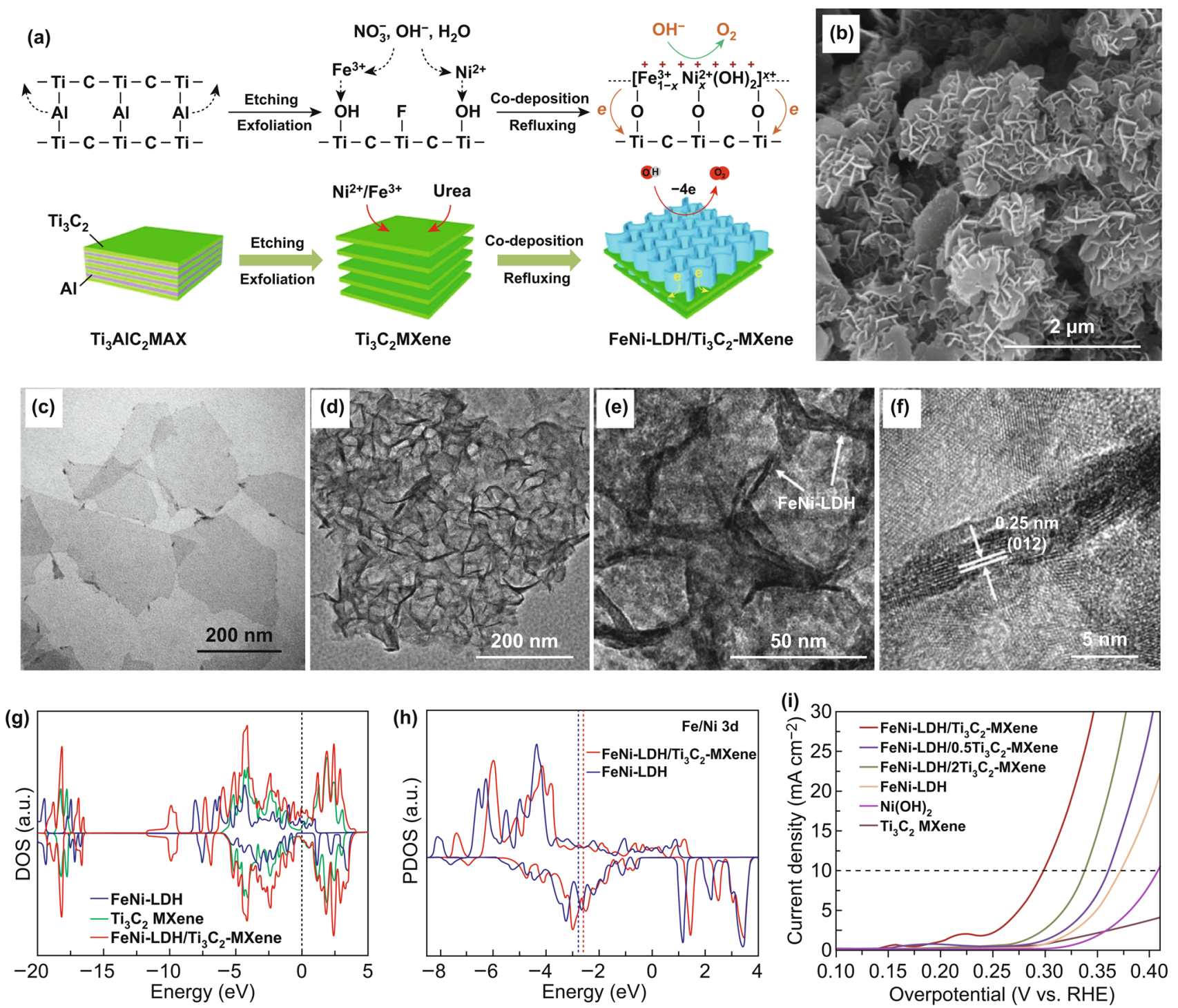

Fig. 13 a Schematic diagram of the preparation of FeNi-LDH/Ti ${ }_{3} \mathrm{C}_{2}$ MXene hybrids. b SEM image, $\mathbf{c}$ TEM image, d-f HRTEM images of FeNi-LDH/Ti ${ }_{3} \mathrm{C}_{2}$ MXene. $\mathbf{g}$ density of states (DOS), $\mathbf{h}$ projected DOS (PDOS) of different samples. $\mathbf{i}$ LSV curves of as-prepared catalysts at $10 \mathrm{mV} \mathrm{s}^{-1}$ in $1 \mathrm{M} \mathrm{KOH}$. Reproduced with permission of Ref. [130]. Copyright 2017 Elsevier Ltd

resistance between NiCo LDH and graphene, and the 3D interconnected porous network offers more exposed active sites and favors the $\mathrm{O}_{2}$ release. Combining with the multiple advantages of 3D N-doped graphene hydrogels, the NGNiCo exhibits favorable electrode kinetics, superior activity, and great durability (Fig. 14i-k).

Recently, some highly conductive 3D networks (e.g., carbon paper/cloth/foam, carbon nanotube/graphene film, and $\mathrm{Ni} / \mathrm{Fe} / \mathrm{Cu}$ foam) are used as the current collector to in situ fabricate binder-free LDH-based electrodes for OER $[133,134]$. Chen et al. fabricated a microfiber electrode by incorporating aligned carbon nanotubes with $\mathrm{NiFe} \mathrm{LDH}$ nanoparticles [133]. This microfiber electrode shows high electrocatalytic surface area and strengthened contact between electrocatalysts and substrate, which also avoids using binders (e.g., Nafion and polytetrafluoroethylene), thus resulting in the outstanding durability and remarkable OER activity with a low overpotential of $255 \mathrm{mV}$ at $180 \mathrm{~mA} \mathrm{~cm}^{-2}$. Likewise, Song et al. developed an integrated flexible electrode by coupling $\mathrm{NiFe} \mathrm{LDH}$ with single-walled carbon nanotubes (SWNT) film via a facile hydrothermal method [134]. The NiFe LDH@SWNT electrode shows the 

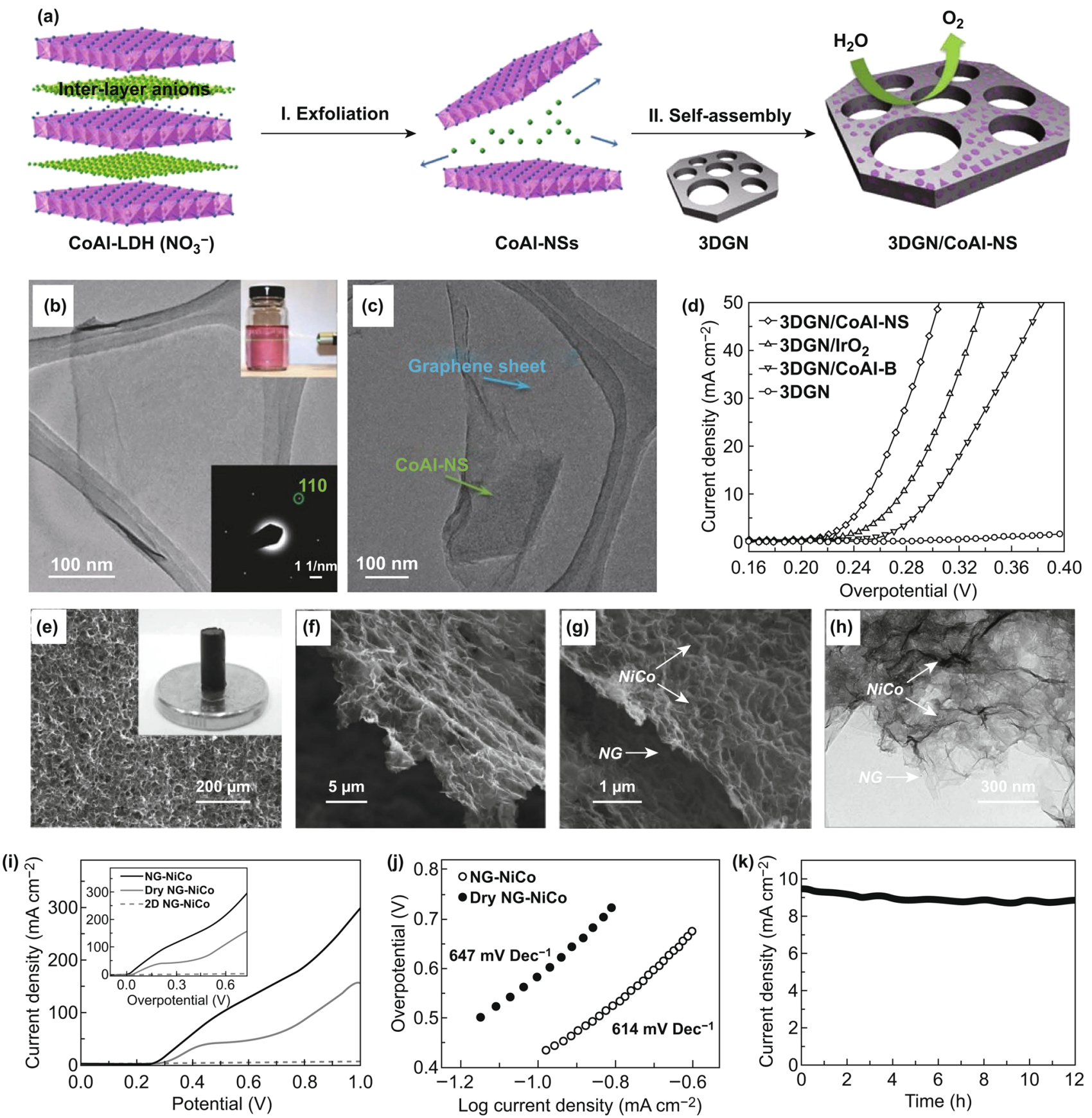

Fig. 14 a Schematic diagram of the fabrication of 3DGN/CoAl-NS. b TEM image and SAED pattern (inset of $\mathbf{b}$ bottom) of the exfoliated CoAl-NS, the inset (top) of $\mathbf{b}$ is photograph showing Tyndall effect of CoAl-NSs solution under irradiation. $\mathbf{c}$ TEM image of 3DGN/CoAlNS. d LSV curves of the catalysts at $1 \mathrm{mV} \mathrm{s}^{-1}$ in $1 \mathrm{M} \mathrm{KOH.} \mathrm{Reproduced} \mathrm{with} \mathrm{permission} \mathrm{of} \mathrm{Ref.} \mathrm{[123].} \mathrm{Copyright} 2016$ WILEY-VCH Verlag GmbH\& Co. KGaA, Weinheim. e-g SEM image and optical image (inset of $\mathbf{e}$ ), $\mathbf{h}$ TEM image of NG-NiCo. $\mathbf{i}$ LSV curves of three catalysts at $50 \mathrm{mV} \mathrm{s}^{-1}$ in $0.1 \mathrm{M} \mathrm{KOH}$. $\mathbf{j}$ Tafel plots for as-prepared samples. $\mathbf{k} i-t$ curve of NG-NiCo at $0.5 \mathrm{~V}$ versus Ag/AgCl. Reproduced with permission of Ref. [113]. Copyright 2013 WILEY-VCH Verlag GmbH\& Co. KGaA, Weinheim

fast reaction kinetics with a Tafel slope of $35 \mathrm{mV} \mathrm{dec}^{-1}$, together with an excellent OER activity with a low overpotential of $250 \mathrm{mV}$ at $10 \mathrm{~mA} \mathrm{~cm}^{-2}$. As mentioned above, the superior OER performance is authentically contributed to the strong interfacial electron coupling between the highly active LDH and the conductive support (SWNT). Yu et al. 
successfully synthesized NiCo LDH nanoarrays vertically grown on carbon fiber papers (NiCo LDH-NA) by a hydrothermal method [135]. Compared with NiCo LDH microspheres (NiCo LDH-MS), the NiCo LDH-NA catalyst has a low Tafel slope of $64 \mathrm{mV}$ decade ${ }^{-1}$ and needs a relatively low overpotential of $307 \mathrm{mV}$ to obtain $10 \mathrm{~mA} \mathrm{~cm}{ }^{-2}$. This high OER activity profits from the synergistic effect of the highly conductive substrate (carbon fiber paper) and vertically oriented LDH nanoarrays with abundant rich active sites, open structure, and high surface areas. Yu et al. synthesized 3D core-shell NiFe LDHs@Cu nanowires grown on $\mathrm{Cu}$ foam $(\mathrm{Cu} @ \mathrm{NiFe} \mathrm{LDH} / \mathrm{CF})$ through chemical oxidation followed by calcination and electronic reduction [136]. $\mathrm{The} \mathrm{Cu}$ nanowires are uniformly coated with few-layer $\mathrm{NiFe}$ LDH nanosheets to form a typical core-shell structure. The obtained 3D core-shell electrode shows the distinctly boosted OER activity, which can be attributed to the following fundamental factors. The 3D Cu nanowires network with high conductivity ensures fast electron transfer and ions diffusion, and the firm adhesion between LDHs and $\mathrm{Cu}$ nanowires grown on $\mathrm{Cu}$ foam is conducive to obtaining the high mechanical stability and good electrical contacts without using binders. The vertically grown LDH nanosheets with enlarged active surface afford more efficient catalytic sites for OER. As for carbon-based or metal-based conductive substrates, the weak hydrophilicity, large density, and poor flexibility limit their practicability. Luo et al. developed a new hollow potato chip-like CoNi-LDH@polypyrrole cotton pads (CoNi-LDH@PCPs) catalytic electrode [124]. Figure 15a, b depicts the synthetic process involving three major steps as follows. Firstly, the polypyrrolecoated cotton pads are prepared by in situ polymerization reaction involving chemical oxidation and electrochemical initiation. Subsequently, the as-prepared PCPs are used as the skeleton to grow ZIF-67 arrays through a facile solution reaction. Finally, the hollow structural CoNi-LDH arrays on PCPs are formed after the ion exchange/etching process. It can be found that the flake-like CoNi-LDH arrays are vertically aligned on the PCPs' surface (Fig. 15c, d). The hollow cavities of the CoNi-LDH arrays can be confirmed from the fragmented part (Fig. 15c $c_{2}$ ). As shown in Fig. $15 c_{3}, c_{4}$, the CoNi-LDH arrays with a quite rough surface show a potato chip-like structure. Due to the existence of the hollow potato chip-like structure, reaction kinetics on the electrode can be effectively expedited. Furthermore, the 3D PCPs framework offers the efficient transport pathways for electrons/ions, and larger open space formed by the adjacent fibers is beneficial to the electrolyte infiltration and bubble evolution. As an OER catalyst, this CoNi-LDH@PCPs electrode exhibits a low overpotential of $350 \mathrm{mV}$ at $10 \mathrm{~mA} \mathrm{~cm}^{-2}$ and a small Tafel slope of $\sim 58 \mathrm{mV} \mathrm{dec}^{-1}$ (Fig. 15e, f).

Recently, LDHs have been combined with conductive metallic substrates to construct 3D hierarchical hybrid arrays. The plentiful catalytic sites from multiple species and $3 \mathrm{D}$ channels are beneficial to further enhance the catalytic performance of the $\mathrm{LDH} /$ conductive support catalysts toward OER. Yuan et al. developed a 3D hierarchical CoFeLDH@NiFe LDH hybrid nanosheet array on nickel foam (CoFe@ NiFe/NF) by a facile hydrothermal process followed by the electrodeposition method [137]. This CoFe@NiFe/ NF catalyst shows high activity and stability for both OER and HER, owing to its unique structural features and strong synergistic effect between two kinds of LDHs. When the CoFe@NiFe/NF is used as both cathode and anode in an alkali electrolyte, it needs a low voltage of $1.59 \mathrm{~V}$ to achieve $10 \mathrm{~mA} \mathrm{~cm}^{-2}$, which is much lower than many other stateof-the-art earth-abundant catalysts. Metal phosphides have been regarded as a promising candidate because of their excellent catalytic activity and metalloid characteristics. Zhou et al. reported ultrathin NiCoP/NiFe LDH nanosheet arrays supported on nickel foam, which can be served as a high-efficiency OER catalyst [138]. Besides the advantages of this 3D hierarchical binder-free structure, the abundant multimetallic catalytic sites of $\mathrm{NiCoP}$ and $\mathrm{NiFe} \mathrm{LDH}$ promote the OER activity. Qian et al. proposed a concept for promoting the catalytic activities for OER by constructing the FeNi-LDH/CoP/carbon cloth (CC) heterojunctions [125]. The self-supporting FeNi-LDH/CoP/CC electrode with an open and $3 \mathrm{D}$ hierarchical $\mathrm{p}-\mathrm{n}$ junction structure is prepared through three steps including the electrodeposition of $\mathrm{Co}(\mathrm{OH})_{2}$ nanosheets array on the $\mathrm{CC}$, phosphatization of $\mathrm{Co}(\mathrm{OH})_{2}$, and electrodeposition of amorphous FeNi-LDH layers on the formed CoP array (Fig. 16a-d). The charge transfer and separation at the interfaces of FeNi-LDH/CoP p-n junctions result in positively charged FeNi-LDH side. $\mathrm{OH}^{-}$ions intend to adsorb on the surface of FeNi-LDH side in the $\mathrm{p}-\mathrm{n}$ junction more strongly compared to individual FeNi-LDH as verified by DFT calculation, which indicates that this positively charged FeNi-LDH side has stronger ability to adsorb targeted $\mathrm{OH}^{-}$compared with individual FeNi-LDH (Fig. 16e). As a result, the FeNi-LDH/CoP/ $\mathrm{CC}$ electrode has the low overpotentials of 231,249 , and 

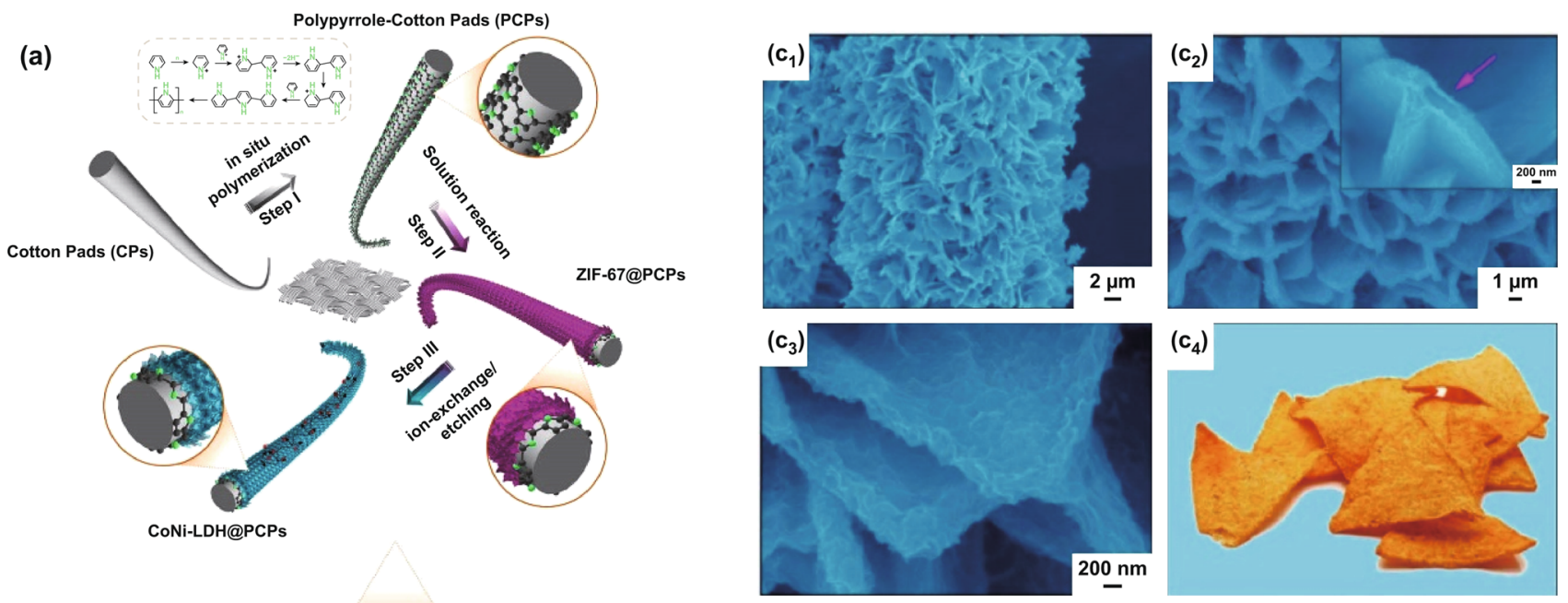

(b)
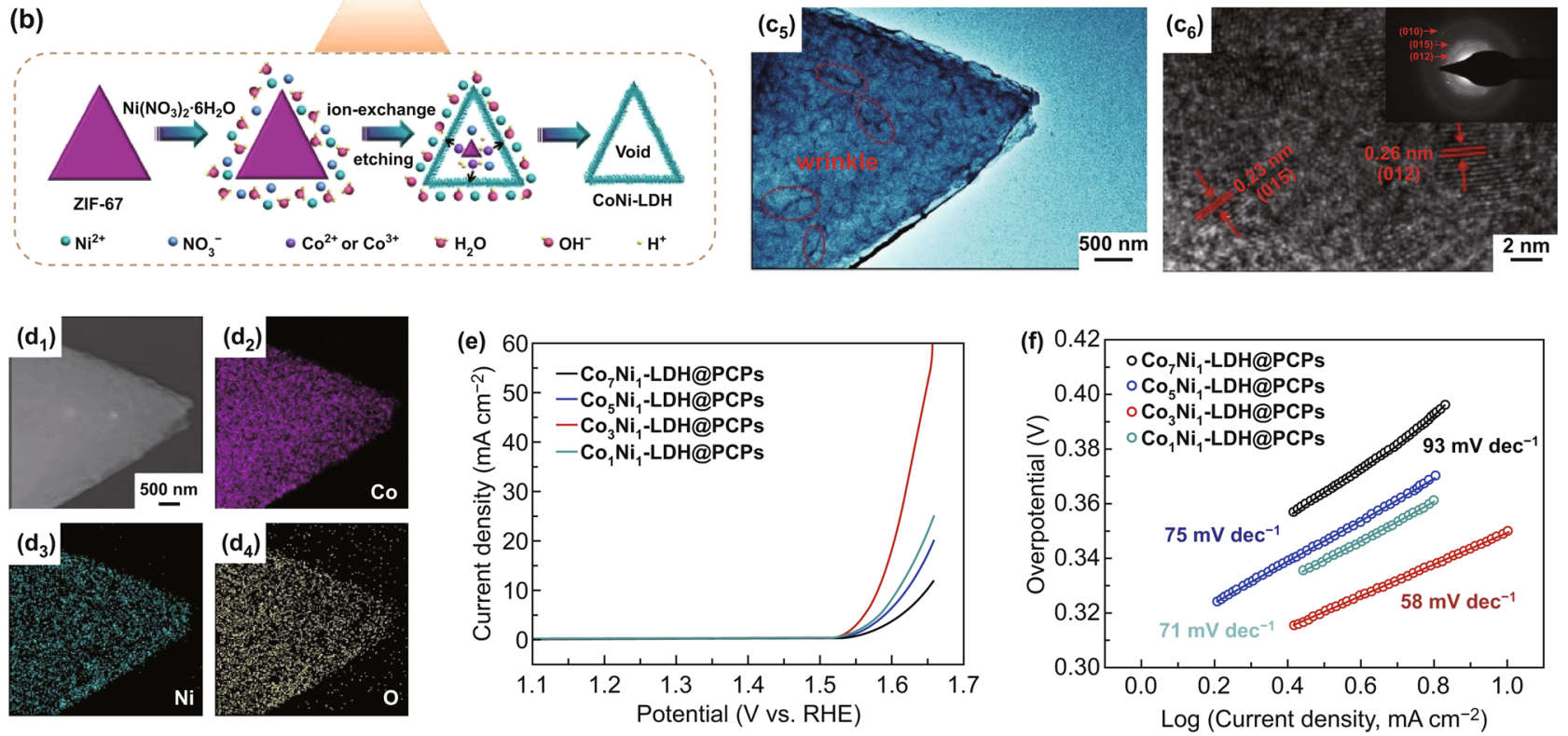

Fig. 15 a Schematic diagram of the preparation process of CoNi-LDH@PCPs. b Formation mechanism of hollow CoNi-LDH arrays. c SEM images (1-3) and HRTEM images (5-6) of CoNi-LDH@ PCPs, and photograph (4) of triangle biscuits. d STEM image (1) and mapping images of CoNi-LDH arrays. e LSV curves of the different CoNi-LDH@PCPs catalysts at $1 \mathrm{mV} \mathrm{s}^{-1}$ in $1 \mathrm{M} \mathrm{KOH}$. f Tafel plots of the different CoNiLDH@PCPs catalysts. Reproduced with permission of Ref. [124]. Copyright 2019 American Chemical Society

$254 \mathrm{mV}$ at 20,100 , and $350 \mathrm{~mA} \mathrm{~cm}^{-2}$ in alkaline media, respectively, and its current density at $1.485 \mathrm{~V}$ increases by 10 times and 100 times compared to the FeNi-LDH/CC and $\mathrm{CoP} / \mathrm{CC}$, respectively. In addition, an extremely small Tafel slope $\left(33.5 \mathrm{mV} \mathrm{dec}^{-1}\right)$ and a large TOF $\left(0.131 \mathrm{~s}^{-1}\right)$ can be obtained (Fig. 16f-h). The fabrication of heterojunctions in catalyst would be a new strategy to promote their catalytic activities by purposefully regulating the electronic structure of active sites. For the past few years, many other 3D hierarchical nanoarrays on conductive 3D networks, such as CoFe $\mathrm{LDH} / \mathrm{Co}_{0.85} \mathrm{Se} /$ carbon cloth, NiFe LDH@ NiFe-Bi/carbon cloth, and $\mathrm{NiSe} / \mathrm{NiFe} \mathrm{LDH} / \mathrm{Ni}$ foam, have been reported as high-performance OER catalysts [139-144].

\section{Summary and Outlook}

Electrochemical water oxidation is a critical process of water splitting which exhibits a great potential for energy storage and conversion. Designing and synthesizing lowcost highly active electrocatalysts are essential to improve the efficiency for applications on an industrial scale. In this 
(a) Bare CC

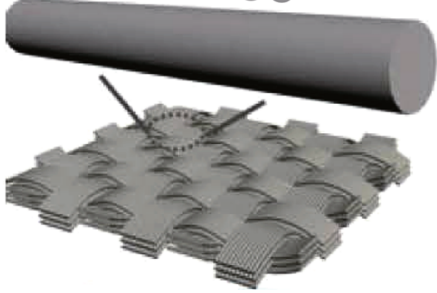

Electrodeposition + Phosphodation

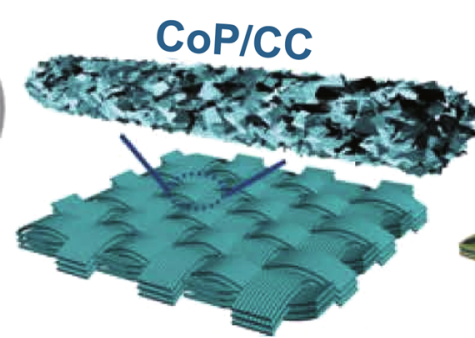

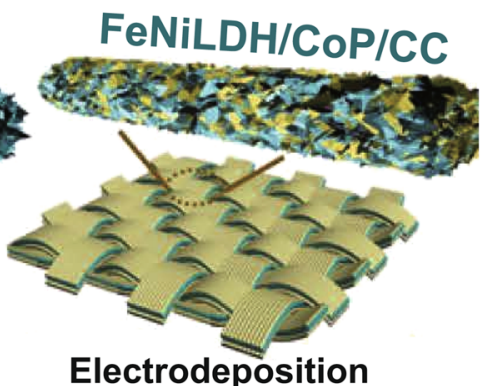

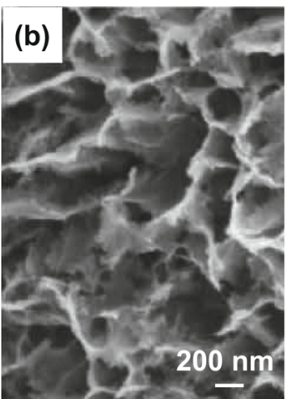

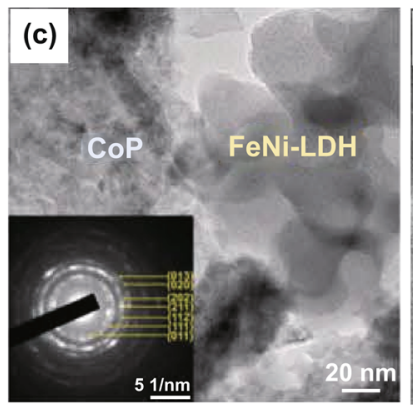
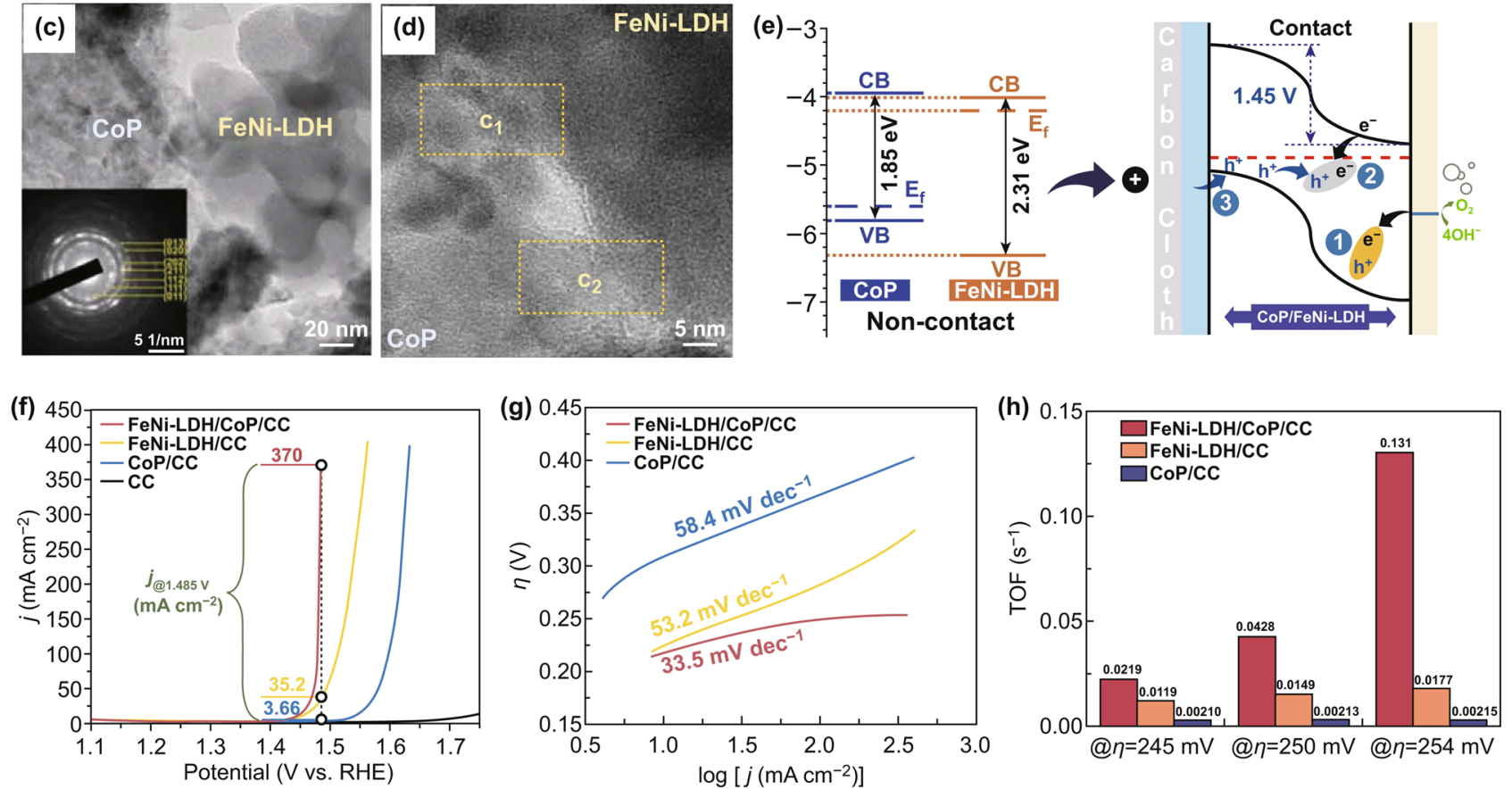

Fig. 16 a Schematic diagram of the fabrication process of FeNi-LDH/CoP/CC composite electrodes. b SEM image, c, d HRTEM images and SAED pattern (inset of $\mathbf{c}$ ) of FeNi-LDH/CoP NSs. e The energy diagrams of CoP and FeNi-LDH and the electrocatalytic mechanism for OER in the FeNi-LDH/CoP/CC p-n junction. f LSV curves of the different CoNi-LDH@PCPs catalysts at 5 mV s ${ }^{-1}$ in 1 M KOH. g Tafel plots of the different catalysts. h TOF at different overpotentials. Reproduced with permission of Ref. [125]. Copyright 2019 Wiley-VCH Verlag GmbH \& Co. KGaA, Weinheim

review, we summarized recent notable developments of LDH nanosheets and their derivates toward OER electrocatalysis, together with important strategies to enhance their electrocatalytic activities. First, various synthetic procedures to control the morphology and phases are presented, covering bottom-up and top-down approaches. Secondly, in order to enhance the intrinsic activity of LDHs, several typical approaches have been introduced, including doping other metal or nonmetal components or creating cavities. Moreover, considering the poor conductivity of LDHs, it becomes very beneficial to exfoliate them into monolayer or few layers and then hybridizing with conductive components.
In situ growing LDH nanosheets on conductive substrates to fabricate $3 \mathrm{D}$ freestanding electrodes have also proven to be an effective methodology to promoting their intrinsic activity.

It is anticipated that the design and synthesis of new composites based on LDHs with controllable structure and morphology for electrochemical water splitting will be the future direction. The remaining challenge is to elaborately tune the electronic structure and control the quantities of active sites in LDHs. It is also needed to probe the electrocatalytic process in situ and elucidate the mechanism in depth, thus providing clear guidance for the rational design 
of LDHs and their derivates as next-generation nonprecious electrocatalysts. It is also noteworthy that the applications of transition metal LDHs may be broadened to other related energy storage fields such as supercapacitors and batteries. Nevertheless, enormous challenges still exist in achieving practical electrochemical water oxidation using these nanocatalysts. Future efforts should be directed toward making full use of the structural superiority of LDHs and probing the fundamental principles, such as systematically investigating the versatile combination of metal cationic species and valence states, modulating anionic gallery as well as tuning interlayer spacing. The catalytic properties under large current conditions and long-term stability have yet to meet the requirements of implementation on any industrial scale. Much more solid works are urgently needed to address these issues.

Acknowledgements This work was supported in part by the WPIMANA, Ministry of Education, Culture, Sports, Science and Technology, and CREST of the Japan Science and Technology Agency (JST) (Grant No. JPMJCR17N1), Japan. T. Sasaki and R. Ma acknowledge the support from JSPS KAKENNHI grant $15 \mathrm{H} 02004$ and $18 \mathrm{H} 03869$, respectively.

Open Access This article is licensed under a Creative Commons Attribution 4.0 International License, which permits use, sharing, adaptation, distribution and reproduction in any medium or format, as long as you give appropriate credit to the original author(s) and the source, provide a link to the Creative Commons licence, and indicate if changes were made. The images or other third party material in this article are included in the article's Creative Commons licence, unless indicated otherwise in a credit line to the material. If material is not included in the article's Creative Commons licence and your intended use is not permitted by statutory regulation or exceeds the permitted use, you will need to obtain permission directly from the copyright holder. To view a copy of this licence, visit http://creativecommons.org/licenses/by/4.0/.

\section{References}

1. M.S. Burke, L.J. Enman, A.S. Batchellor, S. Zou, S.W. Boettcher, Oxygen evolution reaction electrocatalysis on transition metal oxides and (oxy)hydroxides: activity trends and design principles. Chem. Mater. 27, 7549-7558 (2015). https://doi.org/10.1021/acs.chemmater.5b03148

2. J. Suntivich, K.J. May, H.A. Gasteiger, J.B. Goodenough, Y. Shao-Horn, A perovskite oxide optimized for oxygen evolution catalysis from molecular orbital principles. Science 334, 1383-1385 (2011). https://doi.org/10.1126/science.1212858

3. S. Zhao, Y. Wang, J. Dong, C.-T. He, H. Yin et al., Ultrathin metal-organic framework nanosheets for electrocatalytic oxygen evolution. Nat. Energy 1, 16184 (2016). https://doi. org/10.1038/nenergy.2016.184

4. Y. Meng, X. Zhang, W.-H. Hung, J. He, Y.-S. Tsai et al., Highly active oxygen evolution integrated with efficient $\mathrm{CO}_{2}$ to $\mathrm{CO}$ electroreduction. Proc. Natl. Acad. Sci. 116(48), 23915-23922 (2019). https://doi.org/10.1073/pnas.19153 19116

5. A.R. Zeradjanin, Is a major breakthrough in the oxygen electrocatalysis possible? Curr. Opin. Electrochem. 9, 214-223 (2018). https://doi.org/10.1016/j.coelec.2018.04.006

6. L.C. Seitz, C.F. Dickens, K. Nishio, Y. Hikita, J. Montoya et al., A highly active and stable $\mathrm{IrOx} / \mathrm{SrIrO}_{3}$ catalyst for the oxygen evolution reaction. Science 353, 1011-1014 (2016). https://doi.org/10.1126/science.aaf5050

7. Z. Lu, W. Xu, W. Zhu, Q. Yang, X. Lei et al., Three-dimensional $\mathrm{NiFe}$ layered double hydroxide film for high-efficiency oxygen evolution reaction. Chem. Commun. 50, 6479-6482 (2014). https://doi.org/10.1039/C4CC01625D

8. M. Tahir, L. Pan, F. Idrees, X. Zhang, L. Wang, J.-J. Zou, Z.L. Wang, Electrocatalytic oxygen evolution reaction for energy conversion and storage: a comprehensive review. Nano Energy 37, 136-157 (2017). https://doi.org/10.1016/j. nanoen.2017.05.022

9. X. Lu, G.-P. Hao, X. Sun, S. Kaskel, O.G. Schmidt, Highly dispersed metal and oxide nanoparticles on ultra-polar carbon as efficient cathode materials for $\mathrm{Li}-\mathrm{O}_{2}$ batteries. J. Mater. Chem. A 5, 6284-6291 (2017). https://doi.org/10.1039/ C7TA00777A

10. X. Lu, L. Zheng, M. Zhang, H. Tang, X. Li, S. Liao, Synthesis of core-shell structured Ru@Pd/C catalysts for the electrooxidation of formic acid. Electrochim. Acta 238, 194-201 (2017). https://doi.org/10.1016/j.electacta.2017.03.115

11. L. Lv, Z. Yang, K. Chen, C. Wang, Y. Xiong, 2d layered double hydroxides for oxygen evolution reaction: from fundamental design to application. Adv. Energy Mater. (2019). https://doi.org/10.1002/aenm.201803358

12. F. Song, X. Hu, Exfoliation of layered double hydroxides for enhanced oxygen evolution catalysis. Nat. Commun. 5, 4477 (2014). https://doi.org/10.1038/ncomms5477

13. N. Han, F. Zhao, Y. Li, Ultrathin nickel-iron layered double hydroxide nanosheets intercalated with molybdate anions for electrocatalytic water oxidation. J. Mater. Chem. A 3, 16348-16353 (2015). https://doi.org/10.1039/C5TA03394B

14. Y. Wang, D. Yan, S. El Hankari, Y. Zou, S. Wang, Recent progress on layered double hydroxides and their derivatives for electrocatalytic water splitting. Adv. Sci. 5, 1800064 (2018). https://doi.org/10.1002/advs.201800064

15. J. Yu, Q. Wang, D. O'Hare, L. Sun, Preparation of two dimensional layered double hydroxide nanosheets and their applications. Chem. Soc. Rev. 46, 5950-5974 (2017). https://doi. org/10.1039/C7CS00318H

16. Y. Liu, N. Wang, J.H. Pan, F. Steinbach, J. Caro, In situ synthesis of MOF membranes on $\mathrm{ZnAl}-\mathrm{CO}_{3} \mathrm{LDH}$ buffer layermodified substrates. J. Am. Chem. Soc. 136, 14353-14356 (2014). https://doi.org/10.1021/ja507408s 
17. R. Ma, J. Liang, X. Liu, T. Sasaki, General insights into structural evolution of layered double hydroxide: underlying aspects in topochemical transformation from brucite to layered double hydroxide. J. Am. Chem. Soc. 134, 19915-19921 (2012). https://doi.org/10.1021/ja310246r

18. E.S. Zhitova, S.V. Krivovichev, I.V. Pekov, V.O. Yapaskurt, Crystal chemistry of chlormagaluminite, $\mathrm{Mg}_{4} \mathrm{~A}_{12}(\mathrm{OH})_{12} \mathrm{Cl}_{2}\left(\mathrm{H}_{2} \mathrm{O}\right)_{2}$, a natural layered double hydroxide. Minerals 9, 221 (2019). https://doi.org/10.3390/min9040221

19. Z. Cai, X. Bu, P. Wang, J.C. Ho, J. Yang, X. Wang, Recent advances in layered double hydroxide electrocatalysts for the oxygen evolution reaction. J. Mater. Chem. A 7, 5069-5089 (2019). https://doi.org/10.1039/C8TA11273H

20. L. Huang, Y. Zou, D. Chen, S. Wang, Electronic structure regulation on layered double hydroxides for oxygen evolution reaction. Chin. J. Catal. 40, 1822-1840 (2019). https://doi. org/10.1016/S1872-2067(19)63284-5

21. Z. Liu, C.-L. Dong, Y.-C. Huang, J. Cen, H. Yang et al., Modulating the electronic structure of ultrathin layered double hydroxide nanosheets with fluorine: an efficient electrocatalyst for the oxygen evolution reaction. J. Mater. Chem. A 7, 14483-14488 (2019). https://doi.org/10.1039/C9TA03882E

22. R. Ma, J. Liang, K. Takada, T. Sasaki, Topochemical synthesis of $\mathrm{Co}-\mathrm{Fe}$ layered double hydroxides at varied $\mathrm{Fe} /$ Co ratios: unique intercalation of triiodide and its profound effect. J. Am. Chem. Soc. 133, 613-620 (2010). https://doi. org/10.1021/ja1087216

23. N.-T. Suen, S.-F. Hung, Q. Quan, N. Zhang, Y.-J. Xu, H.M. Chen, Electrocatalysis for the oxygen evolution reaction: recent development and future perspectives. Chem. Soc. Rev. 46, 337-365 (2017). https://doi.org/10.1039/C6CS00328A

24. X. Lu, W. Si, X. Sun, B. Liu, L. Zhang, C. Yan, O.G. Schmidt, Pd-functionalized $\mathrm{MnOx}-\mathrm{GeOy}$ nanomembranes as highly efficient cathode materials for $\mathrm{Li}-\mathrm{O}_{2}$ batteries. Nano Energy 19, 428-436 (2016). https://doi.org/10.1016/j.nanoe n.2015.10.027

25. H. Zhang, Ultrathin two-dimensional nanomaterials. ACS Nano 9, 9451-9469 (2015). https://doi.org/10.1021/acsna no. 5 b05040

26. X. Lu, Y. Yin, L. Zhang, S. Huang, L. Xi, L. Liu, S. Oswald, O.G. Schmidt, $3 \mathrm{~d} \mathrm{Ag} / \mathrm{NiO}-\mathrm{Fe}_{2} \mathrm{O}_{3} / \mathrm{Ag}$ nanomembranes as carbon-free cathode materials for $\mathrm{Li}-\mathrm{O}_{2}$ batteries. Energy Storage Mater. 16, 155-162 (2019). https://doi.org/10.1016/j. ensm.2018.05.002

27. T.-B. Hur, T.X. Phuoc, M.K. Chyu, New approach to the synthesis of layered double hydroxides and associated ultrathin nanosheets in de-ionized water by laser ablation. J. Appl. Phys. 108, 114312 (2010). https://doi.org/10.1063/1.35185 10

28. T.X. Phuoc, Y. Soong, M.K. Chyu, Synthesis of Ag-deionized water nanofluids using multi-beam laser ablation in liquids. Opt. Lasers Eng. 45, 1099-1106 (2007). https://doi. org/10.1016/j.optlaseng.2007.06.005

29. T. Sasaki, C. Liang, W.T. Nichols, Y. Shimizu, N. Koshizaki, Fabrication of oxide base nanostructures using pulsed laser ablation in aqueous solutions. Appl. Phys. A 79, 1489-1492 (2004). https://doi.org/10.1007/s00339-004-2827-3

30. P.V. Kazakevich, A.V. Simakin, V.V. Voronov, G.A. Shafeev, Laser induced synthesis of nanoparticles in liquids. Appl. Surf. Sci. 252, 4373-4380 (2006). https://doi.org/10.1016/j. apsusc.2005.06.059

31. G. Compagnini, E. Messina, O. Puglisi, R.S. Cataliotti, V. Nicolosi, Spectroscopic evidence of a core-shell structure in the earlier formation stages of $\mathrm{Au}-\mathrm{Ag}$ nanoparticles by pulsed laser ablation in water. Chem. Phys. Lett. 457, 386390 (2008). https://doi.org/10.1016/j.cplett.2008.04.051

32. B.M. Hunter, J.D. Blakemore, M. Deimund, H.B. Gray, J.R. Winkler, A.M. Müller, Highly active mixed-metal nanosheet water oxidation catalysts made by pulsed-laser ablation in liquids. J. Am. Chem. Soc. 136, 13118-13121 (2014). https ://doi.org/10.1021/ja506087h

33. C. Qiao, Y. Zhang, Y. Zhu, C. Cao, X. Bao, J. Xu, One-step synthesis of Zinc-Cobalt layered double hydroxide (Zn-Co$\mathrm{LDH})$ nanosheets for high-efficiency oxygen evolution reaction. J. Mater. Chem. A 3, 6878-6883 (2015). https://doi. org/10.1039/C4TA06634K

34. Y. Yan, Q. Liu, J. Wang, J. Wei, Z. Gao et al., Single-step synthesis of layered double hydroxides ultrathin nanosheets. J. Colloid Interface Sci. 371, 15-19 (2012). https://doi. org/10.1016/j.jcis.2011.12.075

35. G. Hu, N. Wang, D. O'Hare, J. Davis, One-step synthesis and AFM imaging of hydrophobic LDH monolayers. Chem. Commun. 3, 287-289 (2006). https://doi.org/10.1039/B5143 $68 \mathrm{C}$

36. W.T. Reichle, Synthesis of anionic clay minerals (mixed metal hydroxides, hydrotalcite). Solid State Ionics 22, 135141 (1986). https://doi.org/10.1016/0167-2738(86)90067-6

37. K.T. Ehlsissen, A. Delahaye-Vidal, P. Genin, M. Figlarz, P. Willmann, Preparation and characterization of turbostratic $\mathrm{Ni} / \mathrm{Al}$ layered double hydroxides for nickel hydroxide electrode applications. J. Mater. Chem. 3, 883-888 (1993). https ://doi.org/10.1039/jm9930300883

38. R. Xu, H.C. Zeng, Synthesis of nanosize supported hydrotalcite-like compounds $\mathrm{CoAl}_{x}(\mathrm{OH})_{2+2 x}\left(\mathrm{CO}_{3}\right)_{y}\left(\mathrm{NO}_{3}\right)_{x-2 y} \cdot n \mathrm{H}_{2} \mathrm{O}$ on $\gamma-\mathrm{Al}_{2} \mathrm{O}_{3}$. Chem. Mater. 13, 297-303 (2001). https://doi. org/10.1021/cm000526i

39. I. Nobuo, M. Taki, K. Yoshiro, K. Kenji, A novel synthetic route to layered double hydroxides using hexamethylenetetramine. Chem. Lett. 33, 1122-1123 (2004). https://doi. org/10.1246/cl.2004.1122

40. H. Cai, A.C. Hillier, K.R. Franklin, C.C. Nunn, M.D. Ward, Nanoscale imaging of molecular adsorption. Science 266, 1551-1555 (1994). https://doi.org/10.1126/scien ce.266.5190.1551

41. G. Bitsianes, T.L. Joseph, Topochemical aspects of iron ore reduction. JOM 7, 639-645 (1955). https://doi.org/10.1007/ BF03377553

42. R. Ma, Z. Liu, K. Takada, N. Iyi, Y. Bando, T. Sasaki, Synthesis and exfoliation of $\mathrm{Co}^{2+}-\mathrm{Fe}^{3+}$ layered double hydroxides: an innovative topochemical approach. J. Am. Chem. 
Soc. 129, 5257-5263 (2007). https://doi.org/10.1021/ja069 3035

43. R. Ma, K. Takada, K. Fukuda, N. Iyi, Y. Bando, T. Sasaki, Topochemical synthesis of monometallic $\left(\mathrm{Co}^{2+}-\mathrm{Co}^{3+}\right)$ layered double hydroxide and its exfoliation into positively charged $\mathrm{Co}(\mathrm{OH})_{2}$ nanosheets. Angew. Chem. Int. Ed. 47, 86-89 (2008). https://doi.org/10.1002/anie.200703941

44. J.-H. Lee, D. O'Hare, D.-Y. Jung, Topochemical oxidation of transition metals in layered double hydroxides by anthraquinone-2-sulfonate. Bull. Korean Chem. Soc. 33, 725-727 (2012). https://doi.org/10.5012/bkcs.2012.33.2.725

45. J.H. Lee, Y. Du, D. O'Hare, Growth of oriented thin films of intercalated $\alpha$-cobalt hydroxide on functionalized $\mathrm{Au}$ and Si substrates. Chem. Mater. 21, 963-968 (2009). https://doi. org/10.1021/cm802828z

46. L. Ma, Q. Wang, S.M. Islam, Y. Liu, S. Ma, M.G. Kanatzidis, Highly selective and efficient removal of heavy metals by layered double hydroxide intercalated with the $\mathrm{MoS}_{4}{ }^{2-}$ ion. J. Am. Chem. Soc. 138, 2858-2866 (2016). https://doi. org/10.1021/jacs.6b00110

47. D.-Y. Wang, F.R. Costa, A. Vyalikh, A. Leuteritz, U. Scheler et al., One-step synthesis of organic LDH and its comparison with regeneration and anion exchange method. Chem. Mater. 21, 4490-4497 (2009). https://doi. org/10.1021/cm901238a

48. S. Sene, S. Bégu, C. Gervais, G. Renaudin, A. Mesbah et al., Intercalation of benzoxaborolate anions in layered double hydroxides: toward hybrid formulations for benzoxaborole drugs. Chem. Mater. 27, 1242-1254 (2015). https://doi. org/10.1021/cm504181w

49. L. Ma, S.M. Islam, H. Liu, J. Zhao, G. Sun, H. Li, S. Ma, M.G. Kanatzidis, Selective and efficient removal of toxic oxoanions of $\mathrm{As}(\mathrm{iii}), \mathrm{As}(\mathrm{v})$, and $\mathrm{Cr}(\mathrm{vi})$ by layered double hydroxide intercalated with $\mathrm{MoS}_{4}{ }^{2-}$. Chem. Mater. 29, 3274 3284 (2017). https://doi.org/10.1021/acs.chemmater.7b00618

50. L. Lv, K. Xu, C. Wang, H. Wan, Y. Ruan et al., Intercalation of glucose in NiMn-layered double hydroxide nanosheets: an effective path way towards battery-type electrodes with enhanced performance. Electrochim. Acta 216, 35-43 (2016). https://doi.org/10.1016/j.electacta.2016.08.149

51. W. Liu, S. Xu, R. Liang, M. Wei, D.G. Evans, X. Duan, In situ synthesis of nitrogen-doped carbon dots in the interlayer region of a layered double hydroxide with tunable quantum yield. J. Mater. Chem. C 5, 3536-3541 (2017). https:// doi.org/10.1039/C6TC05463C

52. C. Wang, X. Zhang, X. Sun, Y. Ma, Facile fabrication of ethylene glycol intercalated cobalt-nickel layered double hydroxide nanosheets supported on nickel foam as flexible binder-free electrodes for advanced electrochemical energy storage. Electrochim. Acta 191, 329-336 (2016). https://doi. org/10.1016/j.electacta.2015.12.154

53. Z. Liu, R. Ma, M. Osada, N. Iyi, Y. Ebina, K. Takada, T. Sasaki, Synthesis, anion exchange, and delamination of Co-Al layered double hydroxide: assembly of the exfoliated nanosheet/polyanion composite films and magneto-optical studies. J. Am. Chem. Soc. 128, 4872-4880 (2006). https:// doi.org/10.1021/ja0584471

54. M. Adachi-Pagano, C. Forano, J.-P. Besse, Delamination of layered double hydroxides by use of surfactants. Chem. Commun. (2000). https://doi.org/10.1039/a908251d

55. B.R. Venugopal, C. Shivakumara, M. Rajamathi, Effect of various factors influencing the delamination behavior of surfactant intercalated layered double hydroxides. J. Colloid Interface Sci. 294, 234-239 (2006). https://doi.org/10.1016/j. jcis.2005.06.086

56. V.V. Naik, T.N. Ramesh, S. Vasudevan, Neutral nanosheets that gel: exfoliated layered double hydroxides in toluene. J. Phys. Chem. Lett. 2, 1193-1198 (2011). https://doi. org/10.1021/jz2004655

57. J. Liang, R. Ma, N. Iyi, Y. Ebina, K. Takada, T. Sasaki, Topochemical synthesis, anion exchange, and exfoliation of $\mathrm{Co}-\mathrm{Ni}$ layered double hydroxides: a route to positively charged $\mathrm{Co}-$ $\mathrm{Ni}$ hydroxide nanosheets with tunable composition. Chem. Mater. 22, 371-378 (2010). https://doi.org/10.1021/cm902 $787 \mathrm{u}$

58. T. Hibino, W. Jones, New approach to the delamination of layered double hydroxides. J. Mater. Chem. 11, 1321-1323 (2001). https://doi.org/10.1039/b101135i

59. T. Hibino, Delamination of layered double hydroxides containing amino acids. Chem. Mater. 16, 5482-5488 (2004). https://doi.org/10.1021/cm048842a

60. N. Iyi, T. Sasaki, Decarbonation of MgAl-LDHs (layered double hydroxides) using acetate-buffer $/ \mathrm{NaCl}$ mixed solution. J. Colloid Interface Sci. 322, 237-245 (2008). https:// doi.org/10.1016/j.jcis.2008.02.047

61. L. Li, R. Ma, Y. Ebina, N. Iyi, T. Sasaki, Positively charged nanosheets derived via total delamination of layered double hydroxides. Chem. Mater. 17, 4386-4391 (2005). https://doi. org/10.1021/cm0510460

62. N. Iyi, S. Ishihara, Y. Kaneko, H. Yamada, Swelling and gel/ sol formation of perchlorate-type layered double hydroxides in concentrated aqueous solutions of amino acid-related zwitterionic compounds. Langmuir 29, 2562-2571 (2013). https ://doi.org/10.1021/la304964q

63. I. Langmuir, Oscillations in ionized gases. Proc. Natl. Acad. Sci. 14, 627-637 (1928). https://doi.org/10.1073/ pnas.14.8.627

64. J. Shim, A. Oh, D.-H. Kang, S. Oh, S.K. Jang et al., Highperformance $2 \mathrm{~d}$ rhenium disulfide $\left(\mathrm{ReS}_{2}\right)$ transistors and photodetectors by oxygen plasma treatment. Adv. Mater. 28, 6985-6992 (2016). https://doi.org/10.1002/adma.201601002

65. C. Wang, Y. Zhou, L. He, T.-W. Ng, G. Hong et al., In situ nitrogen-doped graphene grown from polydimethylsiloxane by plasma enhanced chemical vapor deposition. Nanoscale 5, 600-605 (2013). https://doi.org/10.1039/C2NR32897F

66. S.L. Girshick, C.-P. Chiu, Homogeneous nucleation of particles from the vapor phase in thermal plasma synthesis. Plasma Chem. Plasma Process. 9, 355-369 (1989). https:// doi.org/10.1007/BF01083672 
67. M.M. Moshrefi, F. Rashidi, Hydrogen production from methane decomposition in cold plasma reactor with rotating electrodes. Plasma Chem. Plasma Process. 38, 503-515 (2018). https://doi.org/10.1007/s11090-018-9875-5

68. L. Mangolini, E. Thimsen, U. Kortshagen, High-yield plasma synthesis of luminescent silicon nanocrystals. Nano Lett. 5, 655-659 (2005). https://doi.org/10.1021/n1050066y

69. P.K. Chu, J.Y. Chen, L.P. Wang, N. Huang, Plasma-surface modification of biomaterials. Mater. Sci. Eng., R 36, 143-206 (2002). https://doi.org/10.1016/S0927-796X(02)00004-9

70. L. Tao, C.-Y. Lin, S. Dou, S. Feng, D. Chen et al., Creating coordinatively unsaturated metal sites in metal-organicframeworks as efficient electrocatalysts for the oxygen evolution reaction: insights into the active centers. Nano Energy 41, 417-425 (2017). https://doi.org/10.1016/j.nanoe n.2017.09.055

71. Y. Zhang, B. Ouyang, J. Xu, G. Jia, S. Chen, R.S. Rawat, H.J. Fan, Rapid synthesis of cobalt nitride nanowires: highly efficient and low-cost catalysts for oxygen evolution. Angew. Chem. Int. Ed. 55, 8670-8674 (2016). https://doi. org/10.1002/anie.201604372

72. K. Wang, M. Xu, Y. Gu, Z. Gu, J. Liu, Q.H. Fan, Low-temperature plasma exfoliated $\mathrm{N}$-doped graphene for symmetrical electrode supercapacitors. Nano Energy 31, 486-494 (2017). https://doi.org/10.1016/j.nanoen.2016.11.007

73. W. Lu, H. Nan, J. Hong, Y. Chen, C. Zhu et al., Plasmaassisted fabrication of monolayer phosphorene and its Raman characterization. Nano Res. 7, 853-859 (2014). https://doi. org/10.1007/s12274-014-0446-7

74. Y. Wang, Y. Zhang, Z. Liu, C. Xie, S. Feng, D. Liu, M. Shao, S. Wang, Layered double hydroxide nanosheets with multiple vacancies obtained by dry exfoliation as highly efficient oxygen evolution electrocatalysts. Angew. Chem. Int. Ed. 56, 5867-5871 (2017). https://doi.org/10.1002/anie.201701477

75. R. Liu, Y. Wang, D. Liu, Y. Zou, S. Wang, Water-plasmaenabled exfoliation of ultrathin layered double hydroxide nanosheets with multivacancies for water oxidation. Adv. Mater. 29, 1701546 (2017). https://doi.org/10.1002/ adma.201701546

76. Y. Wang, C. Xie, Z. Zhang, D. Liu, R. Chen, S. Wang, In situ exfoliated, N-doped, and edge-rich ultrathin layered double hydroxides nanosheets for oxygen evolution reaction. Adv. Funct. Mater. 28, 1703363 (2018). https://doi.org/10.1002/ adfm.201703363

77. D. Zhou, S. Wang, Y. Jia, X. Xiong, H. Yang et al., Nife hydroxide lattice tensile strain: enhancement of adsorption of oxygenated intermediates for efficient water oxidation catalysis. Angew. Chem. Int. Ed. 58, 736-740 (2019). https://doi. org/10.1002/anie.201809689

78. P. Vialat, C. Mousty, C. Taviot-Gueho, G. Renaudin, H. Martinez, J.-C. Dupin, E. Elkaim, F. Leroux, High-performing monometallic cobalt layered double hydroxide supercapacitor with defined local structure. Adv. Funct. Mater. 24, 48314842 (2014). https://doi.org/10.1002/adfm.201400310

79. N. Parveen, M.H. Cho, Self-assembled 3d flower-like nickel hydroxide nanostructures and their supercapacitor applications. Sci. Rep. 6, 27318 (2016). https://doi. org/10.1038/srep27318

80. R.R. Salunkhe, J. Lin, V. Malgras, S.X. Dou, J.H. Kim, Y. Yamauchi, Large-scale synthesis of coaxial carbon nanotube/ $\mathrm{Ni}(\mathrm{OH})_{2}$ composites for asymmetric supercapacitor application. Nano Energy 11, 211-218 (2015). https://doi. org/10.1016/j.nanoen.2014.09.030

81. J. Wang, Y. Ni, W. Jiang, H. Li, Y. Liu, S. Lin, Y. Zhou, D. Yan, Self-crosslinking and surface-engineered polymer vesicles. Small 11, 4485-4490 (2015). https://doi.org/10.1002/ smll.201500699

82. J. Jiang, F. Sun, S. Zhou, W. Hu, H. Zhang et al., Atomic-level insight into super-efficient electrocatalytic oxygen evolution on iron and vanadium co-doped nickel (oxy)hydroxide. Nat. Commun. 9, 2885 (2018). https://doi.org/10.1038/s4146 7-018-05341-y

83. L.-M. Cao, J.-W. Wang, D.-C. Zhong, T.-B. Lu, Templatedirected synthesis of sulphur doped NiCoFe layered double hydroxide porous nanosheets with enhanced electrocatalytic activity for the oxygen evolution reaction. J. Mater. Chem. A 6, 3224-3230 (2018). https://doi.org/10.1039/C7TA09734D

84. M.K. Bates, Q. Jia, H. Doan, W. Liang, S. Mukerjee, Chargetransfer effects in $\mathrm{Ni}-\mathrm{Fe}$ and $\mathrm{Ni}-\mathrm{Fe}-\mathrm{Co}$ mixed-metal oxides for the alkaline oxygen evolution reaction. ACS Catal. 6, 155-161 (2016). https://doi.org/10.1021/acscatal.5b01481

85. Z. Lu, L. Qian, Y. Tian, Y. Li, X. Sun, X. Duan, Ternary $\mathrm{NiFeMn}$ layered double hydroxides as highly-efficient oxygen evolution catalysts. Chem. Commun. 52, 908-911 (2016). https://doi.org/10.1039/C5CC08845C

86. J.L. Lado, X. Wang, E. Paz, E. Carbó-Argibay, N. Guldris et al., Design and synthesis of highly active Al-Ni-P foam electrode for hydrogen evolution reaction. ACS Catal. 5, 6503-6508 (2015). https://doi.org/10.1021/acscatal.5b01761

87. C. Tang, R. Zhang, W. Lu, L. He, X. Jiang, A.M. Asiri, X. Sun, Fe-doped CoP nanoarray: a monolithic multifunctional catalyst for highly efficient hydrogen generation. Adv. Mater. 29, 1602441 (2017). https://doi.org/10.1002/adma.20160 2441

88. P. Zhou, J. He, Y. Zou, Y. Wang, C. Xie, R. Chen, S. Zang, S. Wang, Single-crystalline layered double hydroxides with rich defects and hierarchical structure by mild reduction for enhancing the oxygen evolution reaction. Sci. China Chem. 62, 1365-1370 (2019). https://doi.org/10.1007/s1142 6-019-9511-x

89. Y. Wang, M. Qiao, Y. Li, S. Wang, Tuning surface electronic configuration of NiFe LDHs nanosheets by introducing cation vacancies (Fe or $\mathrm{Ni}$ ) as highly efficient electrocatalysts for oxygen evolution reaction. Small 14, 1800136 (2018). https ://doi.org/10.1002/smll.201800136

90. A. Mignani, B. Ballarin, M. Giorgetti, E. Scavetta, D. Tonelli et al., Heterostructure of Au nanoparticles-NiAl layered double hydroxide: electrosynthesis, characterization, and electrocatalytic properties. J. Phys. Chem. C 117, 1622116230 (2013). https://doi.org/10.1021/jp4033782

91. L. Xu, Z. Qu, J. Chen, X. Chen, F. Li, W. Yang, Highly dispersed palladium nanoparticles generated in situ on layered 
double hydroxide nanowalls for ultrasensitive electrochemical detection of hydrazine. Anal. Methods 9, 6629-6635 (2017). https://doi.org/10.1039/C7AY02324C

92. W. Zhu, L. Liu, Z. Yue, W. Zhang, X. Yue et al., Au promoted nickel-iron layered double hydroxide nanoarrays: a modular catalyst enabling high-performance oxygen evolution. ACS Appl. Mater. Interfaces 9, 19807-19814 (2017). https://doi. org/10.1021/acsami.7b03033

93. X. Gao, X. Long, H. Yu, X. Pan, Z. Yi, Ni nanoparticles decorated $\mathrm{NiFe}$ layered double hydroxide as bifunctional electrochemical catalyst. J. Electrochem. Soc. 164, H307 (2017). https://doi.org/10.1149/2.0561706jes

94. X. Deng, J. Huang, H. Wan, F. Chen, Y. Lin, X. Xu, R. Ma, T. Sasaki, Recent progress in functionalized layered double hydroxides and their application in efficient electrocatalytic water oxidation. J. Energy Chem. 32, 93-104 (2019). https:// doi.org/10.1016/j.jechem.2018.07.007

95. B. Qiao, A. Wang, X. Yang, L.F. Allard, Z. Jiang et al., Single-atom catalysis of $\mathrm{CO}$ oxidation using Pt1/FeOx. Nat. Chem. 3, 634-641 (2011). https://doi.org/10.1038/nchem .1095

96. P. Liu, Y. Zhao, R. Qin, S. Mo, G. Chen et al., Photochemical route for synthesizing atomically dispersed palladium catalysts. Science 352, 797-800 (2016). https://doi. org/10.1126/science.aaf5251

97. J. Zhang, J. Liu, L. Xi, Y. Yu, N. Chen et al., Single-atom $\mathrm{Au} / \mathrm{NiFe}$ layered double hydroxide electrocatalyst: probing the origin of activity for oxygen evolution reaction. J. Am. Chem. Soc. 140, 3876-3879 (2018). https://doi. org/10.1021/jacs.8b00752

98. B. Zhang, C. Zhu, Z. Wu, E. Stavitski, Y.H. Lui et al., Integrating rh species with $\mathrm{NiFe}$-layered double hydroxide for overall water splitting. Nano Lett. 20, 136-144 (2020). https://doi.org/10.1021/acs.nanolett.9b03460

99. Z. Wang, S.-M. Xu, Y. Xu, L. Tan, X. Wang, Y. Zhao, H. Duan, Y.-F. Song, Single Ru atoms with precise coordination on a monolayer layered double hydroxide for efficient electrooxidation catalysis. Chem. Sci. 10, 378-384 (2019). https://doi.org/10.1039/C8SC04480E

100. R. Valdez, D.B. Grotjahn, D.K. Smith, J.M. Quintana, A. Olivas, Nanosheets of $\mathrm{Co}-(\mathrm{Ni}$ and $\mathrm{Fe})$ layered double hydroxides for electrocatalytic water oxidation reaction. Int. J. Electrochem. Sci. 10, 909-918 (2015)

101. D. Tang, J. Liu, X. Wu, R. Liu, X. Han et al., Carbon quantum dot/NiFe layered double-hydroxide composite as a highly efficient electrocatalyst for water oxidation. ACS Appl. Mater. Interfaces 6, 7918-7925 (2014). https://doi. org/10.1021/am501256x

102. S.N. Baker, G.A. Baker, Luminescent carbon nanodots: emergent nanolights. Angew. Chem. Int. Ed. 49, 6726-6744 (2010). https://doi.org/10.1002/anie.200906623

103. H. Li, X. He, Z. Kang, H. Huang, Y. Liu et al., Watersoluble fluorescent carbon quantum dots and photocatalyst design. Angew. Chem. Int. Ed. 49, 4430-4434 (2010). https ://doi.org/10.1002/anie.200906154
104. Y.-P. Sun, B. Zhou, Y. Lin, W. Wang, K.A.S. Fernando et al., Quantum-sized carbon dots for bright and colorful photoluminescence. J. Am. Chem. Soc. 128, 7756-7757 (2006). https://doi.org/10.1021/ja062677d

105. C. Tang, H.-F. Wang, X.-L. Zhu, B.-Q. Li, Q. Zhang, Advances in hybrid electrocatalysts for oxygen evolution reactions: rational integration of $\mathrm{NiFe}$ layered double hydroxides and nanocarbon. Part. Part. Syst. Charact. 33, 447 (2016). https://doi.org/10.1002/ppsc.201670024

106. S. Wang, D. Yu, L. Dai, Polyelectrolyte functionalized carbon nanotubes as efficient metal-free electrocatalysts for oxygen reduction. J. Am. Chem. Soc. 133, 5182-5185 (2011). https://doi.org/10.1021/ja1112904

107. Z. Xu, X. Fan, H. Li, H. Fu, W.M. Lau, X. Zhao, Edges of graphene and carbon nanotubes with high catalytic performance for the oxygen reduction reaction. PCCP 19, 2100321011 (2017). https://doi.org/10.1039/C7CP03416D

108. M. Gong, Y. Li, H. Wang, Y. Liang, J.Z. Wu et al., An advanced $\mathrm{Ni}-\mathrm{Fe}$ layered double hydroxide electrocatalyst for water oxidation. J. Am. Chem. Soc. 135, 8452-8455 (2013). https://doi.org/10.1021/ja4027715

109. C. Lee, X. Wei, J.W. Kysar, J. Hone, Measurement of the elastic properties and intrinsic strength of monolayer graphene. Science 321, 385-388 (2008). https://doi.org/10.1126/scien ce. 1157996

110. A.A. Balandin, S. Ghosh, W. Bao, I. Calizo, D. Teweldebrhan, F. Miao, C.N. Lau, Superior thermal conductivity of single-layer graphene. Nano Lett. 8, 902-907 (2008). https ://doi.org/10.1021/n10731872

111. X. Long, J. Li, S. Xiao, K. Yan, Z. Wang, H. Chen, S. Yang, A strongly coupled graphene and FeNi double hydroxide hybrid as an excellent electrocatalyst for the oxygen evolution reaction. Angew. Chem. Int. Ed. 53, 7584-7588 (2014). https://doi.org/10.1002/anie.201402822

112. J. Yi, Z. Longzhou, G. Guoping, C. Hua, W. Bei et al., A heterostructure coupling of exfoliated $\mathrm{Ni}-\mathrm{Fe}$ hydroxide nanosheet and defective graphene as a bifunctional electrocatalyst for overall water splitting. Adv. Mater. 29, 1700017 (2017). https://doi.org/10.1002/adma.201700017

113. S. Chen, J. Duan, M. Jaroniec, S.Z. Qiao, Three-dimensional $\mathrm{N}$-doped graphene hydrogel/NiCo double hydroxide electrocatalysts for highly efficient oxygen evolution. Angew. Chem. Int. Ed. 52, 13567-13570 (2013). https://doi.org/10.1002/ anie. 201306166

114. C.H. Choi, M. Kim, H.C. Kwon, S.J. Cho, S. Yun et al., Tuning selectivity of electrochemical reactions by atomically dispersed platinum catalyst. Nat. Commun. 7, 10922 (2016). https://doi.org/10.1038/ncomms 10922

115. C. Tang, H.-S. Wang, H.-F. Wang, Q. Zhang, G.-L. Tian, J.-Q. Nie, F. Wei, Spatially confined hybridization of nanometer-sized $\mathrm{NiFe}$ hydroxides into nitrogen-doped graphene frameworks leading to superior oxygen evolution reactivity. Adv. Mater. 27, 4516-4522 (2015). https://doi.org/10.1002/ adma.201501901

116. J.-H. Zhong, J. Zhang, X. Jin, J.-Y. Liu, Q. Li et al., Quantitative correlation between defect density and heterogeneous 
electron transfer rate of single layer graphene. J. Am. Chem. Soc. 136, 16609-16617 (2014). https://doi.org/10.1021/ja508 $965 \mathrm{w}$

117. D. Zhou, Z. Cai, X. Lei, W. Tian, Y. Bi et al., NiCoFe-layered double hydroxides/N-doped graphene oxide array colloid composite as an efficient bifunctional catalyst for oxygen electrocatalytic reactions. Adv. Energy Mater. 8, 1701905 (2017). https://doi.org/10.1002/aenm.201701905

118. W. Ma, R. Ma, C. Wang, J. Liang, X. Liu, K. Zhou, T. Sasaki, A superlattice of alternately stacked Ni-Fe hydroxide nanosheets and graphene for efficient splitting of water. ACS Nano 9, 1977-1984 (2015). https://doi.org/10.1021/nn506 9836

119. H. Liang, F. Meng, M. Cabán-Acevedo, L. Li, A. Forticaux, L. Xiu, Z. Wang, S. Jin, Hydrothermal continuous flow synthesis and exfoliation of NiCo layered double hydroxide nanosheets for enhanced oxygen evolution catalysis. Nano Lett. 15, 1421-1427 (2015). https://doi.org/10.1021/nl504 872 s

120. M. Luo, Z. Cai, C. Wang, Y. Bi, L. Qian et al., Phosphorus oxoanion-intercalated layered double hydroxides for highperformance oxygen evolution. Nano Res. 10, 1732-1739 (2017). https://doi.org/10.1007/s12274-017-1437-2

121. Y. Li, M. Zhao, Y. Zhao, L. Song, Z. Zhang, FeNi layered double-hydroxide nanosheets on a $3 \mathrm{~d}$ carbon network as an efficient electrocatalyst for the oxygen evolution reaction. Part. Part. Syst. Char. 33, 158-166 (2016). https://doi. org/10.1002/ppsc.201500228

122. L. Wang, X. Huang, J. Xue, Graphitic mesoporous carbon loaded with iron-nickel hydroxide for superior oxygen evolution reactivity. Chemsuschem 9, 1835-1842 (2016). https:// doi.org/10.1002/cssc. 201600323

123. J. Ping, Y. Wang, Q. Lu, B. Chen, J. Chen et al., Self-assembly of single-layer CoAl-layered double hydroxide nanosheets on $3 \mathrm{~d}$ graphene network used as highly efficient electrocatalyst for oxygen evolution reaction. Adv. Mater. 28, 76407645 (2016). https://doi.org/10.1002/adma.201601019

124. W. Wang, Y. Lu, M. Zhao, R. Luo, Y. Yang et al., Controllable tuning of cobalt nickel-layered double hydroxide arrays as multifunctional electrodes for flexible supercapattery device and oxygen evolution reaction. ACS Nano 13, 12206-12218 (2019). https://doi.org/10.1021/acsnano.9b06910

125. K. He, T. Tadesse Tsega, X. Liu, J. Zai, X.-H. Li et al., Utilizing the space-charge region of the FeNi-LDH/CoP p-n junction to promote performance in oxygen evolution electrocatalysis. Angew. Chem. Int. Ed. 58, 11903-11909 (2019). https://doi.org/10.1002/anie.201905281

126. R. Ma, X. Liu, J. Liang, Y. Bando, T. Sasaki, Molecularscale heteroassembly of redoxable hydroxide nanosheets and conductive graphene into superlattice composites for highperformance supercapacitors. Adv. Mater. 26, 4173-4178 (2014)

127. P. Xiong, B. Sun, N. Sakai, R. Ma, T. Sasaki, S. Wang, J. Zhang, G. Wang, 2d superlattices for efficient energy storage and conversion. Adv. Mater. (2019). https://doi.org/10.1002/ adma.201902654
128. M.S. Islam, M. Kim, X. Jin, S.M. Oh, N.-S. Lee, H. Kim, S.-J. Hwang, Bifunctional 2d superlattice electrocatalysts of layered double hydroxide-transition metal dichalcogenide active for overall water splitting. ACS Energy Lett. 3, 952 960 (2018). https://doi.org/10.1021/acsenergylett.8b00134

129. P. Xiong, X. Zhang, H. Wan, S. Wang, Y. Zhao et al., Interface modulation of two-dimensional superlattices for efficient overall water splitting. Nano Lett. 19, 4518-4526 (2019). https://doi.org/10.1021/acs.nanolett.9b01329

130. M. Yu, S. Zhou, Z. Wang, J. Zhao, J. Qiu, Boosting electrocatalytic oxygen evolution by synergistically coupling layered double hydroxide with mxene. Nano Energy 44, 181-190 (2018). https://doi.org/10.1016/j.nanoen.2017.12.003

131. X. Lang, A. Hirata, T. Fujita, M. Chen, Nanoporous metal/ oxide hybrid electrodes for electrochemical supercapacitors. Nat. Nanotechnol. 6, 232-236 (2011). https://doi. org/10.1038/nnano.2011.13

132. Z. Lu, Q. Yang, W. Zhu, Z. Chang, J. Liu, X. Sun, D.G. Evans, X. Duan, Hierarchical $\mathrm{Co}_{3} \mathrm{O}_{4} @ \mathrm{Ni}-\mathrm{Co}-\mathrm{O}$ supercapacitor electrodes with ultrahigh specific capacitance per area. Nano Res. 5, 369-378 (2012). https://doi.org/10.1007/ s12274-012-0217-2

133. R. Chen, G. Sun, C. Yang, L. Zhang, J. Miao et al., Achieving stable and efficient water oxidation by incorporating $\mathrm{NiFe}$ layered double hydroxide nanoparticles into aligned carbon nanotubes. Nanoscale Horizons 1, 156-160 (2016). https://doi.org/10.1039/C5NH00082C

134. H. Liu, J. Zhou, C. Wu, C. Wang, Y. Zhang et al., Integrated flexible electrode for oxygen evolution reaction: layered double hydroxide coupled with single-walled carbon nanotubes film. ACS Sustain. Chem. Eng. 6, 2911-2915 (2018). https://doi.org/10.1021/acssuschemeng.8b00084

135. C. Yu, Z. Liu, X. Han, H. Huang, C. Zhao, J. Yang, J. Qiu, NiCo-layered double hydroxides vertically assembled on carbon fiber papers as binder-free high-active electrocatalysts for water oxidation. Carbon 110, 1-7 (2016). https:// doi.org/10.1016/j.carbon.2016.08.020

136. L. Yu, H. Zhou, J. Sun, F. Qin, F. Yu et al., Cu nanowires shelled with $\mathrm{NiFe}$ layered double hydroxide nanosheets as bifunctional electrocatalysts for overall water splitting. Energy Environ. Sci. 10, 1820-1827 (2017). https://doi. org/10.1039/C7EE01571B

137. R. Yang, Y. Zhou, Y. Xing, D. Li, D. Jiang, M. Chen, W. Shi, S. Yuan, Synergistic coupling of CoFe-LDH arrays with $\mathrm{NiFe}-\mathrm{LDH}$ nanosheet for highly efficient overall water splitting in alkaline media. Appl. Catal. B 253, 131-139 (2019). https://doi.org/10.1016/j.apcatb.2019.04.054

138. L. Zhou, S. Jiang, Y. Liu, M. Shao, M. Wei, X. Duan, Ultrathin CoNiP@layered double hydroxides core-shell nanosheets arrays for largely enhanced overall water splitting. ACS Appl. Energy Mater. 1, 623-631 (2018). https:// doi.org/10.1021/acsaem.7b00151

139. W. Jin, F. Liu, X. Guo, J. Zhang, L. Zheng et al., Selfsupported $\mathrm{CoFe} \mathrm{LDH} / \mathrm{Co}_{0.85} \mathrm{Se}$ nanosheet arrays as efficient electrocatalysts for the oxygen evolution reaction. Catal. Sci. Technol. 9, 5736-5744 (2019) 
140. J. Zhou, L. Yu, Q. Zhu, C. Huang, Y. Yu, Defective and ultrathin nife $\mathrm{LDH}$ nanosheets decorated on $\mathrm{V}$-doped $\mathrm{Ni}_{3} \mathrm{~S}_{2}$ nanorod arrays: a 3d core-shell electrocatalyst for efficient water oxidation. J. Mater. Chem. A 7, 18118-18125 (2019). https://doi.org/10.1039/C9TA06347A

141. F. Kong, W. Zhang, L. Sun, L. Huo, H. Zhao, Interface electronic coupling in hierarchical $\mathrm{FeLDH}(\mathrm{FeCo}) / \mathrm{Co}(\mathrm{OH})_{2}$ arrays for efficient electrocatalytic oxygen evolution. Chemsuschem 12, 3592-3601 (2019). https://doi.org/10.1002/ cssc. 201900943

142. T. Zhang, L. Hang, Y. Sun, D. Men, X. Li, L. Wen, X. Lyu, Y. Li, Hierarchical hetero- $\mathrm{Ni}_{3} \mathrm{Se}_{4} @ \mathrm{NiFe} \mathrm{LDH}$ micro/ nanosheets as efficient bifunctional electrocatalysts with superior stability for overall water splitting. Nanoscale
Horizons 4, 1132-1138 (2019). https://doi.org/10.1039/ C9NH00177H

143. J. Liu, J. Wang, B. Zhang, Y. Ruan, L. Lv et al., Hierarchical $\mathrm{NiCo}_{2} \mathrm{~S}_{4} @ \mathrm{NiFe}$ ldh heterostructures supported on nickel foam for enhanced overall-water-splitting activity. ACS Appl. Mater. Interfaces 9, 15364-15372 (2017). https://doi. org/10.1021/acsami.7b00019

144. L. Yang, L. Xie, R. Ge, R. Kong, Z. Liu et al., Core-shell NiFe-LDH@NiFe-Bi nanoarray: in situ electrochemical surface derivation preparation toward efficient water oxidation electrocatalysis in near-neutral media. ACS Appl. Mater. Interfaces 9, 19502-19506 (2017). https://doi.org/10.1021/ acsami.7b01637 